\title{
Rock Mass Modification Around a Nuclear Waste Repository in Welded Tuff
}

Manuscript Completed: July 1989

Date Published: August 1989

Prepared by

M. G. Mack, T. Brandshaug, B. H. Brady

Itasca Consulting Group, Inc.

1313 5th Street SE, Suite 210

Minneapolis, MN 55414

Prepared for

Division of High-Level Waste Management

Office of Nuclear Material Safety and Safeguards

U.S. Nuclear Regulatory Commission

Washington, DC 20555

NRC FIN D1016 


\section{DISCLAIMER}

This report was prepared as an account of work sponsored by an agency of the United States Government. Neither the United States Government nor any agency thereof, nor any of their employees, make any warranty, express or implied, or assumes any legal liability or responsibility for the accuracy, completeness, or usefulness of any information, apparatus, product, or process disclosed, or represents that its use would not infringe privately owned rights. Reference herein to any specific commercial product, process, or service by trade name, trademark, manufacturer, or otherwise does not necessarily constitute or imply its endorsement, recommendation, or favoring by the United States Government or any agency thereof. The views and opinions of authors expressed herein do not necessarily state or reflect those of the United States Government or any agency thereof. 


\section{DISCLAIMER}

Portions of this document may be illegible in electronic image products. Images are produced from the best available original document. 
ABSTRACT

This report presents the results of numerical analyses to estimate the extent of rock mass modification resulting from the presence of a High Level Waste (HLW) repository. Changes in rock mass considered are stresses and joint deformations resulting from disposal room excavation and thermal effects induced by the heat generated by nuclear waste. Rock properties and site conditions are taken from the Site Characterization Plan Conceptual Design Report (MacDougall et al., 1987) for the potential repository site at Yucca Mountain, Nevada. Analyses were conducted using boundary element and distinct element methods. Room-scale models and repository-scale models were investigated for up to 500 years after waste emplacement. Results of room-scale analyses based on the thermoelastic boundary element model indicate that a zone of modified rock develops around the disposal rooms for both vertical and horizontal waste emplacement. This zone is estimated to extend a distance of roughly two room diameters from the room surface. Results from the repository-scale model, which are based on the thermoelastic boundary element model and the distinct element model, indicate a zone with modified rock mass properties starting approximately $100 \mathrm{~m}$ above and below the repository, with a thickness of approximately $200 \mathrm{~m}$ above and $150 \mathrm{~m}$ below the repository. Slip-prone subhorizontal features are shown to have a substantial effect on rock mass response. The estimates of rock mass modification reflect uncertainties and simplifying assumptions in the models. 
TABLE OF CONTENTS

PAGE

ABSTRACT .

LIST OF FIGURES

vii

LIST OF TABLES.

xii

1.0

INTRODUCTION

1.1 Underground Repository Concept. . . . . . . 1

1.2 Rock Mass Modification By a Repository. . . . 2

1.2 .1 Stress Redistribution. . . . . . . . 2

1.2.2 Construction-Induced Effects . . . . . 2

1.2.3 Thermomechanical Effects . . . . . 3

1.3 Discussion of Prior DOE Analysis. . . . . . . 4

1.4 Purpose and Scope of the Current work . . . . 7

2.0 CONCEPTUAL AND NUMERICAL MODELS OF ROCK MASS

PERFORMANCE. . . . . . . . . . . . . . . . 12

2.1 Flow Mechanism. . . . . . . . . 12

2.2 Separation on Fractures . . . . . . . . 12

2.3 Slip on Fractures . . . . . . . . . . . . 14

2.4 Numerical Models. . . . . . . . . . 15

2.5 The Boundary Element Code HEFF. . . . . . . . 17

2.6 The Distinct Element Code UDEC. . . . . . . 18 
TABLE OF CONTENTS (continued)

\section{PAGE}

3.0 ANALYSis . . . . . . . . . . . . . . . . . . 25

3.1 Reference Conditions. . . . . . . . . . . 25

3.2 Room-Scale Analysis . . . . . . . . . . . 27

3.3 Repository-Scale Analysis Using HEFE. . . . . . 29

3.4 Repository-Scale Analysis Using UDEC. . . . . . 31

4.0 DISCUSSION AND CONCLUSIONS . . . . . . . . . . . . 80

5.0 RECOMMENDATIONS . . . . . . . . . . . . . . . 86

6.0 REFERENCES . . . . . . . . . . . . . . . . . . . 87

APPENDIX A: HEFF DATA. . . . . . . . . . . . . . A-1

APPENDIX B: UDEC DATA. • . . . . . . . . . . . . . . B-1 
LIST OF FIGURES

PAGE

Fig. 1-1 Thermal/Mechanical Stratigraphy at Yucca Mountain [MacDougal] et al., 1987]. . . . . 9

Fig. 1-2 Perspective View of the Underground Facility [MacDougall et al., 1987].......... 10

Fig. 1-3 Plan View of Repository Panel [MacDougall et

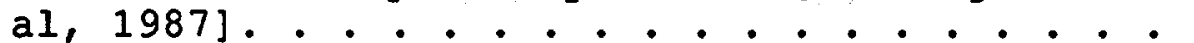

Fig. 2-1 Typical Matrix Saturation Curves for the Unsaturated Zone Hydraulic Units [after Peters and Klavetter, 1988] . . . . . . . . . . . 19

Fig. 2-2 Conductivity Curve for the Repository Unit TSw2 [after Peters and Klavetter, 1988] . . . . . .

Fig. 2-3 Coulombic Friction, Linear Deformation Model for a Joint: (a) normal deformation; (b) shear deformation; (c) shear strength [Crotty and Wardle, 1985]............. 20

Fig. 2-4 Conceptual Room-Scale Model for HEFF . . . . . 21

Fig. 2-5 Conceptual Repository-Scale Model for HEFF . . . 22

Fig. 2-6 Conceptual Repository-Scale Model for UDEC . . . 23

Fig. 2-7 Repository-Scale Model for UDEC, Showing Joint Locations. . . . . . . . . . . . . 24

Fig. 3-1 Waste Form Normalized Power Decay. . . . . . 34

Fig. 3-2 Room Geometry and Waste Lay-Out for Vertical Emplacement [MacDougal] et al., 1987] . ... 35

Fig. 3-3 Room Geometry and Waste Lay-Out for Horizontal Emplacement [MacDougall et al., 1987] . . . . 36

Fig. 3-4 Regions of More Than $10 \%$ Change in Major Principal Stress, Horizontal Emplacement . . . . 37

Fig. 3-5 Regions of More Than 108 Change in Minor Principal Stress, Horizontal Emplacement . . . 


\section{LIST OF FIGURES (continued)}

PAGE

Fig. 3-6 Regions of Joint Aperture Change By a Factor of Two As a Result of Excavation, Horizontal

Emplacement. . . . . . . . . . . . . 39

Fig. 3-7 Regions of Joint slip As a Result of Excavation, Horizontal Emplacement . . . . . . . .

Fig. 3-8 Contours of Rock Temperature $\left({ }^{\circ} \mathrm{C}\right)$ After 100 Years, Horizontal Emplacement. . . . . . .

Fig. 3-9 Contours of Rock Temperature $\left({ }^{\circ} \mathrm{C}\right)$ After 100 Years, Vertical Emplacement. . . . . . . . .

Fig. 3-10 Regions of Joint Aperture Change By a Factor of Two 100 Years After Waste Emplacement, Horizontal Emplacement. . . . . . . . . .

Fig. 3-11 Regions of Joint Aperture Change By a Factor of Two 100 Years After Waste Emplacement, Vertical Emplacement. . . . . . . . . . .

Fig. 3-12 Regions of Joint Slip 25 and 100 Years After Waste Emplacement, Horizontal Emplacement . .

Fig. 3-13 Regions of Joint Slip 25 and 100 Years After Waste Emplacement, Vertical Emplacement . . .

Fig. 3-14 Regions of Joint Slip 100 Years After Waste Emplacement for Vertical and Horizontal

Emplacement $\left(\sigma_{x x} / \sigma_{y y}=3 / 5\right)$. . . . . . .

Fig. 3-15 Regions of Aperture Change By a Factor of Two, 25 Years After Waste Emplacement

$$
\left(\sigma_{X X} / \sigma_{Y Y}=1.5 / 5\right) \cdot . \cdot \cdot \cdot \cdot \cdot \cdot \cdot \cdot \cdot \cdot \cdot \cdot
$$

Fig. 3-16 Regions of Aperture Change By a Factor of Two, 50 Years After Waste Emplacement

$$
\left(\sigma_{\mathrm{XX}} / \sigma_{\mathrm{YY}}=1.5 / 5\right) \cdot . \cdot \text {. . . . . . . . }
$$

Fig. 3-17 Regions of Aperture Change By a Factor of Two, 100 Years After Waste Emplacement

$$
\left(\sigma_{X X} / \sigma_{Y Y}=1.5 / 5\right)
$$


LIST OF FIGURES (continued)

PAGE

Fig. 3-18 Regions of Aperture Change By a Factor of Two, 250 Years After Waste Emplacement $\left(\sigma_{X X} / \sigma_{y Y}=1.5 / 5\right)$..............

Fig. 3-19 Regions of Aperture Change By a Factor of Two, 500 Years After Waste Emplacement

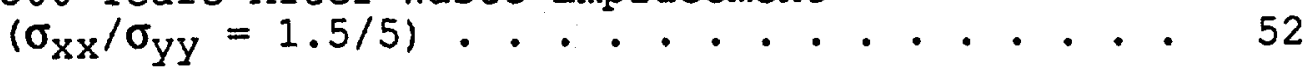

Fig. 3-20 Regions of Aperture Change By a Factor of Two, 25 Years After Waste Emplacement $\left(\sigma_{\mathrm{Xx}} / \sigma_{\mathrm{yy}}=3 / 5\right)$

Eig. 3-21 Regions of Aperture Change By a Factor of Two, 100 Years After Waste Emplacement $\left(\sigma_{X X} / \sigma_{Y Y}=3 / 5\right) 54$

Fig. 3-22 Regions of Aperture Change By a Factor of Two, 500 Years After Waste Emplacement $\left(\sigma_{X X} / \sigma_{Y Y}=3 / 5\right) 55$

Fig. 3-23 Region of Predicted Slip Along Vertical Joints 25 Years After Waste Emplacement. . . . . . 56

Fig. 3-24 Region of Predicted Slip Along Vertical Joints 50 Years After Waste Emplacement. . . . . .

Fig. 3-25 Region of Predicted Slip Along Vertical Joints 100 Years After Waste Emplacement. . . . . .

Fig. 3-26 Region of Predicted Slip Along Vertical Joints 250 Years After Waste Emplacement . . . . .

Fig. 3-27 Region of Predicted Slip Along Vertical Joints 500 Years After Waste Emplacement . . . . .

Fig. 3-28 Region of Predicted Slip Along Vertical Joints 25 Years After Waste Emplacement $\left(\sigma_{X X} / \sigma_{Y Y}=3 / 5\right)$

Fig. 3-29 Region of Predicted Slip Along Vertical Joints 100 Years After Waste Emplacement $\left(\sigma_{X X} / \sigma_{Y Y}=3 / 5\right) 62$

Fig. 3-30 Region of Predicted Slip Along Vertical Joints 500 Years After Waste Emplacement $\left(\sigma_{x x} / \sigma_{y y}=3 / 5\right) 63$

Fig. 3-31 Linear and Hyperbolic Joint Deformation Models . 64 
LIST OE FIGURES (continued)

$\underline{\text { PAGE }}$

Fig. 3-32 Contours of Rock Temperature Rise $\left({ }^{\circ} \mathrm{C}\right) 50$ Years After Waste Emplacement . . . . . . . . . .

Fig. 3-33 Contours of Rock Temperature Rise ( $\left.{ }^{\circ} \mathrm{C}\right) 100$ Years After Waste Emplacement . . . . . . . . .

Fig. 3-34 Contours of Rock Temperature Rise $\left({ }^{\circ} \mathrm{C}\right) 500$ Years After Waste Emplacement . . . . . . . . . .

Fig. 3-35 Change in Joint Aperture From Thermomechanical Effects 50 Years After Waste Emplacement (Joint locations are near the repository center and $500 \mathrm{~m}$ to the right of the center; horizontal features omitted.) . . . . . . . .

Fig. 3-36 Change in Joint Aperture From Thermomechanical Effects 100 Years After Waste Emplacement (Joint locations are near the repository center and $500 \mathrm{~m}$ to the right of the center; horizontal features omitted.) . . . . . . . .

Fig. 3-37 Change in Joint Aperture From Thermomechanical Effects 500 Years After Waste Emplacement (Joint locations are near the repository center and $500 \mathrm{~m}$ to the right of the center; horizontal features omitted.) . . . . . . .

Fig. 3-38 Change in Joint Aperture From Thermomechanical Effects 50 Years After Waste Emplacement on Joint $500 \mathrm{~m}$ From Repository Center: (a) friction angle $=10^{\circ}$ on horizontal features;

(b) friction angle $=28^{\circ}$ on horizontal features

Fig. 3-39 Change in Joint Aperture From Thermomechanical Effects 100 Years After Waste Emplacement on Joint $500 \mathrm{~m}$ From Repository Center: (a) friction angle $=10^{\circ}$ on horizontal features;

(b) friction angle $=28^{\circ}$ on horizontal features

Fig. 3-40 Change in Joint Aperture From Thermomechanical Effects 250 Years After Waste Emplacement on Joint $500 \mathrm{~m}$ From Repository Center: (a) friction angle $=10^{\circ}$ on horizontal features;

(b) friction angle $=28^{\circ}$ on horizontal features 
LIST OF FIGURES (continued)

PAGE

Fig. 3-41 Change in Joint Aperture From Thermomechanical Effects 500 Years After Waste Emplacement on Joint $500 \mathrm{~m}$ From Repository Center: (a) friction angle $=10^{\circ}$ on horizontal features;

(b) friction angle $=28^{\circ}$ on horizontal features

Fig. 3-42 Three Plates Stacked Together . . . . . . . . 75

Fig. 3-43 Location of Predicted Joint Slip After 50 and 100 Years in the UDEC Model . . . . . . . 76

Fig. 3-44 Location of Predicted Joint Slip After 250 and 500 Years in the UDEC Model . . . . . . 77

Fig. 3-45 Location of Predicted Joint Slip in UDEC Model with Horizontal Features for (a) 50 and (b) 100 years (Line thickness is proportional to magnitude of predicted slip.) . .

Fig. 3-46 Location of Predicted Joint Slip in UDEC Model with Horizontal Features for (a) 250 and (b) 500 years (Iine thickness is proportional to magnitude of predicted slip.l....

Fig. 4-1 Conceptual Illustration of the Extent of the Zone of Rock Mass Modification. . . . . . 
-xii-

LIST OF TABLES

PAGE

Table 3-1 ROCK MATERIAL AND JOINT PROPERTIES

[MacDougall et al., 1987] . . . . . . . . 26 


\subsection{INTRODUCTION}

\subsection{Underground Repository Concept}

Current planning for isolation of commercial high-level nuclear waste involves waste emplacement in a repository or Mined Geologic Disposal System at a site at Yucca Mountain, Nevada. The site consists of a layered sequence of welded, non-welded and bedded tuffs, for which the stratigraphy is shown in Fig. 1-1. The unit nominated as the waste emplacement horizon is the welded ash-flow portion of the Topopah Spring Member of the Paintbrush Tuff. At this horizon, the rock mass is unsaturated, with the water table $200 \mathrm{~m}$ to $400 \mathrm{~m}$ below the emplacement horizon (MacDougall et al., 1987). In this medium, it is anticipated that conventional practices for underground design and construction in hard-rock mining will provide stable underground excavations.

Geomechanical conditions at the emplacement horizon are characterized by a competent rock material, prominent vertical and subvertical jointing, and faults which transgress the site environs. These include the Bow Ridge, Paintbrush, Ghost Dance, Midway Valley and Severe Wash faults. Detailed site investigation during repository construction may reveal other faults and prominent structural features. In geomechanical terms, the conditions described for the repository domain are in no way exceptional relative to underground hard-rock mining experience.

The conceptual design for the repository resembles a room-andpillar mine in a shallow dipping orebody. A general isometric view of the underground facilities is shown in Fig. 1-2, and a detailed plan view of a repository panel is shown in Fig. 1-3. Independently of whether canister emplacement holes are oriented vertically or horizontally, by mining standards, the area extraction ratio over the repository horizon will be low, probably less than 20 percent.

Construction of a repository and emplacement of heat-emitting waste packages will result in modification of the natural state of stress and mechanical integrity of the host rock mass in a localized zone around the rooms of the repository and around the repository as a whole. A particular concern with such rock mass modification is the prospective change in rock mass hydraulic properties, and increase in permeability to fluid flow. Formal definition and prediction of the extent of this zone are of consequence because they convey general notions about the nature of repository interaction with the host medium, and its capacity for long-term containment of nuclear waste. 


\subsection{Rock Mass Modification By a Repository}

An outline paper on rock mass response to repository construction, operation and waste containment (U.S. NRC, 1986) suggests that four (4) factors should be considered in the estimation of the extent of rock mass modification. These are:

(1) stress redistribution;

(2) construction and excavation;

(3) thermomechanical effects; and

(4) thermochemical effects.

With the exception of thermochemical effects, which are not considered in this report, it is worth reviewing the nature of host rock mass response associated with these factors.

1.2.1 Stress Redistribution - When an excavation is constructed in a rock mass, generation of the boundary surfaces reduces the traction on them from that corresponding to the natural state of stress to zero. Construction of the excavation is therefore mechanically equivalent to imposing, on the contour of the boundaries, distributions of traction equal in magnitude but opposite in sense to those which existed in the pre-mining state. Introduction of these excavation-induced tractions modifies the state of stress in the host rock around the opening, and induces displacements in the vicinity of the excavation. The magnitude and extent of the change in the stress distribution are determined by the initial state of stress, the size, shape and orientation of the excavation, the site structural geology, and the rock mass strength and deformation properties. Because identification of the zone of modified rock mass properties requires taking into account specific initial properties of the rock mass, definition of a modified zone in terms of stress changes exclusively is not feasible.

1.2.2 Construction-Induced Effects - A previous study (U.S. NRC, 1986) suggested that mechanical and hydraulic property changes resulting from construction of underground excavations are confined to about a half-room diameter from the excavation surface. From the numerical analyses reported here, it is not possible to assess the amount of mechanical modification that may result from repository construction. However, constructioninduced interactions with the surrounding rock are associated 
with impact and vibration of excavation machinery and the uncontrolled dynamic effects of blasting. Tunnel boring machines, mechanical miners, and controlled/smooth-wall blasting techniques are among the excavation methods available to restrict modification of the rock adjacent to an excavation. In general, smoothwall blasting will result in more pronounced changes than the other two methods. Blasting will produce a blast-induced fractured zone (i.e., frequent randomly-oriented new fractures of the intact rock) immediately adjacent to the excavation with some fractures emanating radially some distance beyond the zone. In addition, relative shear displacement and separation may occur along any natural joints or discontinuities in the proximity of the excavation, resulting in a zone of loosened rock.

Field investigations confirm these general notions of rock mass modification due to construction activities. Obert and Duvall (1967) report core drilling, stress determinations, and seismic tests made in the walls of underground openings that indicate fractures and loosened joints are present to a depth ranging from 1 to 2 meters from the face of the excavation. Observations from the stripa mine in Sweden (Kelsall et al., 1982) showed that blast-induced fractures extended to a depth of 0.1 to $1 \mathrm{~m}$ from the face of the opening, with an average depth of $0.3 \mathrm{~m}$. In a summary of work performed by the USBM, Hocking and St.John (1979) propose a general conclusion that the blast-fractured zone should extend only 5 to 10 charge diameters for low energy explosives such as used in smooth-wall blasting, resulting in a blast fractured zone of about $0.35 \mathrm{~m}$ around the opening. While the extent of mechanical modification of the host rock due to construction of the underground opening depends on the quality of the rock as well as the excavation method, it can be expected that such effects will be contained within a distance of roughly one-half a room diameter from the face of the excavation for the size of openings considered in a HLW repository.

1.2.3 Thermomechanical Effects - Thermally-induced stresses in rock can produce new cracks, and also can result in the opening and closing of existing joints. In cases where fluid flow in fractures is a significant part of the overall flow, new or newly-opened fractures may increase flow significantly. On the other hand, where matrix flow predominates, the effect of fracture closure may be to increase the matrix flow. Matrix flow can be a significant proportion of the flow if the medium is unsaturated, which may be the case for the tuffs at Yucca Mountain. Increased rock permeability may occur close to the heat sources, due to thermal cracking, but this may be compensated for by increased compressive stresses from rock thermal expansion and subsequent joint aperture closure. 
Another potential thermomechanical effect is a reduction in the horizontal compressive stress in regions of the host rock some distance above and below the repository horizon. This would be a transient phenomenon caused by differential thermal expansion of the rock, and would be expected to decrease with time. However, for any sub-vertical joints or discontinuities in these regions, a reduction in the horizontal compressive stress will permit opening of joints (i.e., an increase in the fracture permeability). The vertical stresses are not expected to be significantly influenced by thermomechanical effects. Therefore, in the same region, fracture permeability along horizontal joints is not expected to change substantially. However, deformation of horizontal joints may affect the response of vertical joints, so both vertical and horizontal joints are considered in section 3 .

\subsection{Discussion of Prior DOE Analysis}

A notion called "the disturbed zone" has been the subject of previous study by the Department of Energy, as reported by Langkopf (1987). In the report, the disturbed zone is assumed to be that region in which an order-of-magnitude permeability change (or equivalently, a factor-of-two porosity change) occurs. Analyses conducted previously were reviewed to determine the extent of this region. Langkopf (1987) reviewed the analyses based on the following premises.

1. The disturbed zone boundary is the starting point from which pre-waste-emplacement groundwater travel times are to be computed.

2. Only changes based on "expected" conditions are used to establish the disturbed zone boundary.

3. Only repository-induced changes in permeability and porosity are used to define the disturbed zone.

4. The disturbed zone boundary is assumed not to be time-dependent, but to be fixed at the furthest extent to which changes are experienced over all time.

5. The disturbed zone is defined as a planar surface below the repository, because groundwater flow in the unsaturated zone is essentially vertically downwards. 
Taking account of these concepts, Langkopf summarized results of computer analyses and laboratory experiments and suggested a 10cation of the disturbed zone boundary for the repository site at Yucca Mountain. The report concludes that "... there is no evidence of changes in intrinsic hydrologic properties that could significantly change the groundwater travel time from the repository to the water table" and, for this reason, suggests that the nominal boundary of the disturbed zone be located $10 \mathrm{~m}$ below the lower boundary of the waste packages.

Considering the premises proposed by langkopf, the first four seem reasonable and consistent with the intent of the regulations. The fifth, however, requires further consideration. Langkopf (1987) states that some studies have indicated the possibility of lateral flow. In addition, it is possible that effects such as thermally-induced buoyancy and thermochemical sealing of possible flowpaths may induce either lateral or upward flow. In Chapter 4 of Langkopf's report, a summary of the expected conditions at the site is included, reporting matrix conductivities and porosities for the hydrogeologic units underlying the site, including a reference to mean saturation data reported by Montazer and Wilson (1984). In the Topopah Spring welded tuff unit (i.e., the repository horizon), the mean saturation level reported is 65\%, with a standard deviation of $19 \%$ (Montazer and Wilson, 1984). Most of the fractures in the Topopah spring unit are reported to be near-vertical, with as many as 42 fractures per cubic meter (Scott et al., 1983). Fracture porosity has been estimated from $0.018 \%$ to $0.28 \%$ for the Topopah Spring unit (Sinnock et al., 1984; Peters et al., 1986). Langkopf (1987) also includes a discussion of the expected flow mechanisms at the Yucca Mountain site. It is thought that the transients caused by surface precipitation are damped out by the time the Topopah spring unit is reached (Wang and Narasimhan, 1986).

The capillary-bundle theory for unsaturated flow has been used to describe water movement in the unsaturated zone. This theory is based on the fact that the surface tension in the small-diameter pores causes water to move into the matrix rather than the fractures. Under this theory, the fractures actually offer resistance to flow rather than preferential pathways and, therefore, fracture closing increases rock mass flow. Although this may be counter-intuitive, it is an observed and accepted phenomenon in soils (Baver et al., 1972), and is caused by the same surface forces that cause capillary rise. Under saturated conditions, the reverse applies, and fracture opening increases flow. Langkopf (1987) qualifies the assumption of unsaturated flow as follows. 
1. Perched water could accumulate, causing fracture flow.

2. Inhomogeneity and variations in groundwater flux could cause fracture flow.

3. Pockets of air trapped in small pores could cause flow to move to larger pores or fractures.

4. Periodic high-infiltration events at the surface could change the flow mechanism.

The ambient stresses and temperatures at the site are also estimated, based on results of hydrofracturing tests and borehole measurements, respectively.

Analyses concerned with hydrologic property changes that could result from repository heat output and excavation are also reviewed by Langkopf (1987). The results of several such analyses are reported, which indicate that joint movement is limited to the rock within 2 or $3 \mathrm{~m}$ of the walls of the underground openings. Analyses by Labreche (1986), which report vertical joint closure by a factor of 2 within a $60 \mathrm{~m}$ radius of the borehole for horizontal emplacement are also mentioned.

For saturated intact tuff samples, Langkopf (1987) reports that the permeability is insensitive to changes in temperature, but the permeabilities of fractured samples can exhibit a variation depending on conditions, including the effective stress. zimmerman et al. (1986) have concluded that fracture permeability is not very sensitive to either stress or temperature changes. The apparent inconsistency between these results may be caused by the fact that the degree of saturation may have an effect on the permeability.

For example, if fracture flow is controlling the rate, changes in fracture aperture will have a large effect but, if matrix flow is rate-controlling, fracture aperture may not have a noticeable effect on the overall permeability. Because the proposed repository will be located in the unsaturated zone, it would be helpful if permeabilities were available from unsaturated tests.

As noted above, the principal conclusion from the study by Langkopf (1987) is that the extent of the disturbed zone is very small, and suggests that, conservatively, its boundary may be located at an elevation $10 \mathrm{~m}$ below the waste packages. 


\subsection{Purpose and Scope of the Current Work}

The purpose of this work was to obtain an estimate of the size of the zone of rock mass modification around a HLW repository for conditions similar to those expected at the proposed Yucca Mountain site. The performance of rock in this zone may then be related to those in the disturbed zone considered by Langkopf (1987). The estimate has been based on the results of numerical simulation of the performance of the host rock mass under repository operating conditions, taking account of pseudo-static loading in the rock mass due to the field stresses and the thermomechanical loading. Thus, consideration of change in rock mass properties due to any dynamic effects at the site has been specifically excluded from this study. The analysis has been conducted by determining changes in the state of stress in the repository host rock due to excavation of openings and thermal loading, and evaluating the effect of these changes on the intrinsic hydraulic properties of the rock, specifically fracture permeability as a result of joint slip or joint opening. The work has considered only two of the four effects identified previously-i.e., stress redistribution in the rock as a result of excavating the repository rooms and thermomechanical effects in the rock as a result of heat generating waste stored in the repository. These effects have been considered for a time period of up to 500 years after waste emplacement. Construction-induced effects and thermochemical effects have not been included in this study. However, construction-induced effects may be considered independently. They have been discussed in section 1.3.2, based on work by several investigators (Obert and Duval1, 1967; Kelsall et al., 1982; Hocking and St.John, 1979).

The groundwater flow mechanism in the Topopah spring unit at Yucca Mountain is uncertain. It is generally assumed that unsaturated conditions prevail at the repository site, which would suggest that the flow of groundwater would occur predominately through the matrix. However, the data is not sufficient to exclude the prospect of regions of very high levels of saturation where fracture flow may occur.

It is noted that in the current analyses, factors that influence groundwater flow through vertical fractures are the primary consideration. Zones are identified in the host rock where changes in the fracture permeability may significantly enhance or retard the groundwater flow. Slip on vertical fractures, or opening of vertical fractures by a factor of two are considered significant with respect to the determination of the zone of modified rock mass mechanical and hydraulic properties. The role of continuous 
subhorizontal planes of weakness, such as bedding planes between the members of the sedimentary sequence, is examined with respect to their influence on separation and slip on the vertical joints.

In assessing the results of the analysis, it is important to not that the results reflect the assumptions and idealizations incorporated in the models, and the degree of certainty with which essential model input parameters are known. For example, because of uncertainty about the in-situ state of stress, it is necessary to perform analyses for a range of assumed in-situ states of stress. 


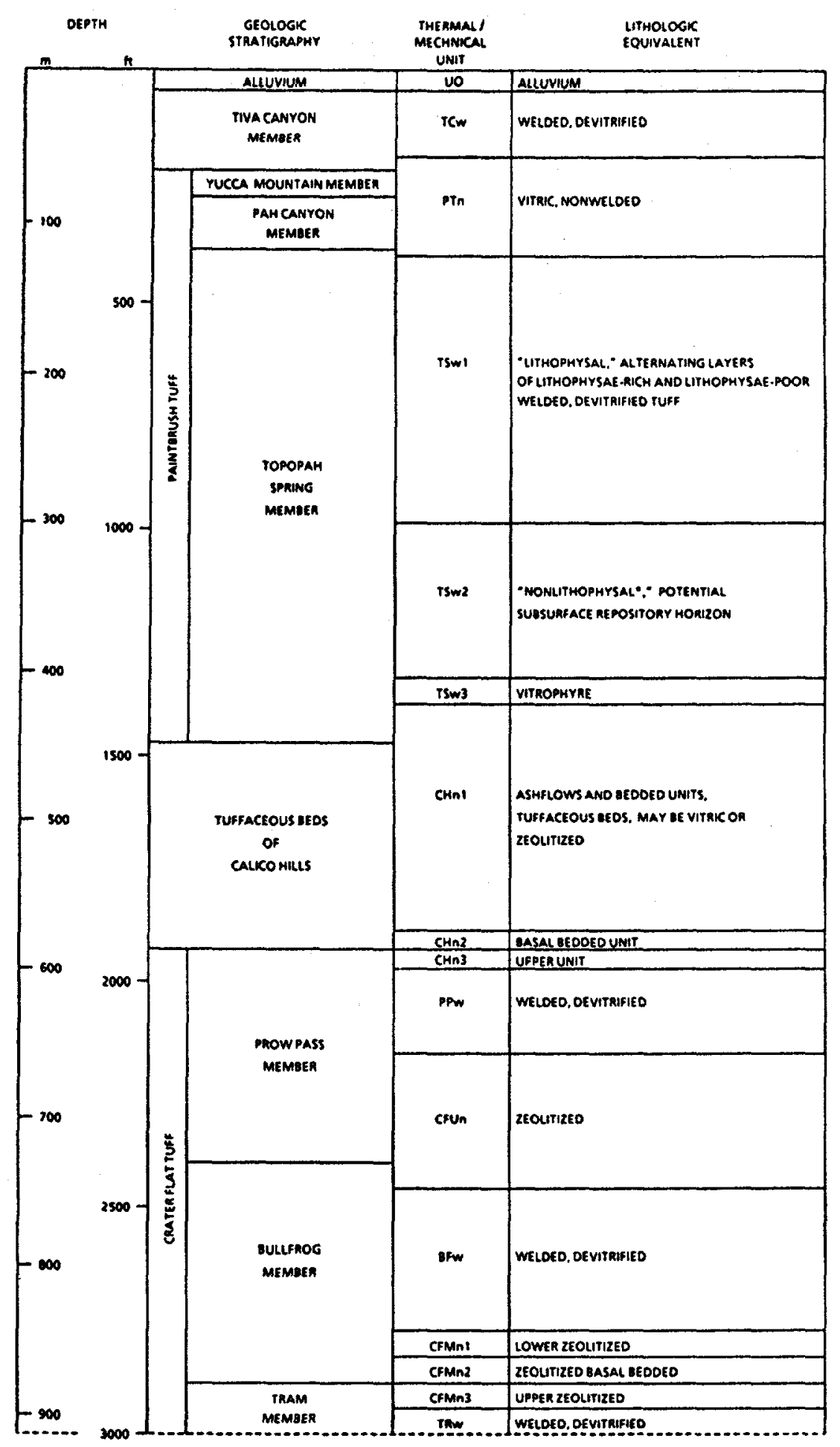

Fig. 1-1 Thermal/Mechanical Stratigraphy at Yucca Mountain [MacDougall et al., 1987] 


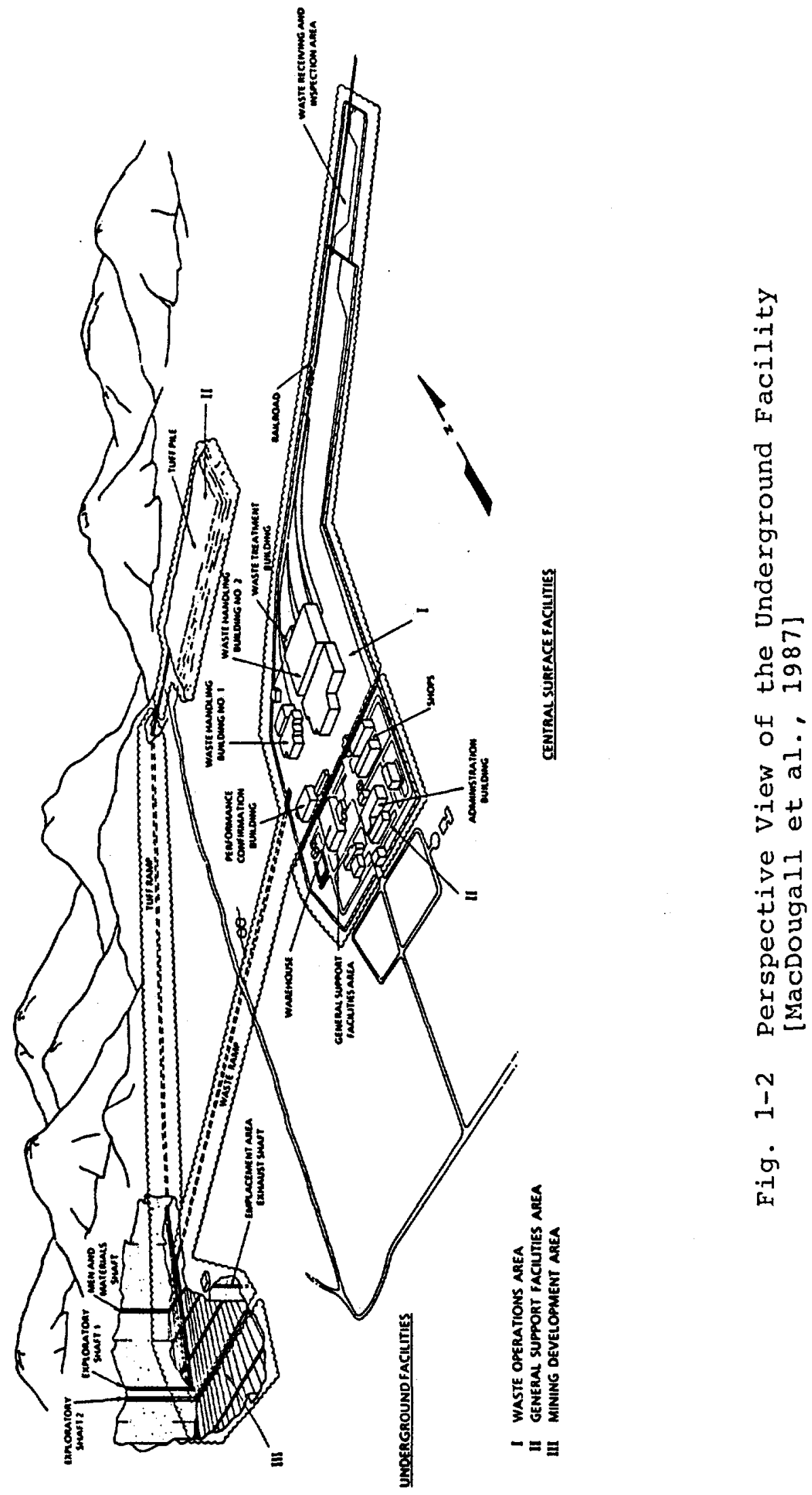




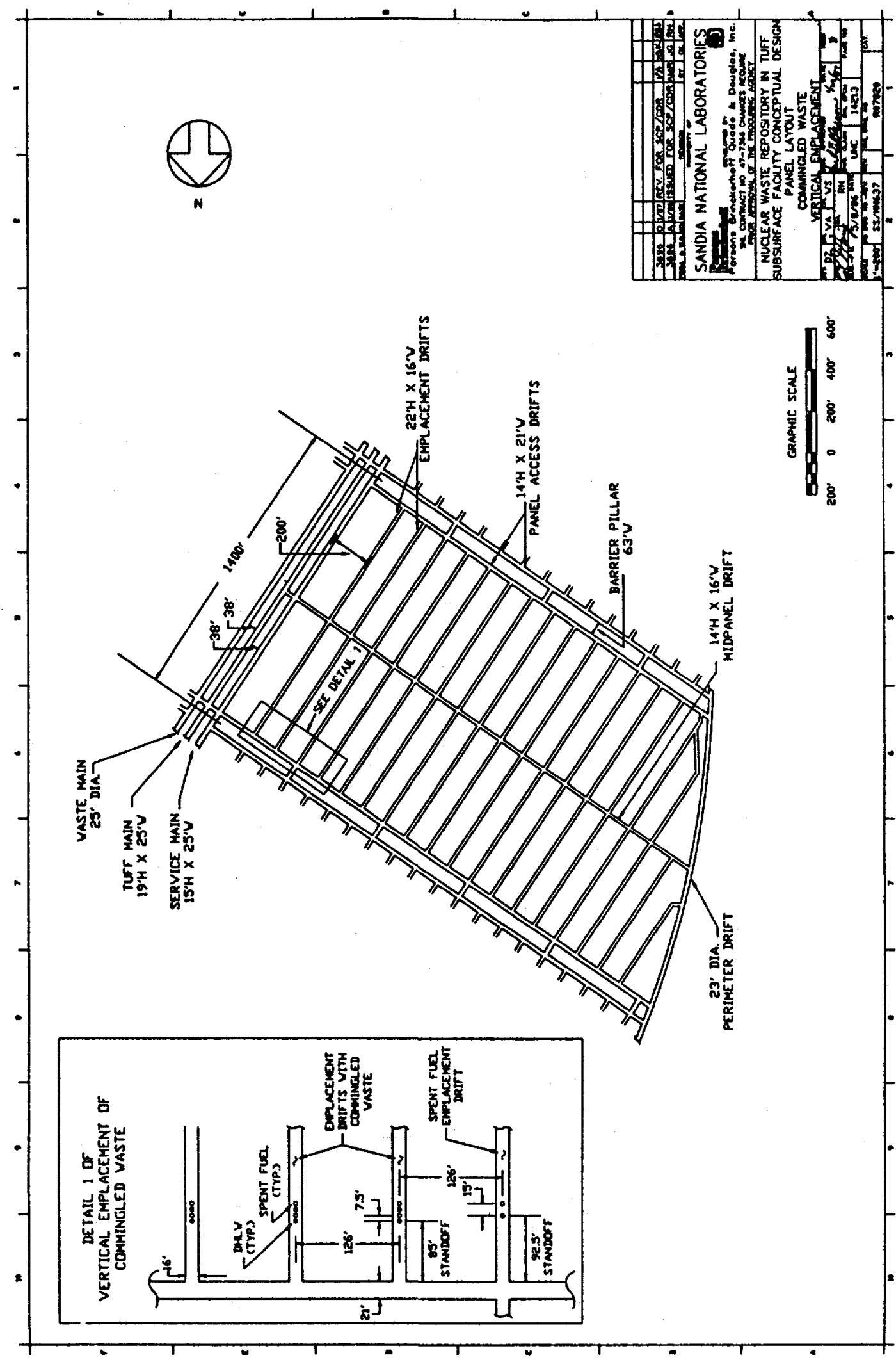

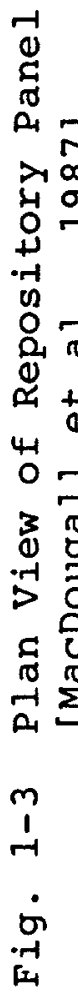




\subsection{CONCEPTUAL AND NUMERICAL MODELS OF ROCK MASS PERFORMANCE \\ 2.1 Flow Mechanism}

There are two possible flowpaths for groundwater in fractured, porous rock. These are fractures, either of geologic origin or caused by the repository, and the rock matrix. Depending on the level of saturation and water flux, flow will be greater in one or the other of these. Peters and Klavetter (1988) describe a model of water movement in unsaturated, fractured rock. The major features of their model are:

(1) the fracture conductivity for flow across the fractures is sufficiently high that flow is controlled by the adjacent matrix permeability;

(2) the average fracture conductivity for water movement in the plane of the fracture is highly dependent on fracture saturation or pressure head; and

(3) if the vertical flux is less than the saturated conductivity of the matrix, water will tend to flow mainly in the matrix.

If the flux is greater than the matrix conductivity, the matrix will saturate, and the fractures will transport water. As a corollary to this, if the fractures are predominantly in one direction (as they are at the Yucca Mountain site), the rock mass conductivity will become anisotropic as greater levels of saturation are reached. Figures $2-1$ and 2-2, due to Peters and Klavetter (1988), show the relation between hydraulic conductivity, saturation level, and pressure head. Under conditions of saturated flow, the fractures control the flow rate while, under unsaturated conditions, matrix flow becomes the controlling mode of water movement. Thus, an analysis to identify a zone of modified rock mass hydraulic properties must take account of the different modes of groundwater movement under the different possible conditions of saturation in the rock mass.

\subsection{Separation on Fractures}

The primary factor controlling the opening and closing of fractures in rock is the magnitude of the normal stress acting on the fracture. For interlocked fractures the following expression, 
due to Bandis et al. (1983), may be used to relate fracture aperture in terms of the normal stress (Bandis et al., 1983):

$$
\Delta v_{j}=\left(a \sigma_{n}\right) /\left(1+b \sigma_{n}\right)
$$

where $\Delta v_{j}=$ joint aperture change,

$$
\sigma_{\mathrm{n}}=\text { normal stress on the joint, and }
$$

$a, b=$ joint characteristic parameters.

The Site Characterization Plan Conceptual Design Report (SCPCDR) for Yucca Mountain (MacDougall et al., 1987) reports the recommended value of the average unstressed fracture aperture in the Topopah Spring as 18 micrometers, and the half-closure stress as 1.1 MPa. Substituting these values into Eq. (1) provides the following values for the joint closure parameters:

$$
\begin{aligned}
& a=0.016 \mathrm{~mm} \mathrm{MPa}^{-1}, \text { and } \\
& b=0.909 \mathrm{MPa}^{-1} .
\end{aligned}
$$

Thus, from the initial normal stress (i.e., that corresponding to the assumed in-situ stress state in the rock) and the predicted final state of normal stress on a fracture, the initial and final joint apertures, and hence the aperture ratio, can be calculated.

It can be shown (Snow, 1968) that fracture permeability can be related to fracture aperture through a cubic relation of the form

$$
\mathrm{k}=\mathrm{N} \mathrm{e}^{3 / 12}
$$

where $e$ is the effective aperture, and

$\mathrm{N}$ is the number of fractures per unit distance. 
Thus, a factor-of-two change in aperture causes approximately one order of magnitude change in permeability. The expression in Eq. (1) relating joint normal stress and normal deformation has been used in this work to estimate joint apertures and aperture ratios under different states of normal stress. An aperture ratio of less than 0.5 or more than 2 has been chosen to indicate a significant change in permeability.

\subsection{Slip on Fractures}

The capacity of a structural feature to resist slip and maintain the undisturbed state of the rock mass is determined by the shear strength of the joint. The shear strength is related to the normal stress acting on the feature. One of the most common expressions used to relate shear strength and normal stress is the Mohr-Coulomb criterion which is stated as:

$$
\tau=c+\sigma_{\mathrm{n}} \tan \phi
$$

where $\tau=$ joint shear strength,

$$
\begin{aligned}
\sigma_{\mathrm{n}} & =\text { normal stress on feature, } \\
c & =\text { joint cohesion, and } \\
\phi & =\text { joint friction angle. }
\end{aligned}
$$

The Mohr-Coulomb criterion has been used in this work to indicate zones of possible joint slip. For the Topopah spring welded unit, the cohesion is taken as $0.1 \mathrm{MPa}$, and the angle of friction as $28^{\circ}$ (MacDougall et al., 1987, Chapter 2).

When the interfaces between the welded tuff and adjacent members of the sequence have been represented, friction angles of $28^{\circ}$ and $10^{\circ}$ have been used, with no cohesion. A $10^{\circ}$ friction angle represents the shear strength of a clay-filled feature at a state of residual strength, while $28^{\circ}$ corresponds to that for the rough vertical joints. Although $10^{\circ}$ is probably a very low value, it serves to illustrate the effect of possible slip on horizontal features.

The effect of slip on fracture flow is not easily quantified. For rough joints in a pre-peak strength condition, slip is accompanied by dilation (Goodman, 1976). The effect of slip on joint 
permeability is rather complex. Comprehensive analysis requires the application of a joint deformation model similar to that described by Barton et al. (1985). However, such models are not necessarily well-behaved in the numerical schemes in which they are implemented. In this study, it has been assumed that all slip causes dilation, and this leads to some increase in permeability. Therefore, zones of potential slip are indicated, but the effect on groundwater flow has not been quantified.

\subsection{Numerical Models}

There are several different numerical models which provide the capacity to analyze changes in the state of stress in the rock in the vicinity of a repository and which therefore can be used to estimate the extent of the disturbed zone. The codes used in this work are the thermoelastic boundary element code HEFF [Brady (1980), (1988) ], which can efficiently predict the thermomechanical behavior of the rock, and the distinct element code UDEC (Itasca, 1989), which allows joints to be incorporated explicitly into the model.

Although a thermoelastic code like HEFF does not simulate inelastic rock behavior, a first-order, engineering estimate of the extent of such behavior can be inferred by applying appropriate criteria to the stress distribution determined in the elastic analysis. For example, the domain in which joint slip is possible may be estimated from the calculated thermoelastic stress distribution and the Mohr-Coulomb criterion for joint slip described by Eq. (3). This procedure is justified and illustrated by Bray (1987). It should not be confused with an elasto-plastic analysis, where provision is made for stress redistribution to occur. However, it is an accepted engineering practice which can be used to identify regions of prospective inelastic rock behavior. By analogy, it may be applied, in conjunction with the joint closure criterion defined by Eq. (1), to map regions around a repository where significant changes in joint aperture are possible. This approach corresponds, in effect, to taking a single joint, placing it at different locations in the model, and examining the effect of the predicted stress field on the joint. The expression in Eq. (1) for change in aperture is not applicable for tensile stresses. To overcome this problem in the current work, if regions of tensile stresses are predicted, a joint aperture increase by a factor of two is indicated. 
The distinct element code UDEC (Itasca, 1989) is well suited, in principle, for investigation of the thermomechanical performance of joints in a rock mass. The analytical scheme provides for the explicit evaluation of both the normal and shear deformation of joints, and permits analysis of the kinematics of block motion in a block-jointed rock mass, accounting for potential sliding and rotation of individual blocks. In such an analysis, a critical input is the assumed model for joint deformation and strength, and the set of parameters which describe the site-specific joint properties incorporated in the joint model. For example, the linear deformation, Coulombic friction model illustrated in Fig. 2-3 is the simplest formal description of joint deformation and strength. It is a 6-parameter model. Unless these parameters are determined in appropriate tests, the reliability of the calculations of rock mass response may not be any better than that determined from the simple continuum analysis.

Through an extended time, the heat output from the repository will affect an extensive region of the host rock. It is therefore necessary to investigate the host rock beyond that included in a room-scale model. This can be accomplished by analyzing effects on a repository scale. In this work, HEFE has been used for room-scale and repository-scale analyses, while UDEC has been used only for a repository-scale analysis. The conceptual roomand repository-scale models used with HEFF are illustrated in Figs. 2-4 and 2-5, while Fig. 2-6 shows the conceptual repository-scale model used with UDEC. It is noted that room-scale models for both horizontal and vertical waste emplacement were investigated using HEFF. However, in Fig. 2-4, only the vertical waste emplacement concept is shown. The room geometries and waste lay-out reflect those given in the SCPCDR (MacDougall et al., 1987).

In the HEFF models, the rock is considered to be homogeneous and isotropic with rock mass properties corresponding to those of tuff from the Topopah Spring unit. In the UDEC model, explicit vertical joints are included. The rock mass between joints is considered homogeneous and isotropic, with properties of tuff from the Topopah spring unit. The models do not account for the stratigraphy at the Yucca Mountain site in detail but, in some cases, features above and below the repository horizon are modeled explicitly, as shown in Fig. 2-7. 


\subsection{The Boundary Element Code HEFF}

HEFE is a two-dimensional thermoelastic boundary element program for the analysis of homogeneous, isotropic, linear elastic rock masses. Boundary element methods have the advantage that only the surface of excavations must be discretized, rather than the entire problem domain, as is required by methods such as finite elements, finite differences, and distinct elements. The HEFF formulation includes the effects of heat sources embedded in the rock mass. Each waste container is represented as a series of decaying heat sources. The assumption in the analysis is that heat losses to the ventilation air stream are insignificant in comparison with heat transfer by conduction to the rock mass interior. This permits calculation of temperature and the associated thermal stresses from the analytical solutions for a series of point heat sources in an infinite medium. Superposition of temperature and induced stress from the various sources is possible due to the linear constitutive behavior of the rock mass.

The boundary element solution procedure imposes a zero traction boundary condition at the excavation surfaces. The solution is thus equivalent to assuming that the excavation is filled with a material with the thermal properties of rock, but the mechanical properties of air. In spite of this simplifying assumption, it is proposed that HEFF is suitable for the room- and repositoryscale analyses described in this report. Although the temperature field very close to the rooms is affected, to some extent, by the assumption of equivalent thermal properties of rock and air, the effects are not sufficient to cause substantial differences in the thermomechanical predictions, and will attenuate some distance from the excavation.

From the elastic analysis, changes in joint normal and shear stress can be calculated for a plane oriented in the same direction as the joint by a simple two-dimensional stress transformation. This permits joint apertures to be calculated using Eq. (1) and factors of safety against joint slip by applying the Mohr-Coulomb criterion of Eq. (3). Careful evaluation of the results is important when using these post-processing techniques in order not to misinterpret the effects indicated. For example, the zone of slip indicated by the elastic analysis may underestimate the zone obtained when stress re-distribution is taken into account in a non-linear analysis. 


\subsection{The Distinct Element Code UDEC}

UDEC is a two-dimensional distinct element code. Three basic features of distinct element methods make them suitable for modeling discontinua:

(1) the rock mass is modeled as an assembly of interacting blocks;

(2) the block boundaries are treated as discontinuities, and joint behavior can be described for them;

(3) an explicit timestepping algorithm allows large displacements, rotations and non-linear constitutive behavior to be modeled.

These features all distinguish UDEC from HEFF, in which the rock mass is treated as an elastic continuum, and joint behavior is estimated only from the resulting elastic stress state. UDEC is thus suited to the analysis of problems in which joint behavior, both normal to the joints and in shear, is likely to dominate the overall rock response. Of course, the existence of joints in a rock mass does not imply that the medium necessarily exhibits the discontinuum behavior requiring analysis with distinct elements. In this work, UDEC has been used to predict the thermomechanical response of the rock on a repository scale, where a limited number of discontinuities may express the discontinuous nature of the rock mass. 


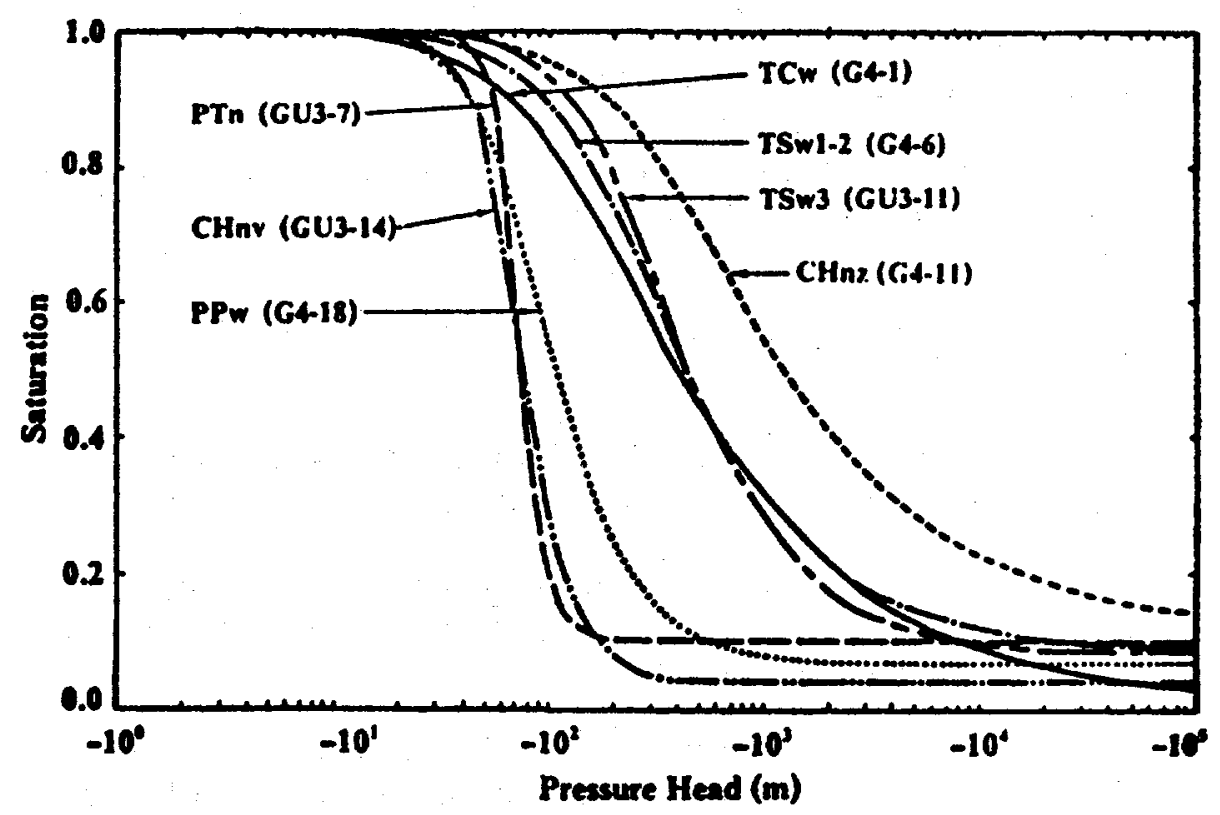

Fig. 2-1 Typical Matrix Saturation Curves for the Unsaturated Zone Hydraulic Units [after Peters and Klavetter, 1988]

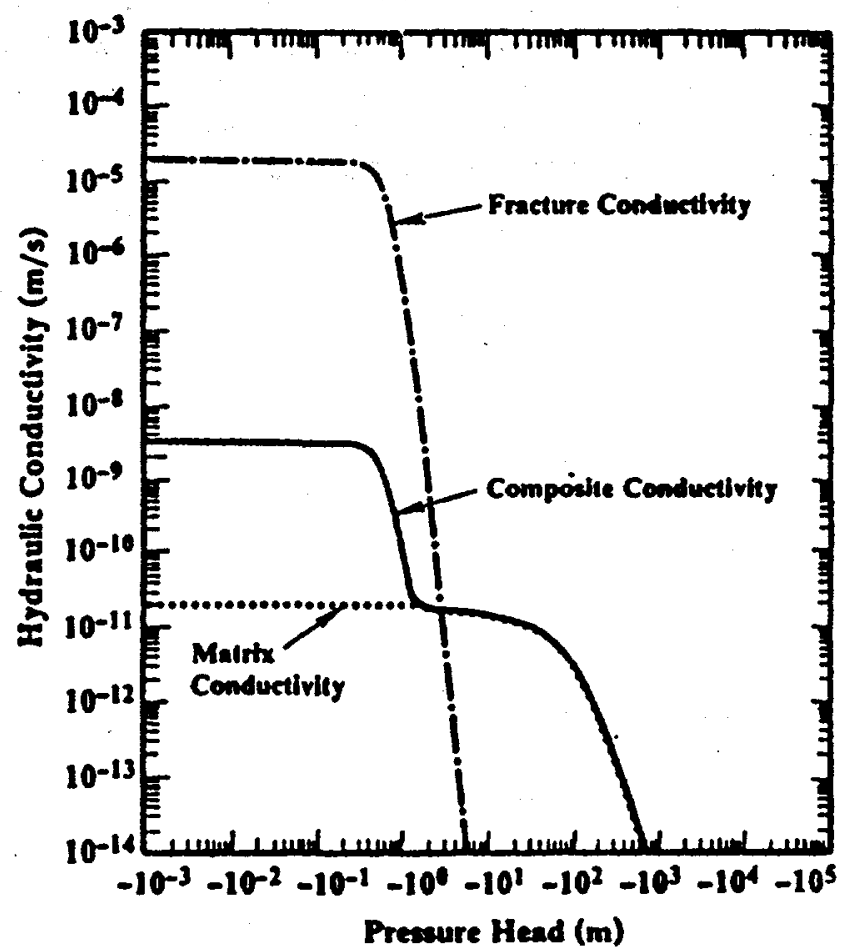

Fig. 2-2 Conductivity Curve for the Repository Unit TSw2 [after Peters and Klavetter, 1988] 


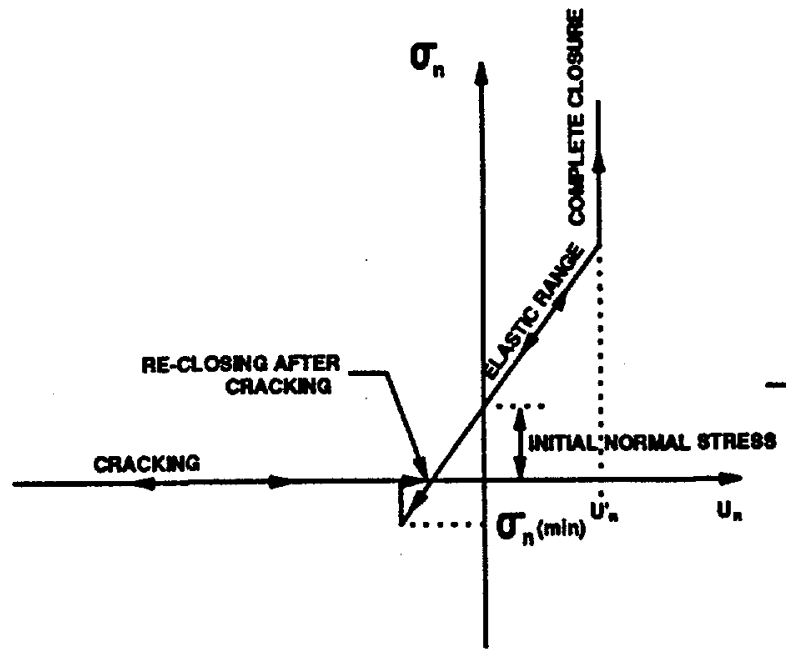

(a)

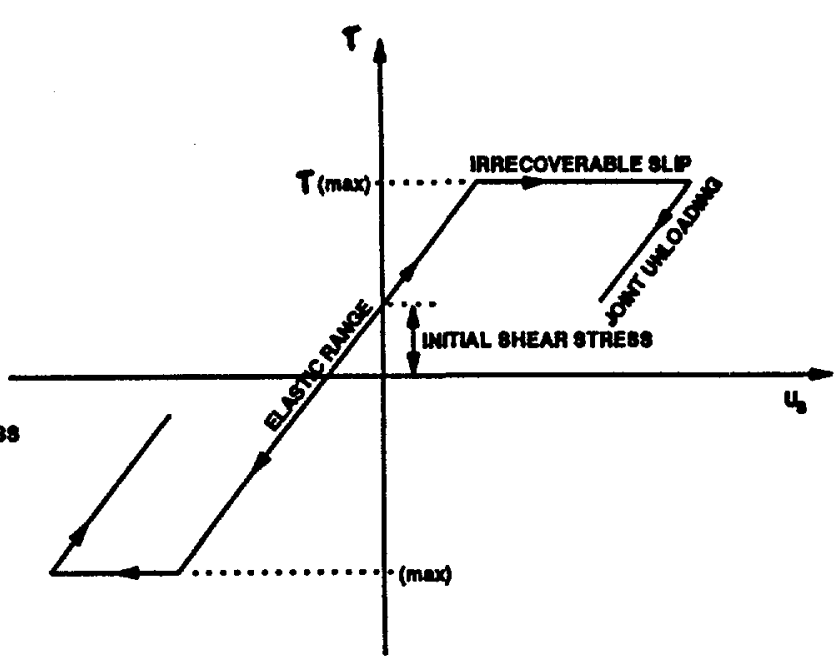

(b)

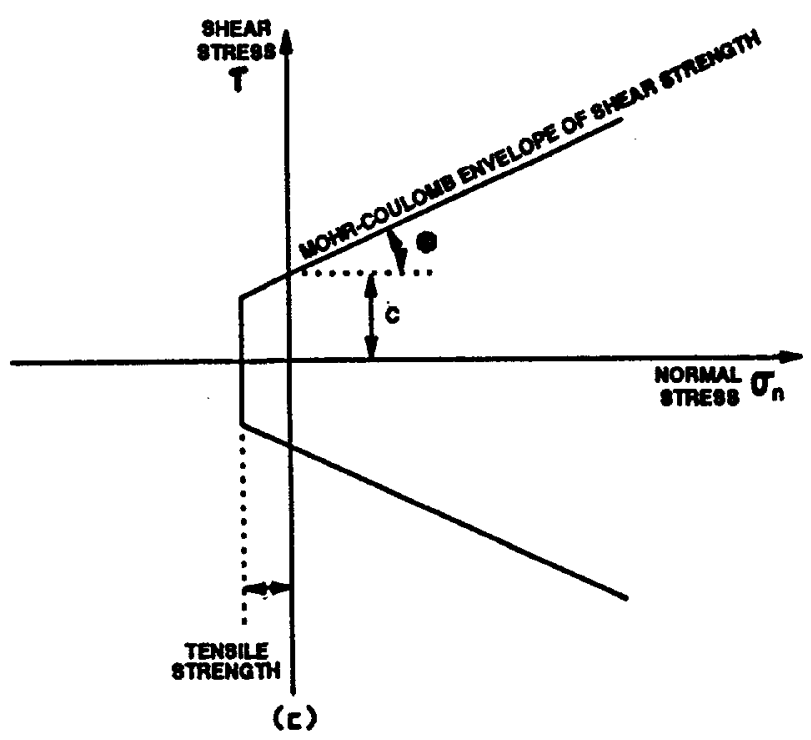

Fig. 2-3 Coulombic Friction, Linear Deformation Model for a Joint: (a) normal deformation; (b) shear deformation; (c) shear strength [Crotty and wardle, 1985] 


\section{Room-scale Conceptual Model, Vertical Emplacement}

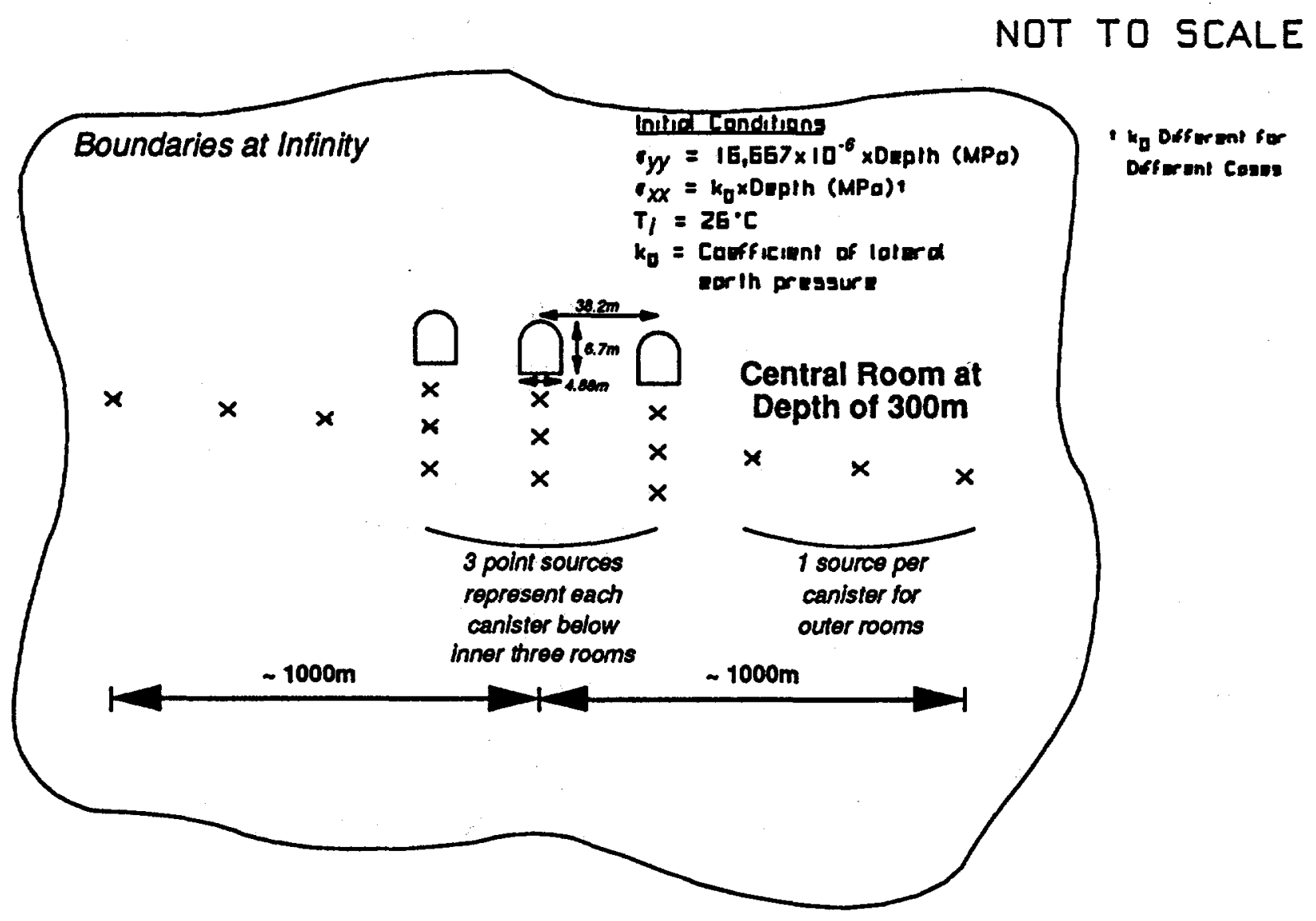

Fig. 2-4 Conceptual Room-Scale Model for HEFF 


\section{Repository-scale Conceptual Model, Vertical Emplacement}

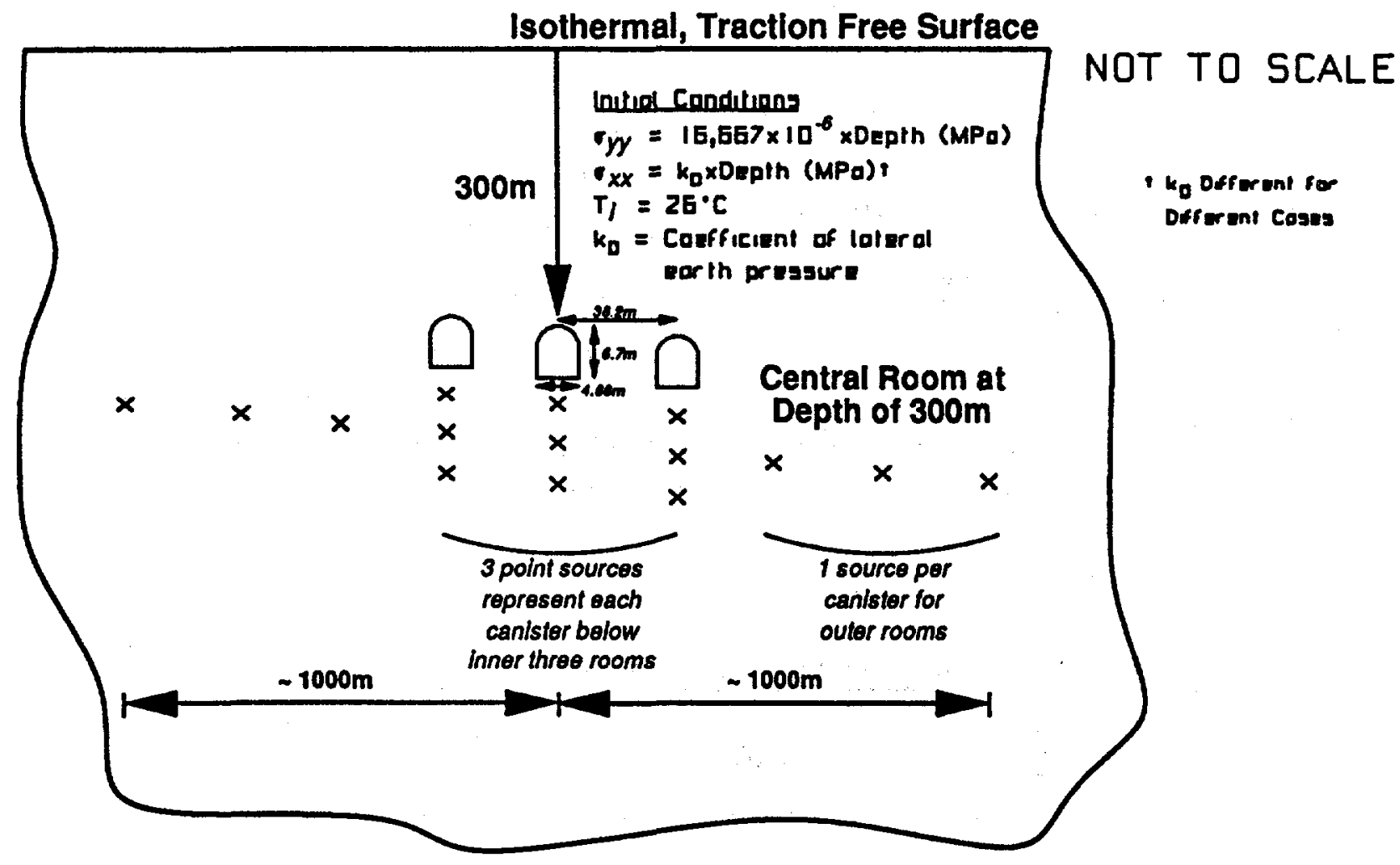

Fig. 2-5 Conceptual Repository-Scale Model for HEFF 


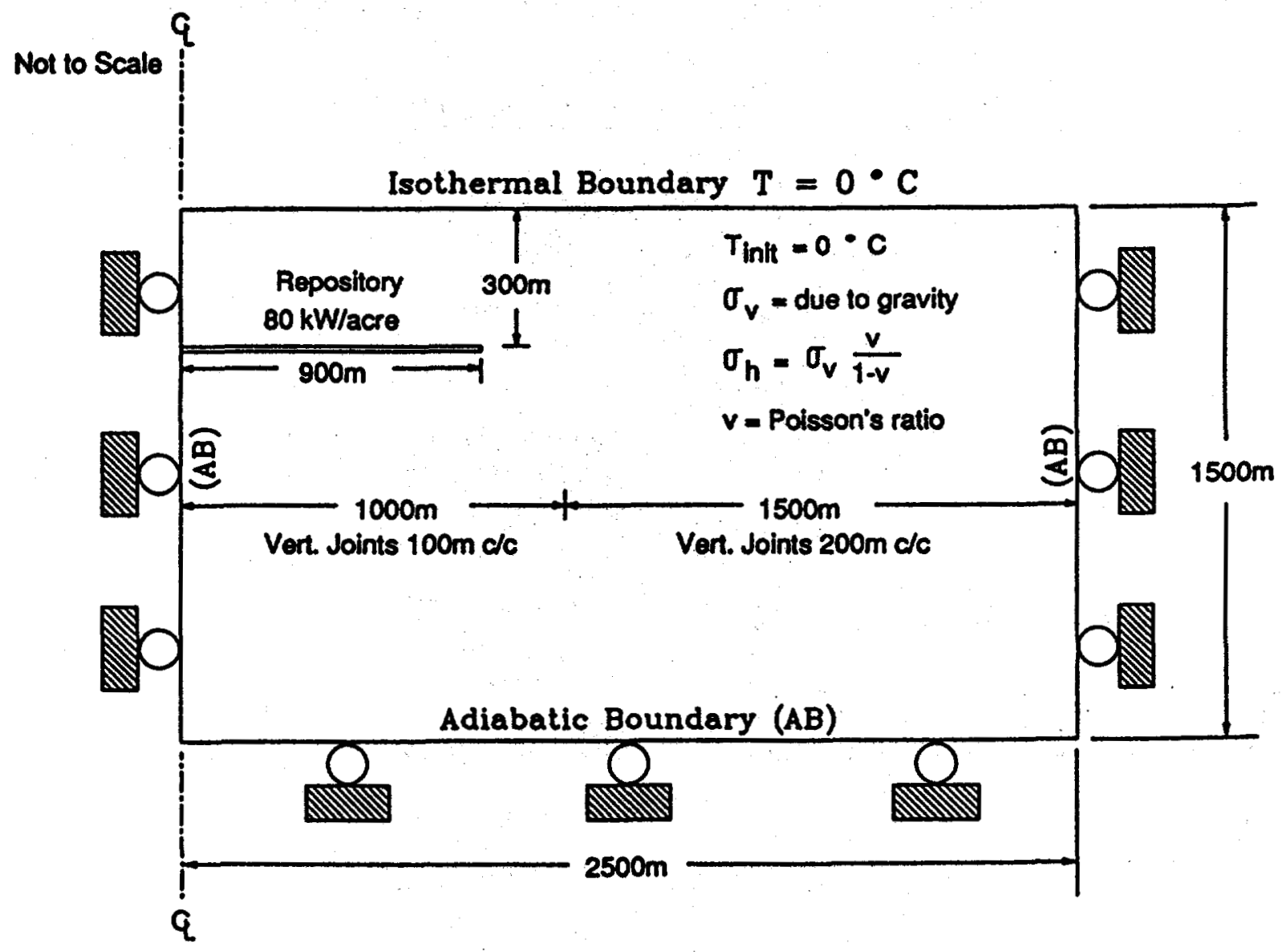

Fig. 2-6 Conceptual Repository-Scale Model for UDEC 


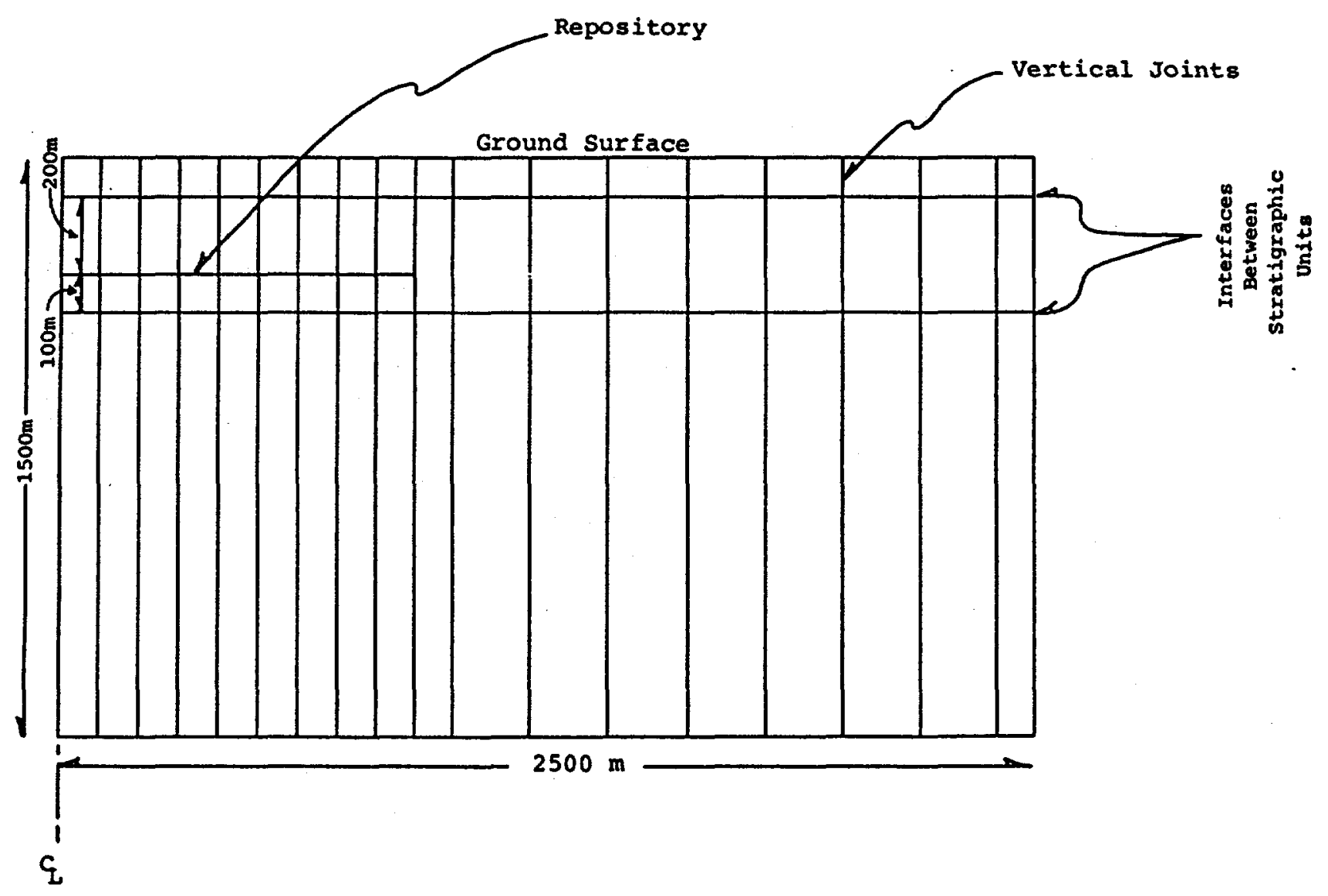

Fig. 2-7 Repository-Scale Model for UDEC, Showing Joint Locations 


\subsection{ANALYSIS}

\subsection{Reference Conditions}

The potential repository at Yucca Mountain is to be developed in the "non-lithophysal" Topopah Spring member, on a plane dipping at about $6^{\circ}$ to the East, at an average depth of about $300 \mathrm{~m}$. The material property values used for the analyses are taken from the recommended and design values for the Topopah Spring member listed in the SCPCDR (MaCDougall et al., 1987, Chapter 2). Table 3-1 summarizes the properties used. The initial power of a spent Fuel (SF) container at the time of emplacement may range from 2.3 $\mathrm{kW}$ to $3.4 \mathrm{~kW}$ (O'Brian, 1985). In this work, the initial power is set conservatively to $3.2 \mathrm{~kW}$. The initial power of the DefenseHigh-Level-Waste (DHLW) container is chosen as $0.42 \mathrm{~kW}$ after Peters (1983). The thermal decay characteristics of SF and DHLW are given by Peters (1983) for waste ten years out of the reactor:

$$
\begin{aligned}
& \text { Spent Fuel } \quad P(t)=0.54 \exp (\ln (0.5) t / 89.3)+ \\
& 0.44 \exp (\ln (0.5) t / 12.8) \\
& \text { DHLW } \quad P(t)=0.86 \exp (\ln (0.5) t / 34.2)+ \\
& 0.14 \exp (\ln (0.5) t / 15.2)
\end{aligned}
$$

where $P(t)=$ normalized power, and

$$
t=\text { time in years. }
$$

The normalized power as a function of time, as described from the above equations as well as that given by Mansure (1985) for SF are shown in Fig. 3-1. It can be seen that the two approximations for $S E$ are very similar.

The room geometries for vertical and horizontal emplacement of waste canisters shown in Figs. 3-2 and 3-3, respectively, were obtained from the SCPCDR (MacDougall et al., 1987). The initial thermal loading can be inferred from these figures, by considering the geometrical layout of the containers and the source characteristics. It is worth noting that the thermal loading from these sources is closer to $80 \mathrm{~kW} /$ acre rather than the $57 \mathrm{~kW} /$ acre figure quoted in several sources (e.g., Langkopf, 1987). 
Table 3-1

ROCK MATERIAL AND JOINT PROPERTIES

[MacDougall et al., 1987]

\section{PROPERTY}

Density $\left(\mathrm{kg} / \mathrm{m}^{3}\right)$

Deformation Modulus (GPa)

Poisson's Ratio

Cohesion (MPa)

Friction Angle (degrees)

Normal Stiffness (1) (MPa/m)

Shear Stiffness (2) (MPa/m)

Thermal Conductivity (W/mK)

Specific Heat Capacity (J/kgK)

Coefficient of Thermal

Expansion $\left(10^{-} \mathrm{K}^{-1}\right)$

\section{ROCK MATERIALS}

2340

15.1

0.2
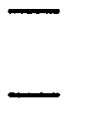

$3.5 \times 10^{5}$

$3.5 \times 10^{5}$

2.07

961.5

10.7
0.1

28

JOINTS

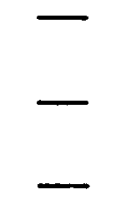

-

(1) assumed value

(2) value within range given in SCPCDR, Chapter 2 
Fracture dip angles between $70^{\circ}$ and $90^{\circ}$ were considered in the study, as most fractures at the site are reported in this range (MacDougall et al., 1987, Chapter 2). Results of initial analyses showed, however, that there was very little difference in response between joints of different dips within this range. Therefore, all the results reported here are for joints dipping at $90^{\circ}$ (i.e., vertical joints).

The initial states of stress considered in the analysis were (a) $\sigma_{X X}=1.5 \mathrm{MPa}, \sigma_{Y Y}=5 \mathrm{MPa}$; and (b) $\sigma_{X X}=3 \mathrm{MPa}, \sigma_{Y y}=5 \mathrm{MPa}$. In each case, the vertical and horizontal directions were taken to be principal stress directions.

\subsection{Room-Scale Analysis}

Room-scale analysis was conducted with the code HEFF to investigate the effects of vertical and horizontal waste emplacement and initial stress conditions on joint apertures and potential joint slip. Since HEFF is a code for two-dimensional analysis, the vertical section considered is assumed to be constructed through the repository center.

In the performance of the analysis, it is neither possible nor necessary to model every disposal room and every heat source (i.e., every waste container). Based on the concept of a zone of influence, it can be determined that the significant effects of an excavation on a rock mass are confined within three to five excavation diameters. For example, the stress change around a circular hole in an elastic medium has a magnitude inversely proportional to the square of the number of diameters from the hole (e.g. Brady and Brown, 1985, Chapter 7). For a $5 \mathrm{~m}$ diameter room in a hydrostatic stress field, for example, the stress change from excavation is reduced to 5 percent of the initial value less than $10 \mathrm{~m}$ from the wall. For the repository designs currently under consideration, the rooms for vertical emplacement are located about $35 \mathrm{~m}$ apart, and the rooms for horizontal emplacement more than $200 \mathrm{~m}$ apart. At these distances, it can be assumed that adjacent rooms do not influence each other mechanically.

To demonstrate mechanical isolation of rooms in the HEFF analysis, two rooms were modeled for the horizontal emplacement concept and three rooms for the vertical concept. The effect of heat transfer was modeled to a distance of about $1000 \mathrm{~m}$ on either side of the disposal rooms-i.e., heat-generating waste within a radius of about $1000 \mathrm{~m}$ was represented. This corresponds to modeling almost the entire repository. A two-dimensional approximation to the waste packages for vertical emplacement was made, as they are effectively infinite out-of-plane line sources in a two- 
dimensional model. The spacing between boreholes and known initial container power for DHLW and Spent Fuel (SF) were averaged to obtain the overall thermal loading. The overall decay curve was taken as a suitably weighted average of the DHLW and SF thermal decay curves. The disposal rooms were each modeled by 30 boundary elements. As noted previously, the two criteria used in these analyses to estimate the disturbed zone are aperture changes (resulting from a change in normal stress on the joints) and potential joint slip (resulting from excessive shear stresses along the joints).

In the room-scale analysis, the joint constitutive model given by Eq. (1) was used to estimate joint aperture behavior, and the Mohr-Coulomb criterion given in Eq. (3) was used to estimate joint slip. Eigures $3-4$ and 3-5 illustrate the modification of the originally uniform state of stress in the medium resulting from excavation of the disposal room for horizontal emplacement. The regions shown in these figures represent a change of more than 10 percent in the principal stress relative to the initial conditions $\left(\sigma_{x x} / \sigma_{y y}=1.5 / 5\right)$. Figure $3-6$ shows the contour within which joint apertures are predicted to decrease by more than a factor of two as a result of excavation. Only a small region in the floor of the disposal room experiences this change. There are no regions predicted where joints open by a factor of two as a result of excavation. When applying the Mohr-coulomb criterion and the recommended joint strength parameters listed in Table 3-1 to the state of stress after excavation, the predicted region of joint slip is indicated in Fig. 3-7. The region of potential slip of vertical joints is contained within about two room diameters from the excavation surface. Results for the vertical waste emplacement room are similar.

Contours of predicted temperatures around the disposal rooms after 100 years are shown in Figs. 3-8 and 3-9, for horizontal and vertical waste emplacement, respectively. It is noted that the horizontally emplaced waste is not shown in Fig. 3-8, as it is located outside the scale of the figure. In both cases, the rock temperatures have increased appreciably around the disposal rooms, with a maximum temperature of about $160^{\circ} \mathrm{C}$ in the vicinity of the vertically emplaced waste. This suggests that potential boiling of the pore water could take place in a large region of the host rock. However, this phenomenon is not considered in these analyses. The effects of elevated rock temperatures on the aperture of vertical joints are shown in Figs. 3-10 and 3-11 for an elapsed time of 100 years after waste emplacement. Except for some smaller regions adjacent to the walls, vertical joints are predicted to close by a factor of two all around the disposal rooms. There are no regions predicted where joints open by a factor of two. 
Regions in which the factor of safety against slip on vertical joints is predicted to be less than unity after 25 and 100 years are shown in Figs. 3-12 and 3-13 for horizontal and vertical emplacement, respectively. There is very little change predicted with increasing time, and very little difference between the disposal rooms for vertical and horizontal emplacement. Changing the initial horizontal stress from 1.5 to $3 \mathrm{MPa}$ (i.e., $\sigma_{\mathrm{xx}} / \sigma_{\mathrm{yy}}=$ $3 / 5)$ has no effect on the predicted joint slip as shown in Figure 3-14 for both the horizontal and vertical emplacement rooms.

\subsection{Repository-Scale Analysis Using HEFF}

In order to evaluate the potential for aperture changes and joint slip at greater distances from the disposal rooms, HEEE has been used to model rock mass response on a repository scale. The heat source approximations used for this model are the same as those for the room-scale model. Because the thermomechanical effects for vertical and horizontal waste emplacement are similar on a repository scale, only results from vertical emplacement are illustrated. The conceptual repository-scale model for HEFF is illustrated in Fig. 2-5. In this model, an in-situ stress gradient is applied, with both the horizontal and vertical stress at the ground surface being zero, and increasing linearly to specified values at the repository center.

Figures 3-15 to 3-19 illustrate predicted regions of a potential factor-of-two aperture change for an initial stress state $\sigma_{\mathrm{XX}} / \sigma_{\mathrm{YY}}$ $=1.5 / 5$ at the repository horizon. The results show that a region around the repository of aperture closure by a factor of two increases throughout the time period analyzed (i.e., 0 to 500 years), while a region, above and below the repository, of aperture opening by a factor of two increases for about the first 100 years and decreases for subsequent elapsed times. However, a substantial region of joint opening by a factor of two remains even after 250 years. After 500 years the region has virtually disappeared. Because of the initial stress gradient (i.e., the assumed in-situ stress), the predicted region of joint aperture increase by a factor of two is more pronounced above the repository than below. It is important to bear in mind, however, that, near the surface, the assumed stress condition is probably not a good representation of in-situ stresses.

The effect of changing the initial horizontal stress from 1.5 to 3 $\mathrm{MPa}\left(\mathrm{i} . \mathrm{e} ., \sigma_{\mathrm{Xx}} / \sigma_{\mathrm{YY}}=3 / 5\right)$ is shown in Figures $3-20$ to $3-22$. Qualitatively the results are similar. However, the effects are less pronounced when a higher initial horizontal stress is used. Since $\sigma_{X X}$ is the normal stress on the $90^{\circ}$ joints, a smaller initial value of $\sigma_{x x}$ will produce a larger response with the same absolute stress change, since it implies a greater relative stress change. 
After applying the Mohr-Coulomb criterion defined in Eq. (3) to the stress field predicted in the repository-scale model, the results show that slip may be induced along vertical joints above and below the repository. The location and size of the regions of predicted slip follow closely the location and the size of the predicted regions of joint aperture opening. This can be expected since the joint shear strength decreases with decreasing normal stress. The magnitudes of the shear deformations (i.e., the slip) are not determined in the HEFF analyses. However, to affect the aperture, slip need occur only by infinitesimal adjustments sufficient to accommodate the thermal deformations resulting from the heat generating waste. The development of the regions of joint slip for the time period analyzed (i.e., 0 to 500 years) is shown in Figs. 3-23 to 3-27. The somewhat irregular shapes of the predicted regions should be disregarded, as this is caused by the resolution of the contouring algorithm. The important information that is conveyed is the general location and size of the regions. Although the majority of joint slip is predicted to occur above the repository, substantial regions are also shown to be induced below the repository throughout a period of about 250 years.

The effect of increasing the initial horizontal stress from 1.5 to $3 \mathrm{MPa}$ at the repository horizon (i.e., $\sigma_{\mathrm{xx}} / \sigma_{\mathrm{yy}}=3 / 5$ ) is shown in Figs. 3-28 to 3-30. As would be expected, the higher horizontal stress has the effect of decreasing the regions of predicted joint slip, in particular below the repository. Above the repository, even with the higher horizontal stress, a substantial region of slip is still present after 100 years of waste isolation. Again, however, it is important to remember that the state of stress near the irregular ground surface is likely to be anomalous.

It is important to note that dissipation of strain energy in the form of joint slip is not incorporated in these analyses. Occurrence of joint slip could be expected to affect both the size of the regions of joint slip predicted in these analyses and the regions of joint closure or opening. In addition, an isotropic deformation modulus is used, while the actual site indicates rock with moderately frequent joints which are predominantly vertical, which implies orthotropic deformation behavior. This could also be expected to affect the range of joint slip and joint opening or closure predicted in these analyses.

The results of particular interest are the predicted development of aperture increases and joint slip at distances above and below the repository relatively soon after initial waste emplacement, and their persistence through approximately 250 years of waste isolation. These results, which are thermomechanical effects, signal a potential for an increase in the fracture permeability in large regions at the site. If joint opening from the reduction in 
normal stress is associated with joint slip, as indicated, the fracture permeability may be permanently increased.

\subsection{Repository-Scale Analysis Using UDEC}

The purpose of using UDEC in this work is: (a) to investigate the explicit behavior of vertical joints for thermomechanical effects; (b) to investigate the effect of structural features parallel to the repository, such as interfaces between geologic units; (c) to study the response of structural features, such as the Ghost Dance Fault, which are sub-perpendicular to the repository horizon; and (d) to compare rock mass response with that inferred from the HEFF analyses for a repository-scale model.

Simplifications of site conditions were made in constructing the UDEC model because it would be impractical to include vertical joints in the model with the frequency suggested in the SCPCDR (MacDougall et al., 1987). Therefore, explicit vertical joints were placed at an interval of $100 \mathrm{~m}$ above and below the repository, and at an interval of $200 \mathrm{~m}$ beyond the edge of the repository, with rock mass properties assigned to the rock between the joints. This allows a reasonable evaluation of the effects of joints for a practical amount of computational effort. In addition, a linear joint deformation model is used. This deformation model is described in Fig. 3-31. Although joint deformation models have been shown to be nonlinear (e.g., Bandis et al., 1983), a linear approximation is believed to be sufficient for the purpose of investigating the general joint behavior in these analyses. For comparison, the nonlinear constitutive joint model described in Eq. (1) and used in the HEFF analyses, is also included in Eig. 3-31. The stiffness of the linear joint model is higher than the nonlinear model at lower stresses, while the opposite is true at higher stresses.

The conceptual repository-scale model used with UDEC is shown in Figs. 2-6 and 2-7. The locations of horizontal interface corresponding to the upper and lower limits of the welded tuff are shown, as well as the vertical joints and boundary conditions. Note that the left boundary is taken as a plane of symmetry and that only half of the repository is modeled. The initial areal power density is $80 \mathrm{~kW} / a c r e$, which is the same as for the HEFF room-scale and repository-scale models. The initial horizontal and vertical stress field varies linearly with depth from zero at the surface, to a horizontal and vertical stress at the repository horizon of approximately $2 \mathrm{MPa}$ and $7 \mathrm{MPa}$, respectively.

Thermomechanical effects from the presence of the repository were investigated up to 500 years after the initial waste emplacement. 
Figures 3-32 to 3-34 illustrate the predicted heat transfer in the rock surrounding the repository as contours of temperature change for various times up to 500 years.

The effect of heat transfer on the mechanical behavior of vertical joints $100 \mathrm{~m}$ and $500 \mathrm{~m}$ to the right of the repository centerline is shown in Figs. 3-35 to 3-41. These figures show the predicted change in aperture of vertical joints at various times as a function of elevation. The changes in apertures shown arise only from thermomechanical effects (i.e., the presence of the repository). Note the elevations of the ground surface and the repository indicated in these figures. Negative aperture changes indicate that the joint has closed relative to its initial position, while positive aperture changes indicate it has opened.

Figures 3-35 to 3-37 show the aperture changes with the horizontal features above and below the repository omitted. Eigures 3-38 to 3-41 show the same results with these features included. In the second set of figures, however, only the aperture of the joint 500 $m$ from the repository center is shown, with friction angles of $28^{\circ}$ and $10^{\circ}$ on the horizontal interfaces.

These figures illustrate substantial joint closure as a result of high horizontal stresses induced from thermal expansion of the rock in the close vicinity of the repository. The region of joint closure increases with time, which is consistent with the results from the HEFF repository-scale model. Beyond the region of joint closure (above and below the repository) there are regions where joints are predicted to open. This behavior is also consistent with the results of the HEFF analyses. Because a linear joint material model was used in the UDEC model, the results cannot be compared directly to those obtained using HEFF. However, the results from the UDEC model confirm the joint normal behavior (i.e., aperture opening and closure) implied by the results in the HEFF repository-scale model. Comparison of the results with and without the horizontal features shows the possible effects of horizontal joint movement. Some of the effects are discussed below.

Figure 3-38 shows a small jump in aperture change after 50 years (normal displacement) at the lower boundary of the welded tuff (100 $\mathrm{m}$ below the repository). This corresponds to a shear displacement along the interface between the geologic units. The fact that the results using $10^{\circ}$ and $28^{\circ}$ friction angles on the horizontal features are identical suggests that this is elastic deformation rather than permanent slip. On the whole, this figure is similar to Fig. 3-35, without the horizontal features, except for the small amount of slip below the repository.

After 100 years, the effect of the different friction angles is more pronounced. Slip both above and below the repository is re- 
flected in Fig. 3-39. Above the repository, the aperture increase above the interface is inhibited by the slip, but just below the interface, joint opening is greater when slip occurs. Below the repository, the effect of the interface slip is also to localize the aperture change in the welded tuff.

After 250 years (Fig. 3-40), these effects are expressed as significant changes in the condition (i.e., aperture) of vertical joints outside the layer in which the repository is located. Another effect which may occur is a reduction in the aperture decrease within the repository host horizon. This is not clearly visible in the results presented here, probably because the horizontal features are too far $(100 \mathrm{~m}$ and $200 \mathrm{~m})$ from the repository. An analogy to this model of response is to consider three layers. welded together, but with their ends free, as shown in Fig. 3-42. If the center layer is heated uniformly, but the other two are kept cold, high compressive stresses will be generated in the center layer, matched by tensions in the outer layers. If the three layers are free to slide, however, the center one will simply expand, and no stresses will develop in any of the layers. Because compressive stresses result in aperture reduction, and because tensions cause openings, it is apparent that shear displacement on horizontal features can reduce the effect of heating on the aperture of vertical joints.

Figures $3-43$ and $3-44$ illustrate the joint slip predicted in the UDEC model as a result of thermomechanical effects when the horizontal features are omitted. As noted previously, discrete vertical joints were presented in the UDEC model above and below the repository at $100 \mathrm{~m}$ horizontal intervals. Slip on these features occurs primarily above the repository, which is consistent with the results of the HEFF model. Only a small region of joint slip (i.e., along one joint) is predicted after 100 years below the edge of the repository.

Figures 3-45 and 3-46 show the slip when the interfaces are induced. It is apparent that significant amounts of slip can occur on horizontal features. For example, after 250 years, $130 \mathrm{~mm}$ of shear displacement is indicated above the repository and, even after 500 years, there is still almost $100 \mathrm{~mm}$ of shear displacement. In reality, there will probably be more horizontal joints than the two modeled here. Then, the displacement will be distributed over a much greater area, so it is unlikely to be concentrated on one or two structural features, unless these have substantially lower shear strength than others. 


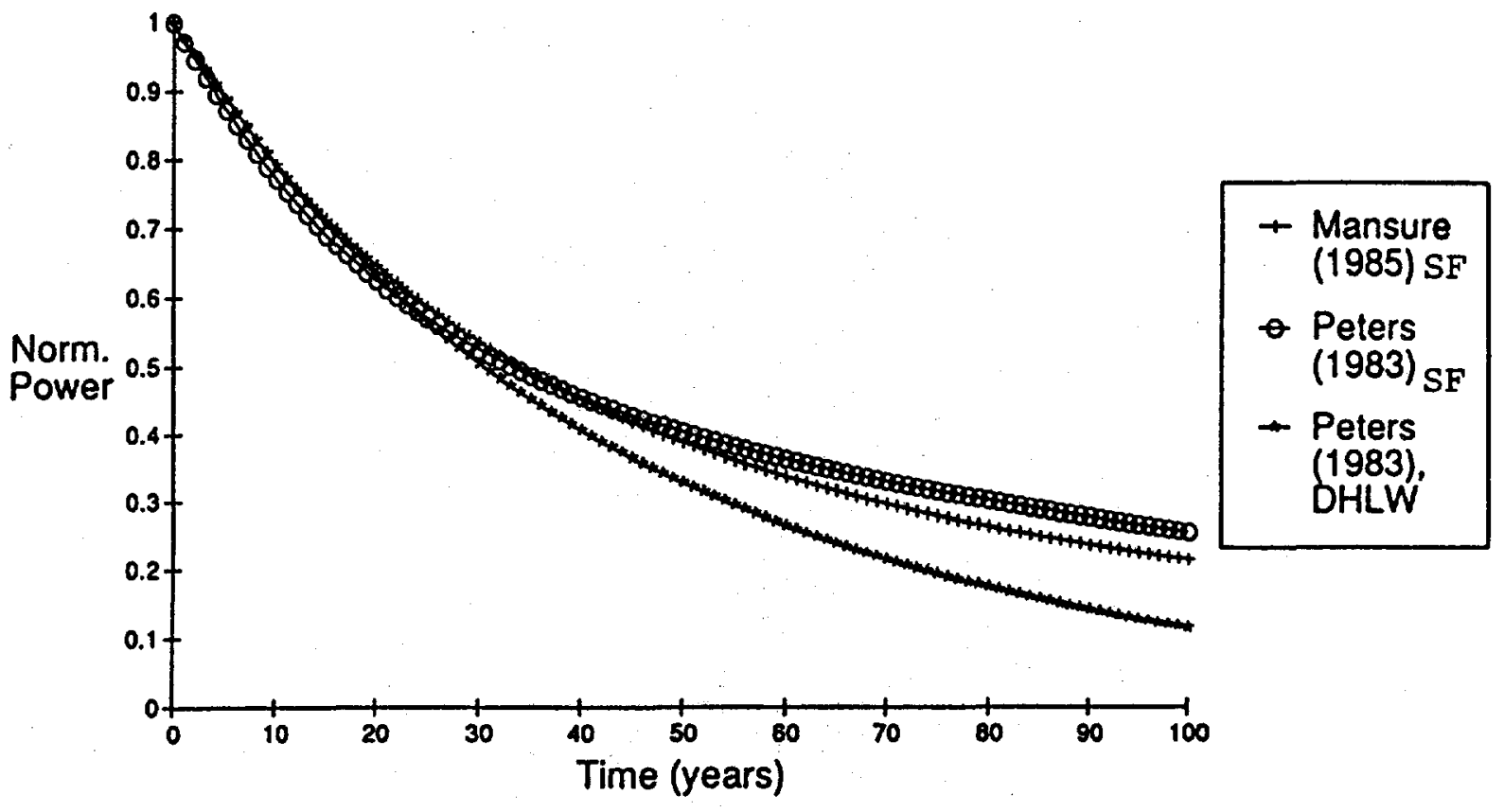

Fig. 3-1 Waste Form Normalized Power Decay 


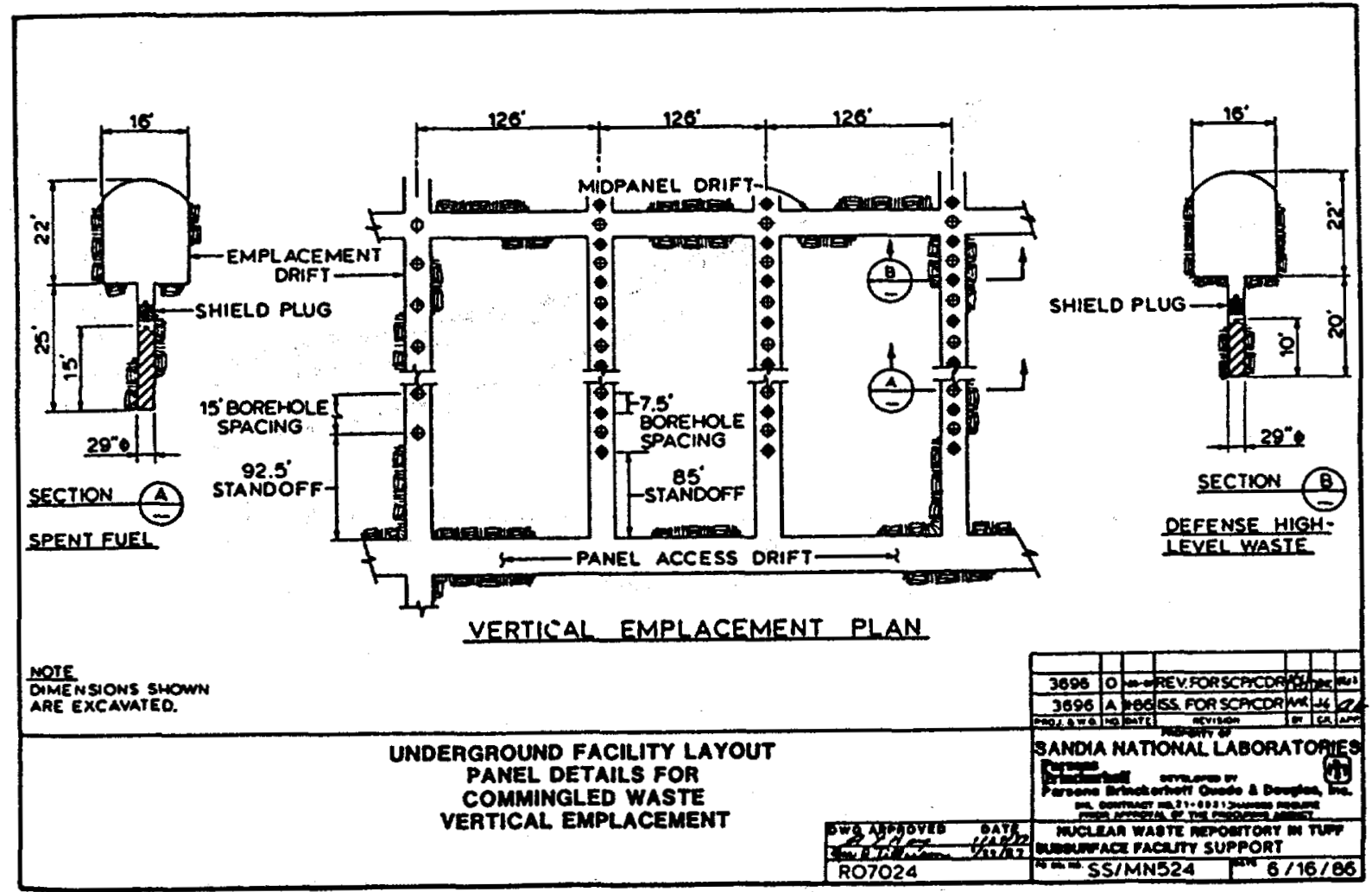

Fig. 3-2 Room Geometry and Waste Lay-Out for Vertical Emplacement [MacDougall et al., 1987] 


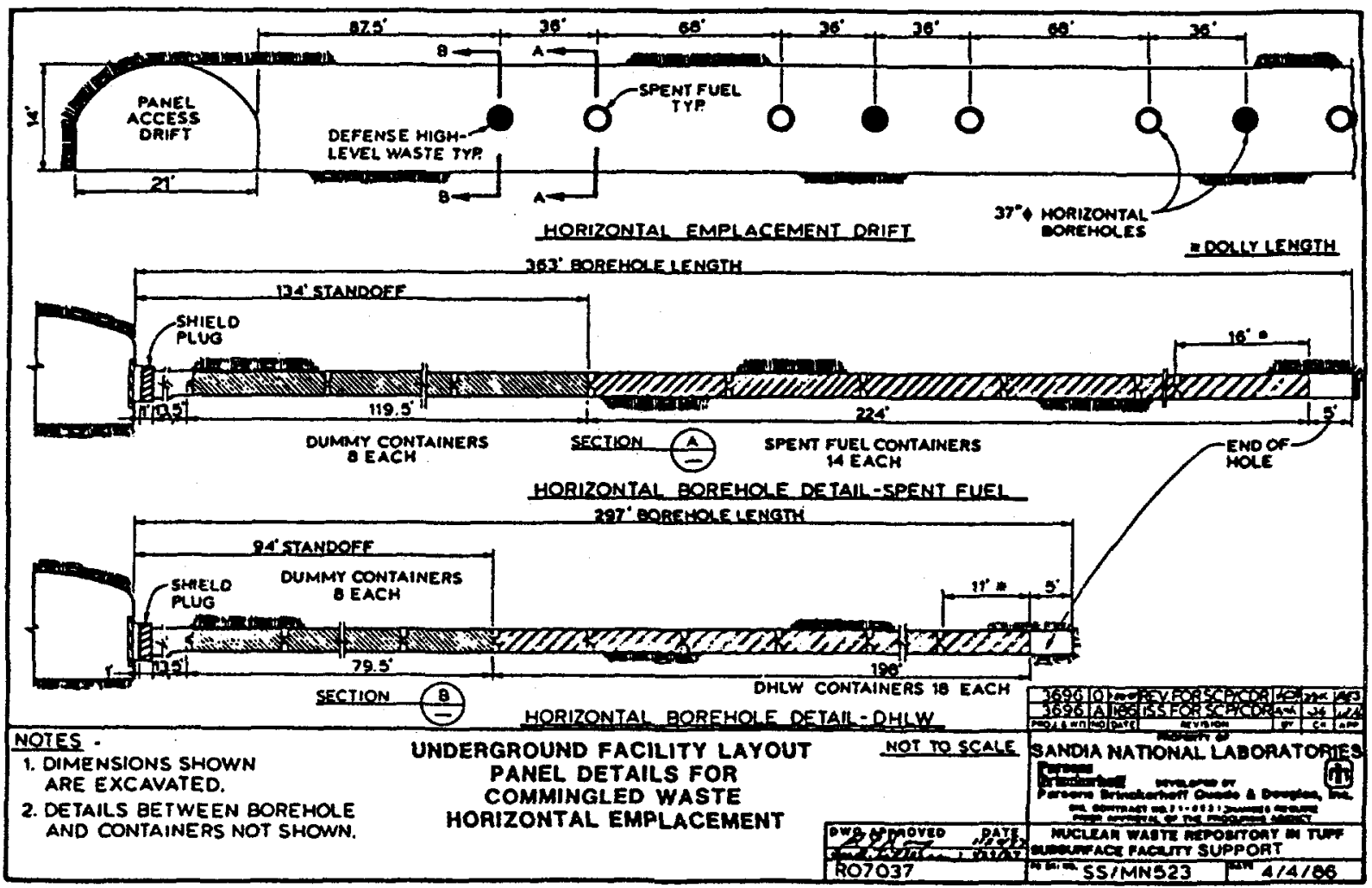

Fig. 3-3 Room Geometry and Waste Lay-Out for Horizontal Emplacement [MacDougall et al., 1987] 


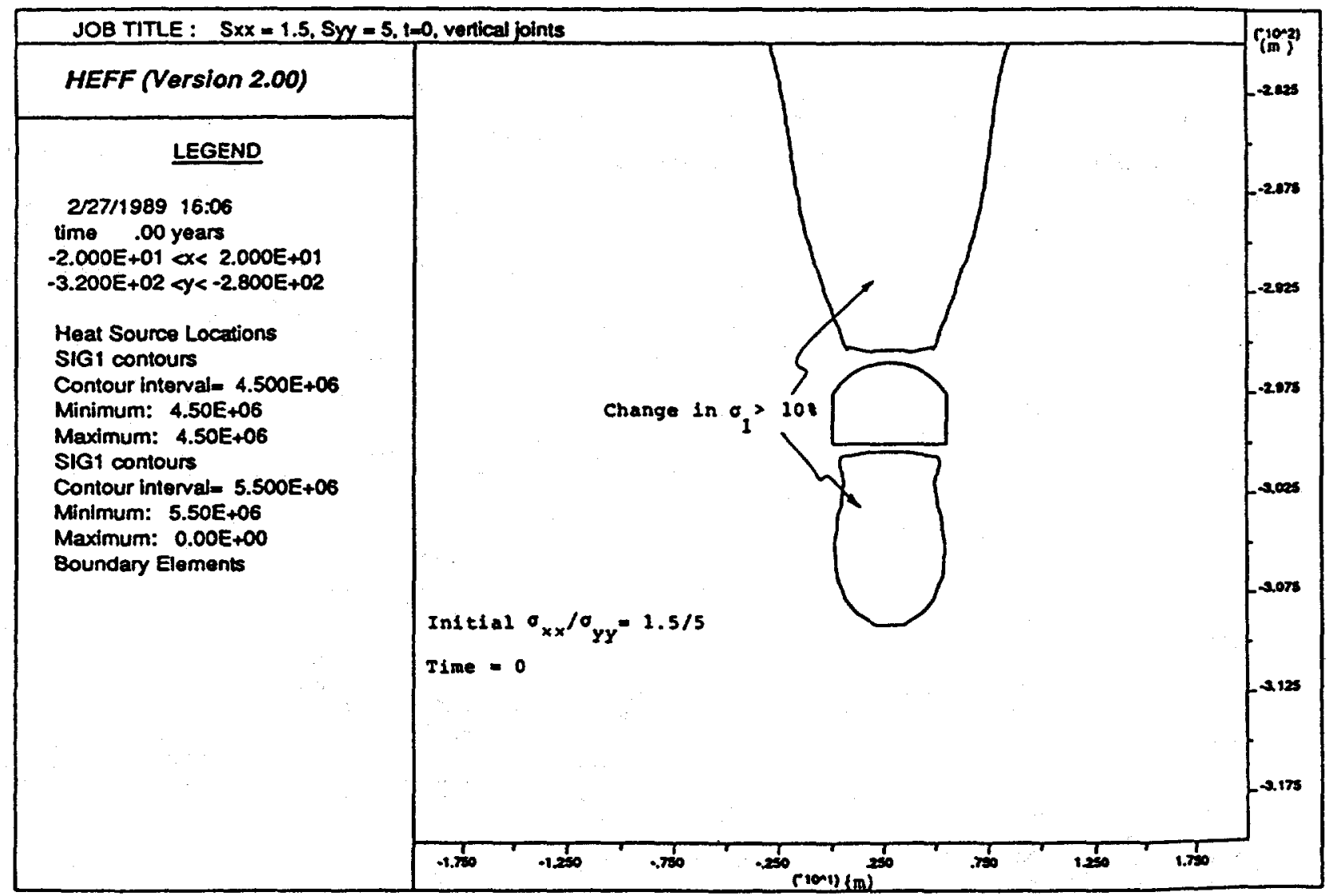

Fig. 3-4 Regions of More Than $10 \%$ Change in Major Principal Stress, Horizontal Emplacement 


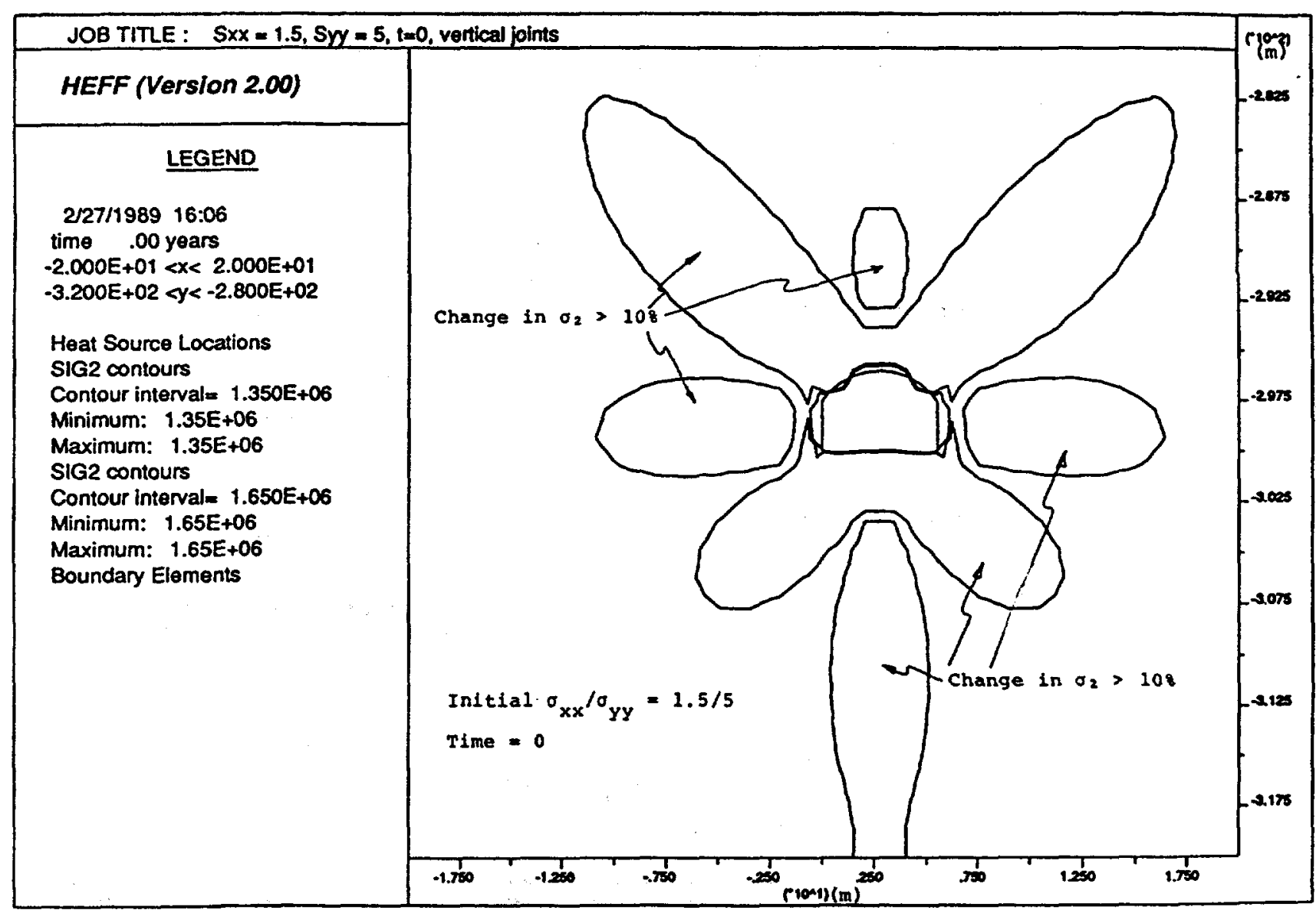

Fig. 3-5 Regions of More Than $10 \%$ Change in Minor Principal Stress, Horizontal Emplacement 


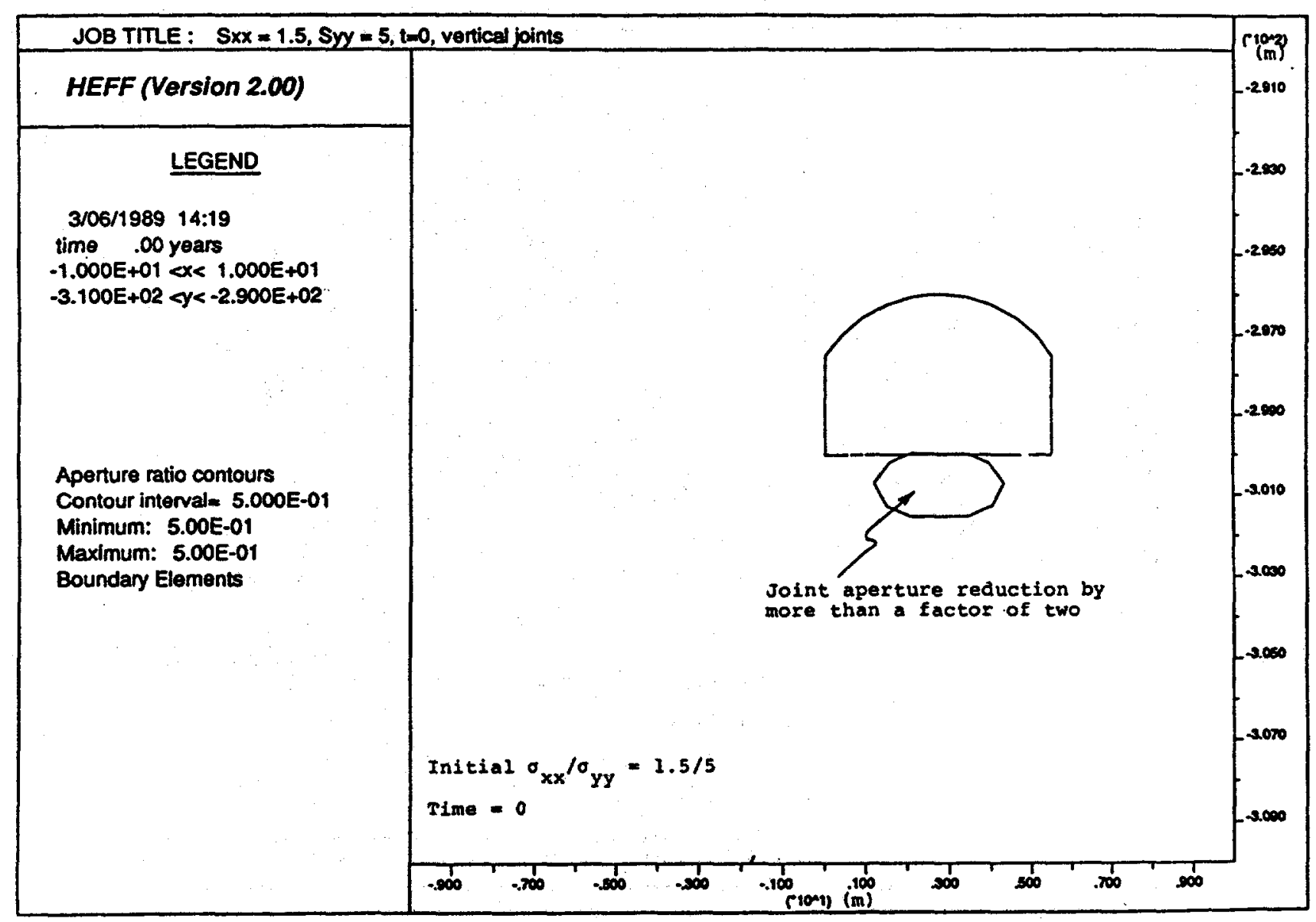

Fig. 3-6 Regions of Joint Aperture Change By a Factor of Two As a Result of Excavation, Horizontal Emplacement 


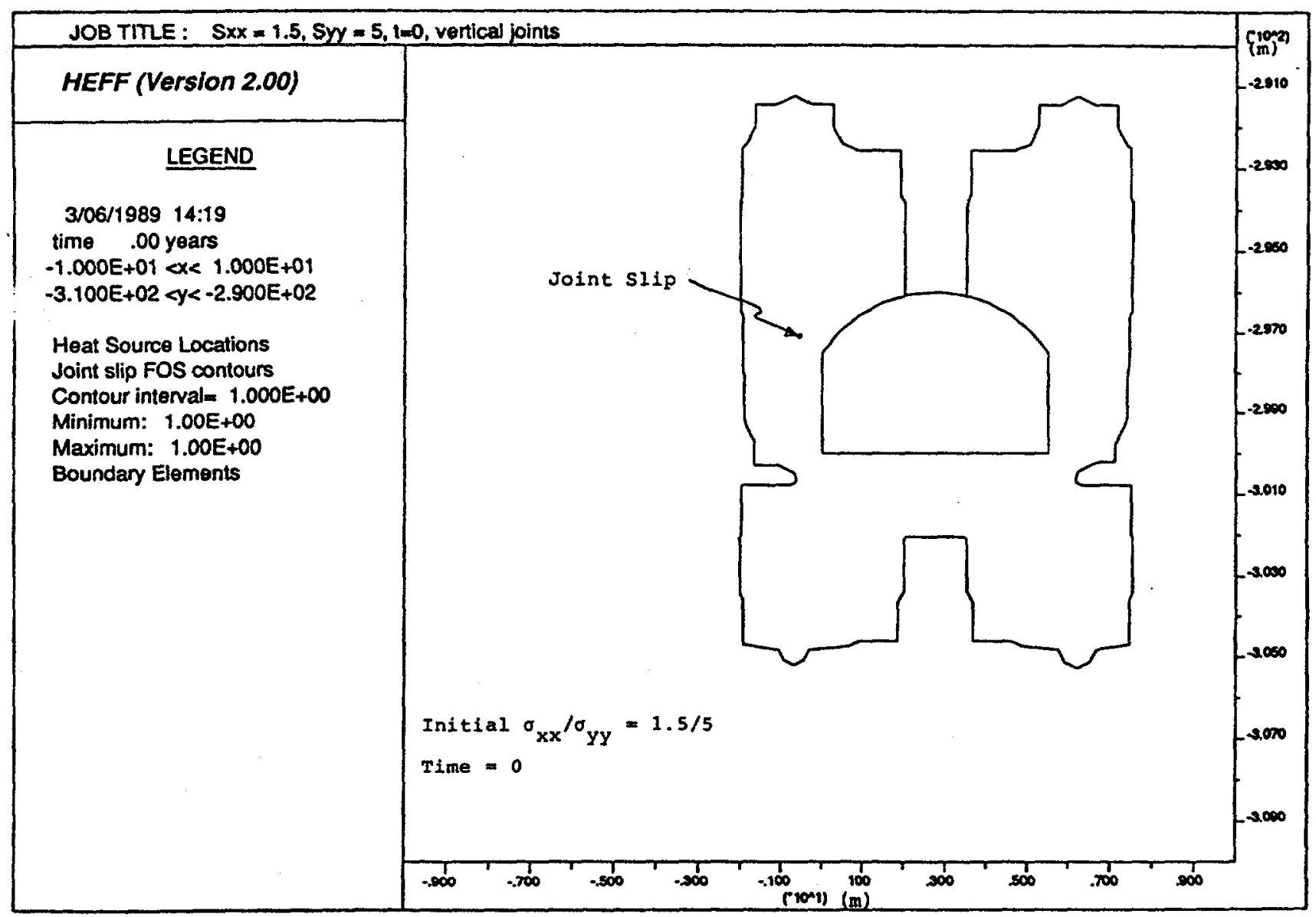

Fig. 3-7 Regions of Joint Slip As a Result of Excavation, Horizontal Emplacement 


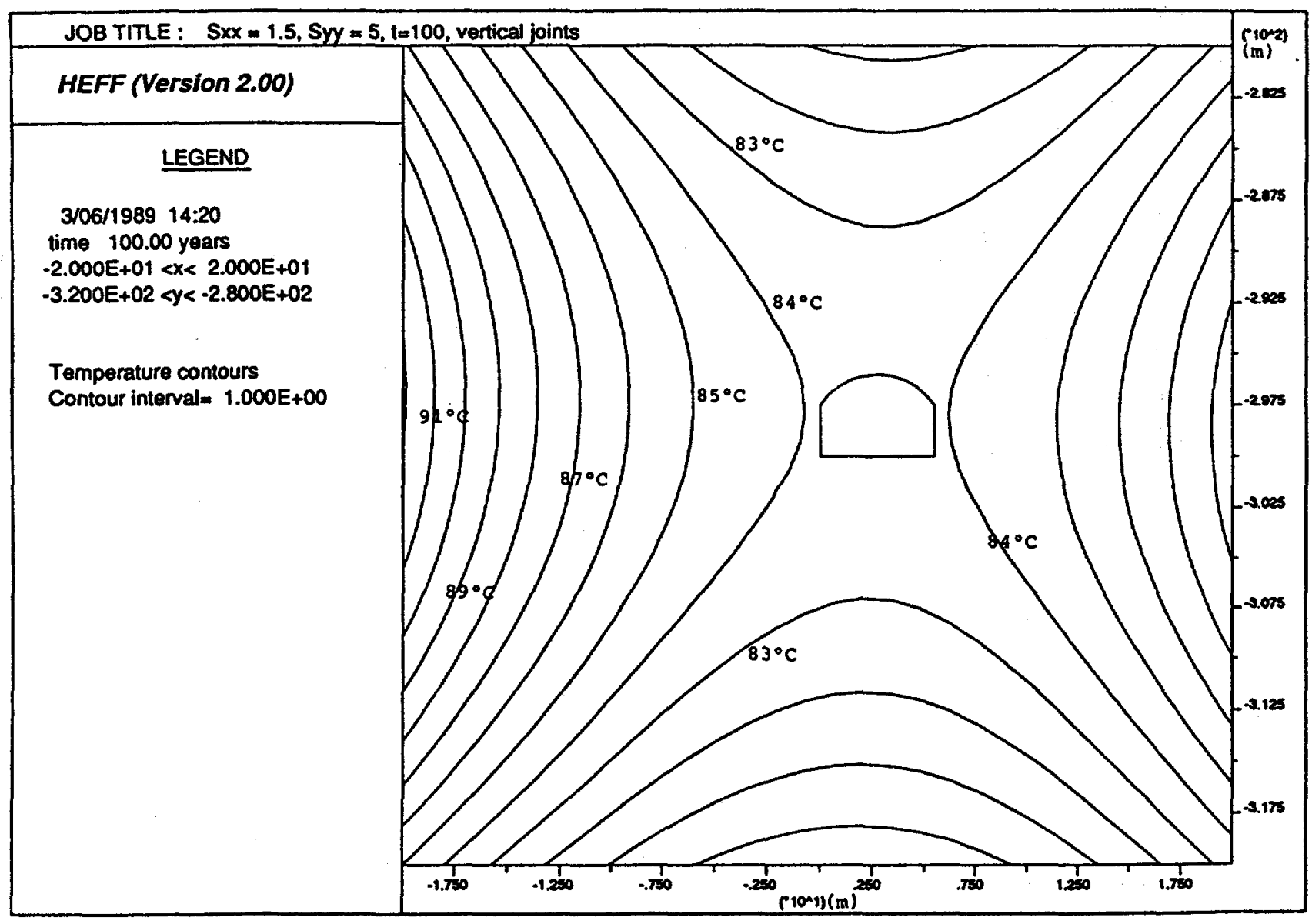

Fig. 3-8 Contours of Rock Temperature $\left({ }^{\circ} \mathrm{C}\right)$ After 100 Years, Horizontal Emplacement 


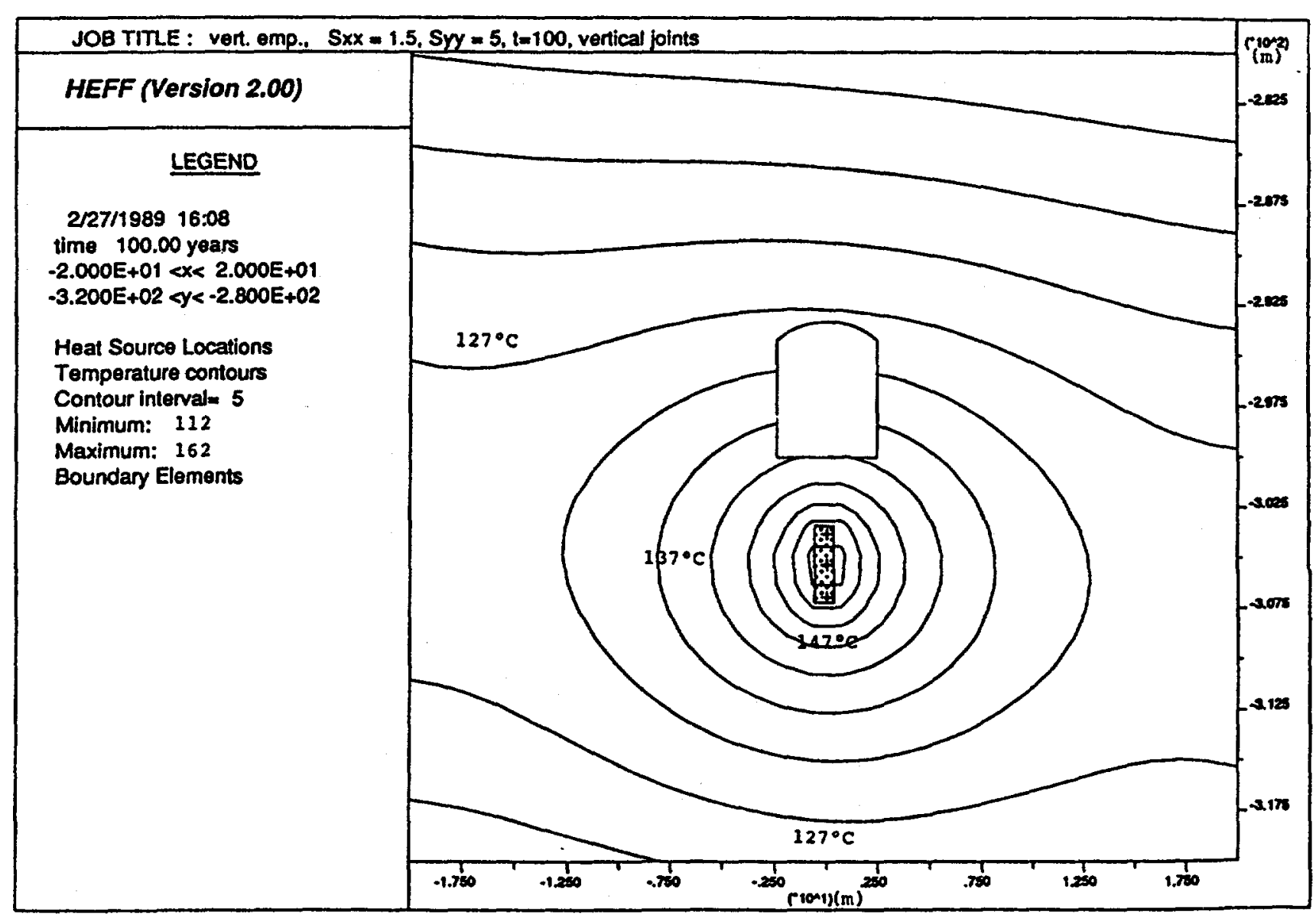

Fig. 3-9 Contours of Rock Temperature $\left({ }^{\circ} \mathrm{C}\right)$ After 100 Years, Vertical Emplacement 


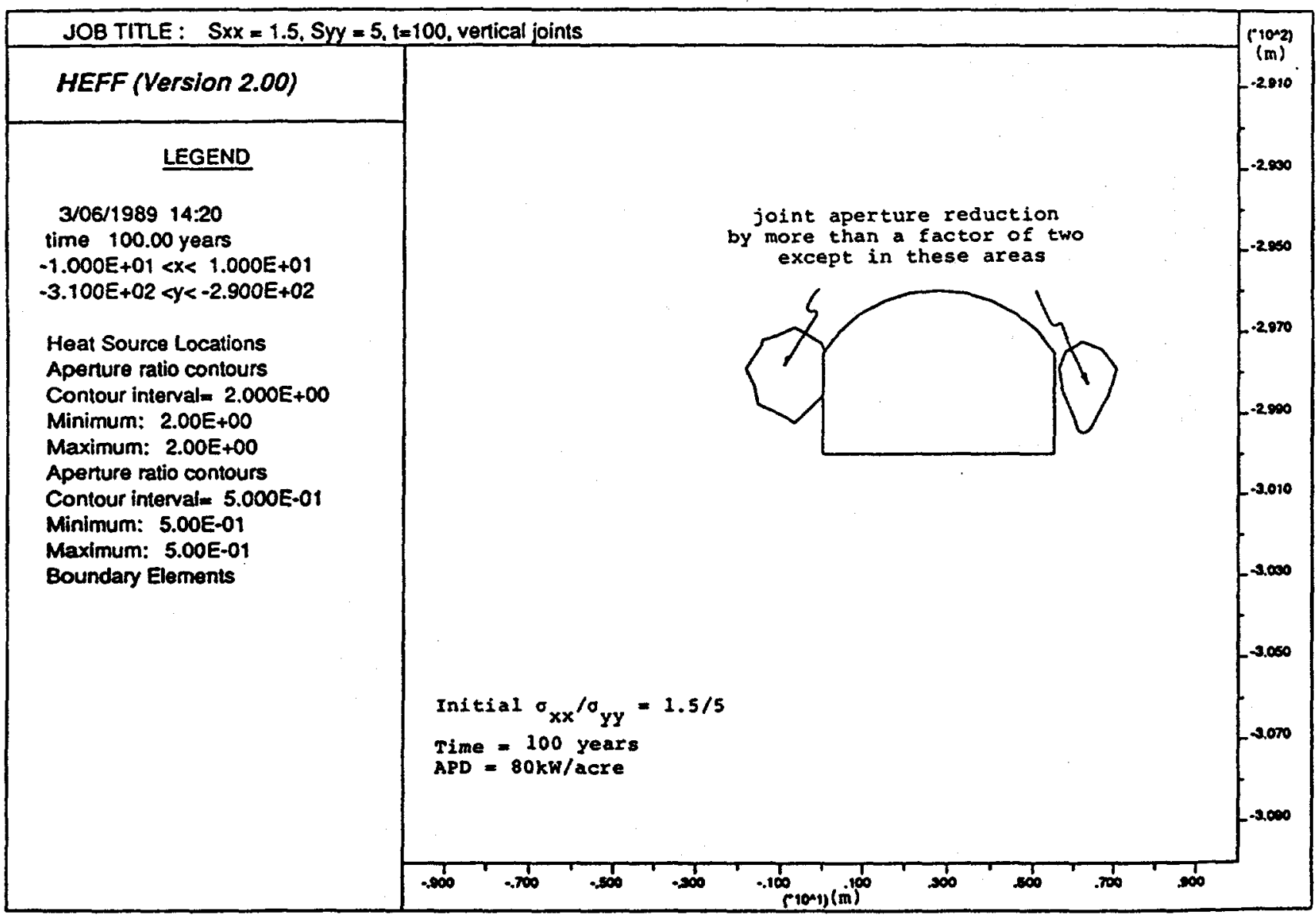

Fig. 3-10 Regions of Joint Aperture Change By a Eactor of Two 100 Years After Waste Emplacement, Horizontal Emplacement 


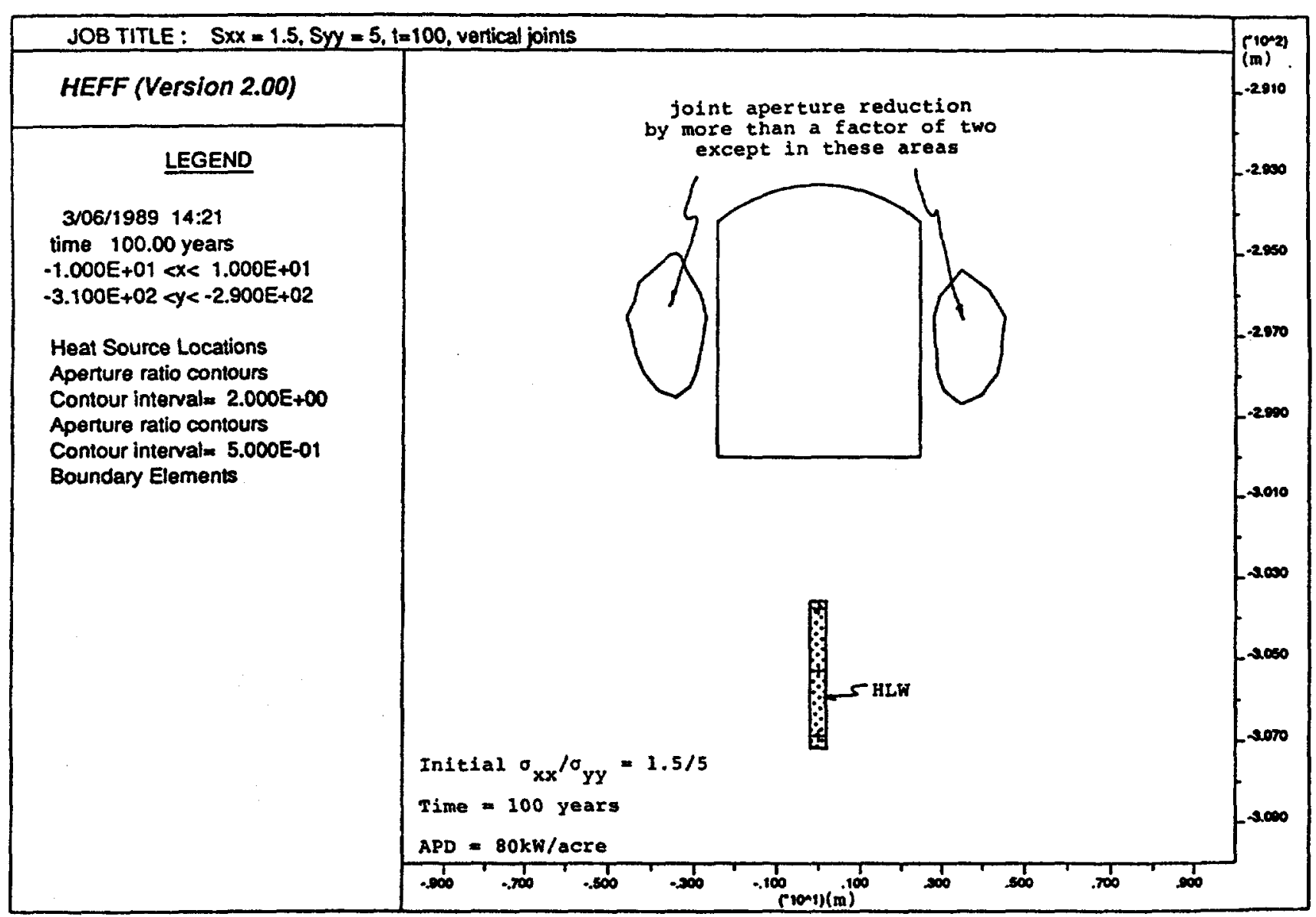

Fig. 3-11 Regions of Joint Aperture Change By a Factor of Two 100 Years After Waste Emplacement, Vertical Emplacement 

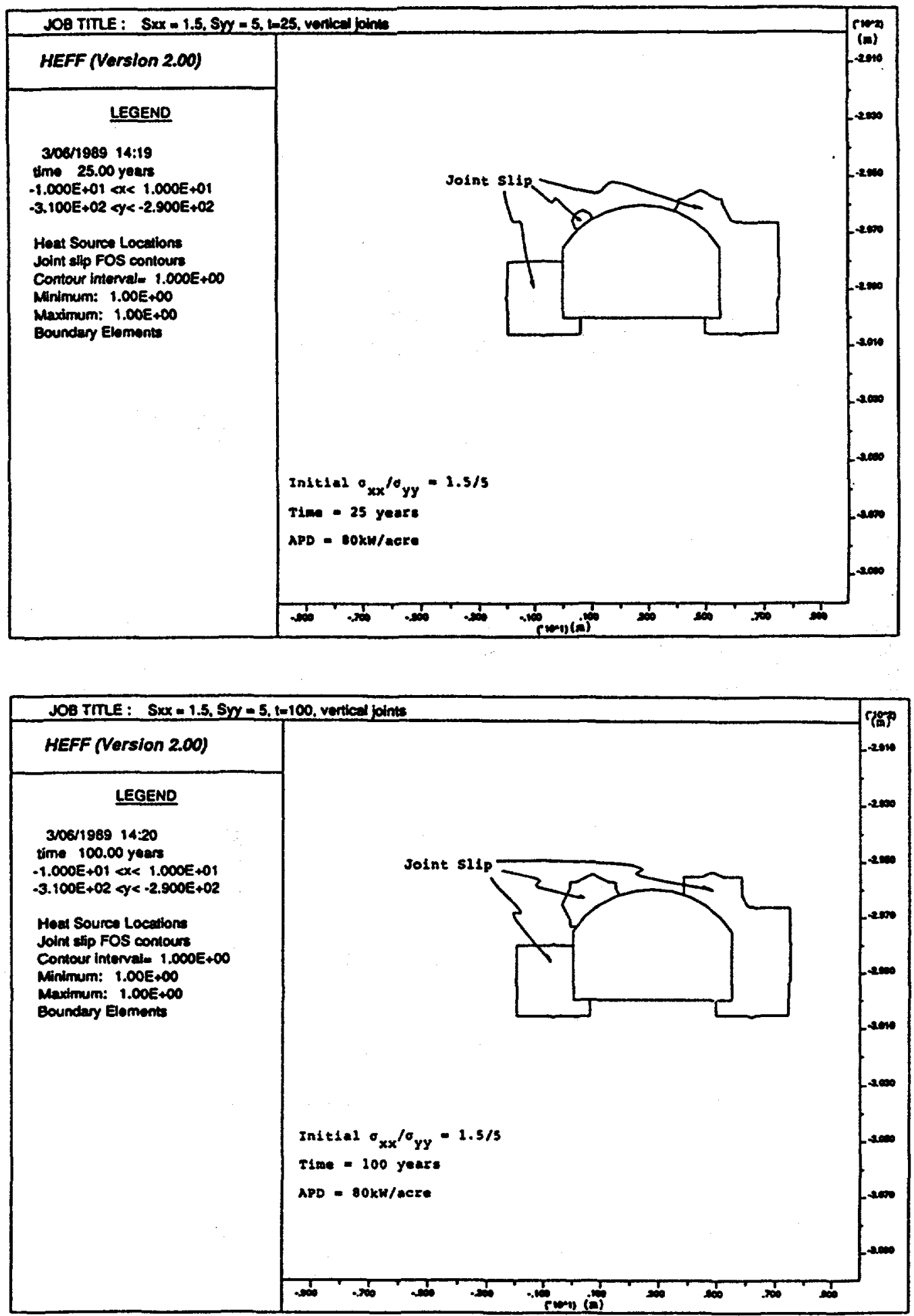

Eig. 3-12 Regions of Joint Slip 25 and 100 Years After Waste Emplacement, Horizontal Emplacement 

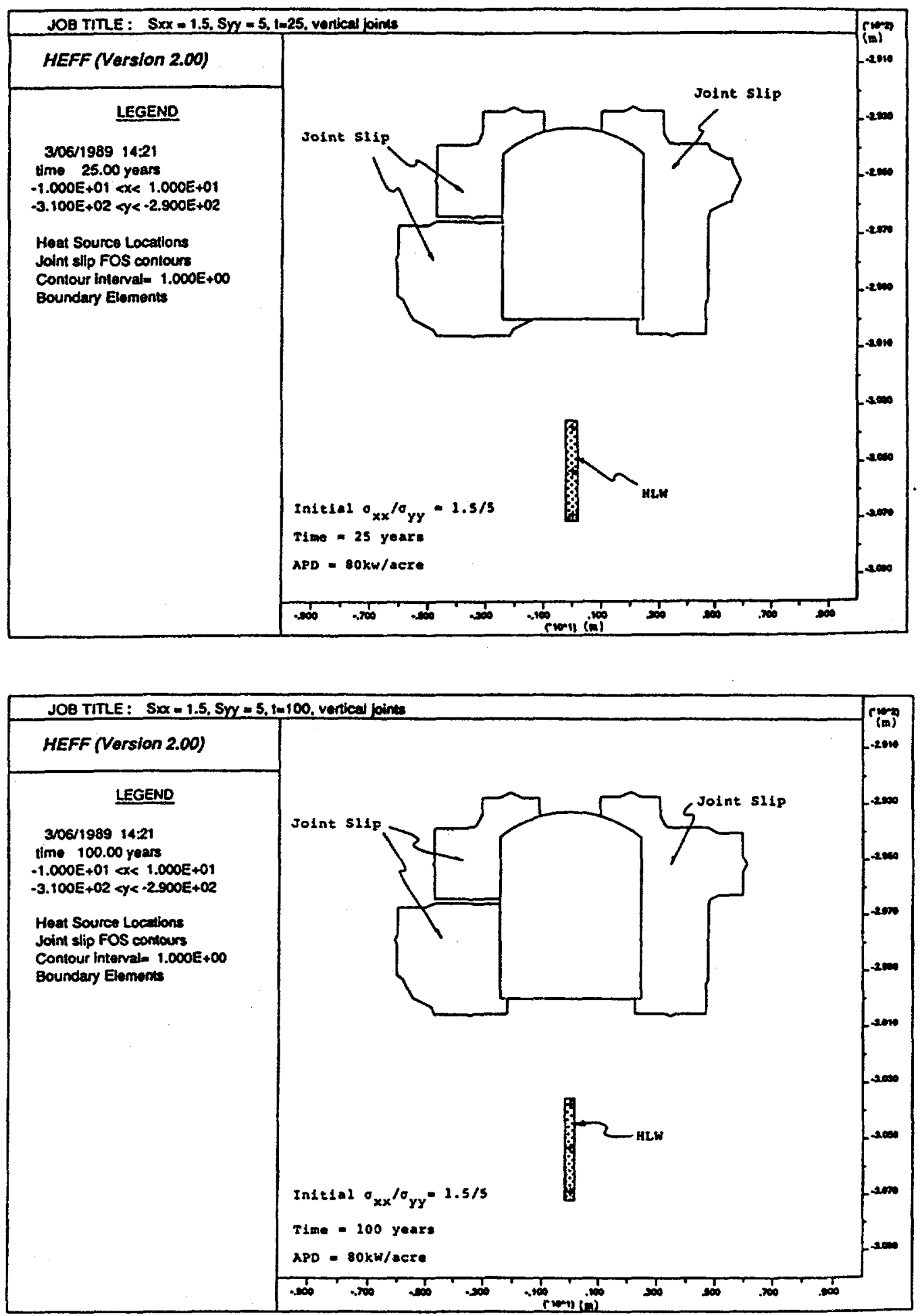

Fig. 3-13 Regions of Joint Slip 25 and 100 Years After Waste Emplacement, Vertical Emplacement 

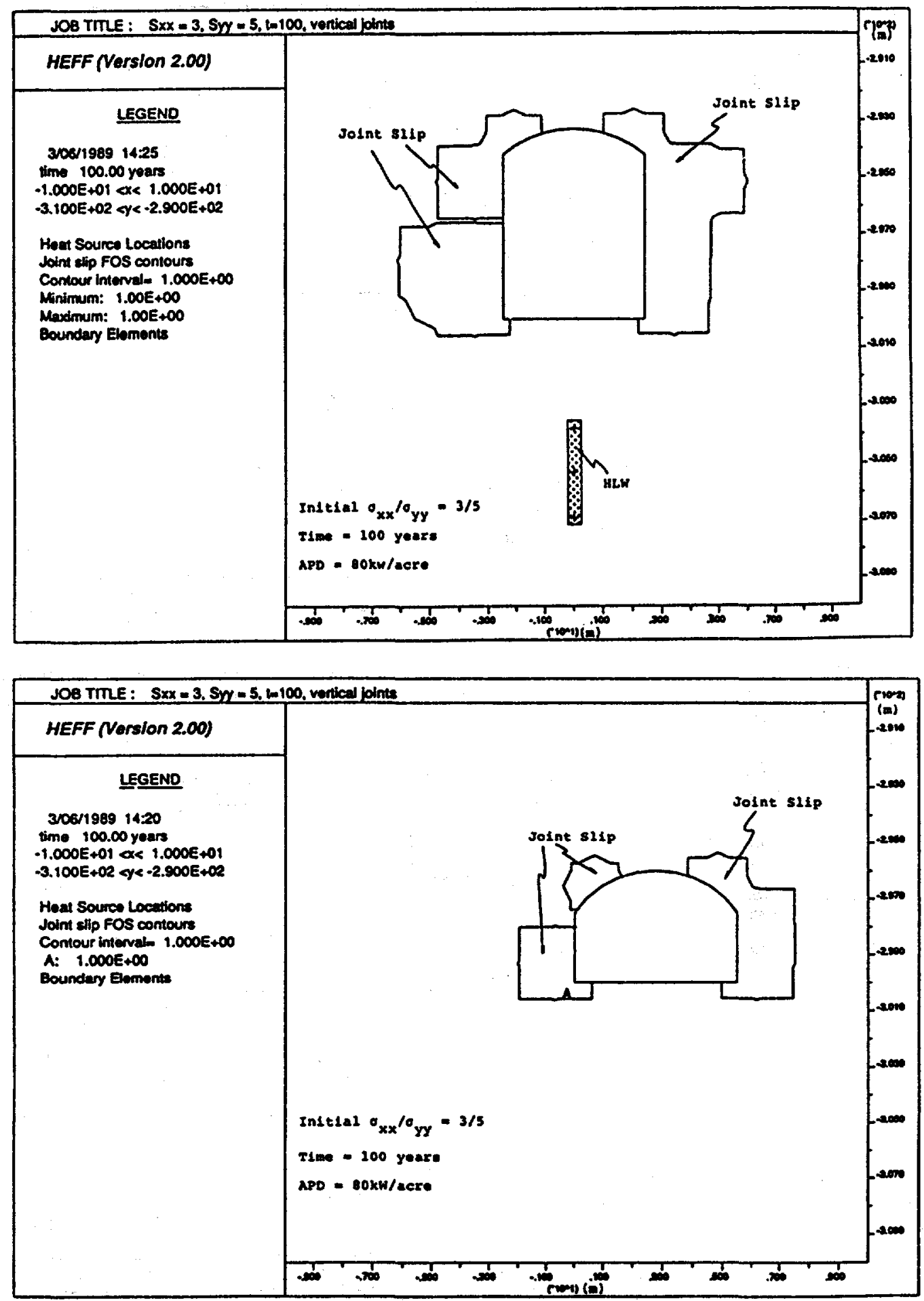

Fig. 3-14 Regions of Joint Slip 100 Years After Waste Emplacement for Vertical and Horizontal Emplacement $\left(\sigma_{x x} / \sigma_{y y}=3 / 5\right)$ 


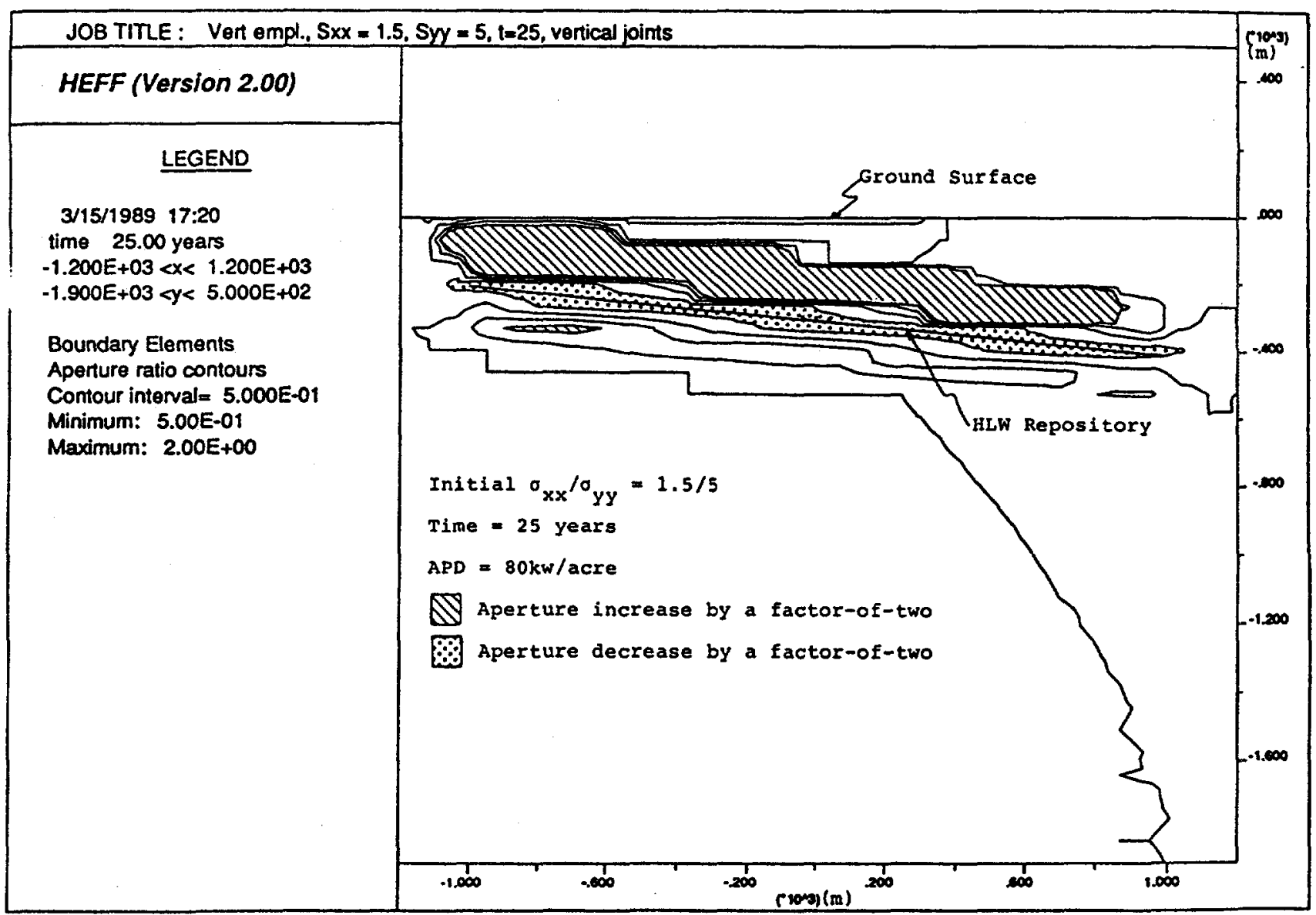

Eig. 3-15 Regions of Aperture Change By a Eactor of Two, 25 Years After waste Emplacement $\left(\sigma_{x x} / \sigma_{Y y}=1.5 / 5\right)$ 


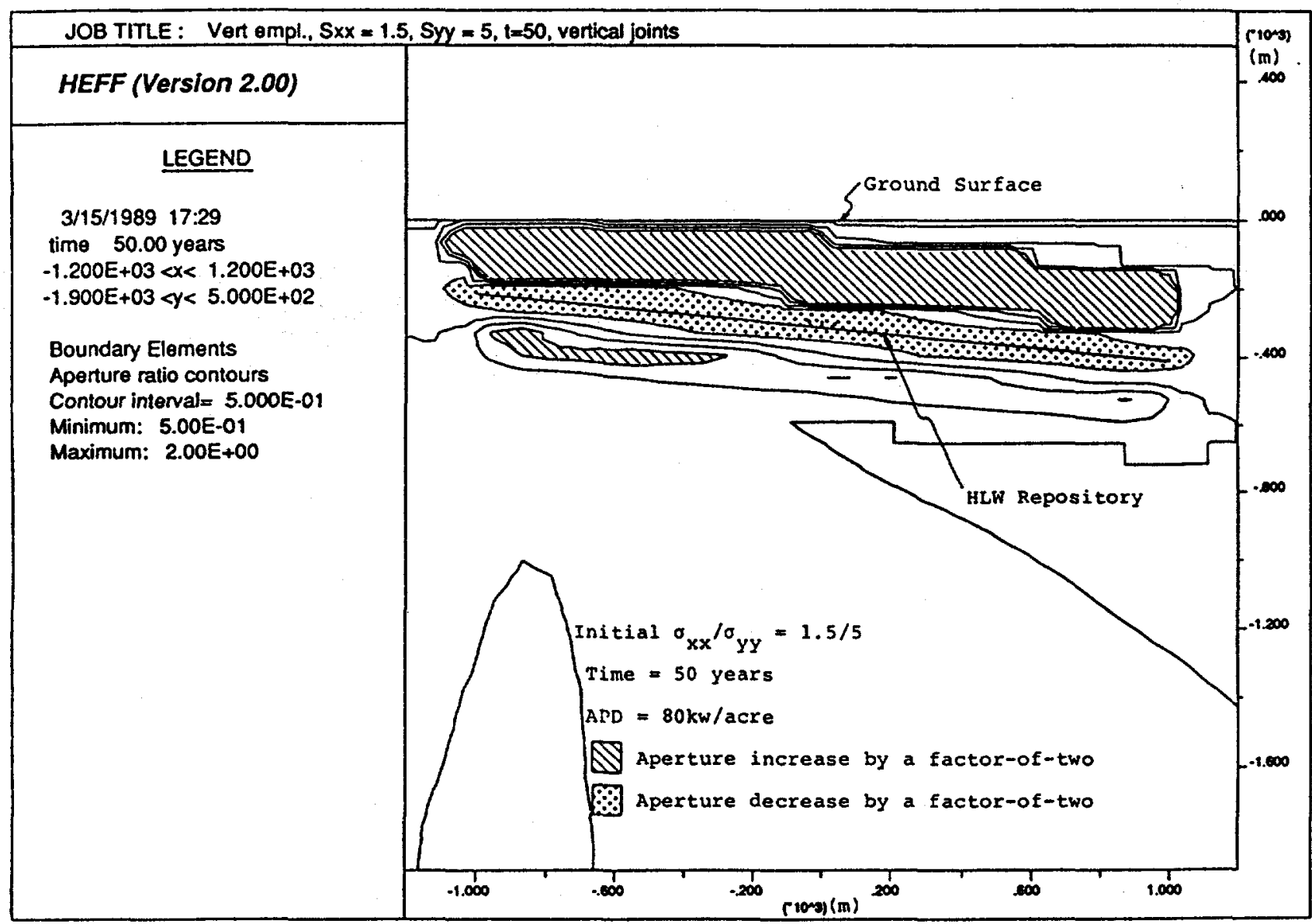

Fig. 3-16 Regions of Aperture Change By a Factor of Two, 50 Years After Waste Emplacement $\left(\sigma_{X X} / \sigma_{Y y}=1.5 / 5\right)$ 


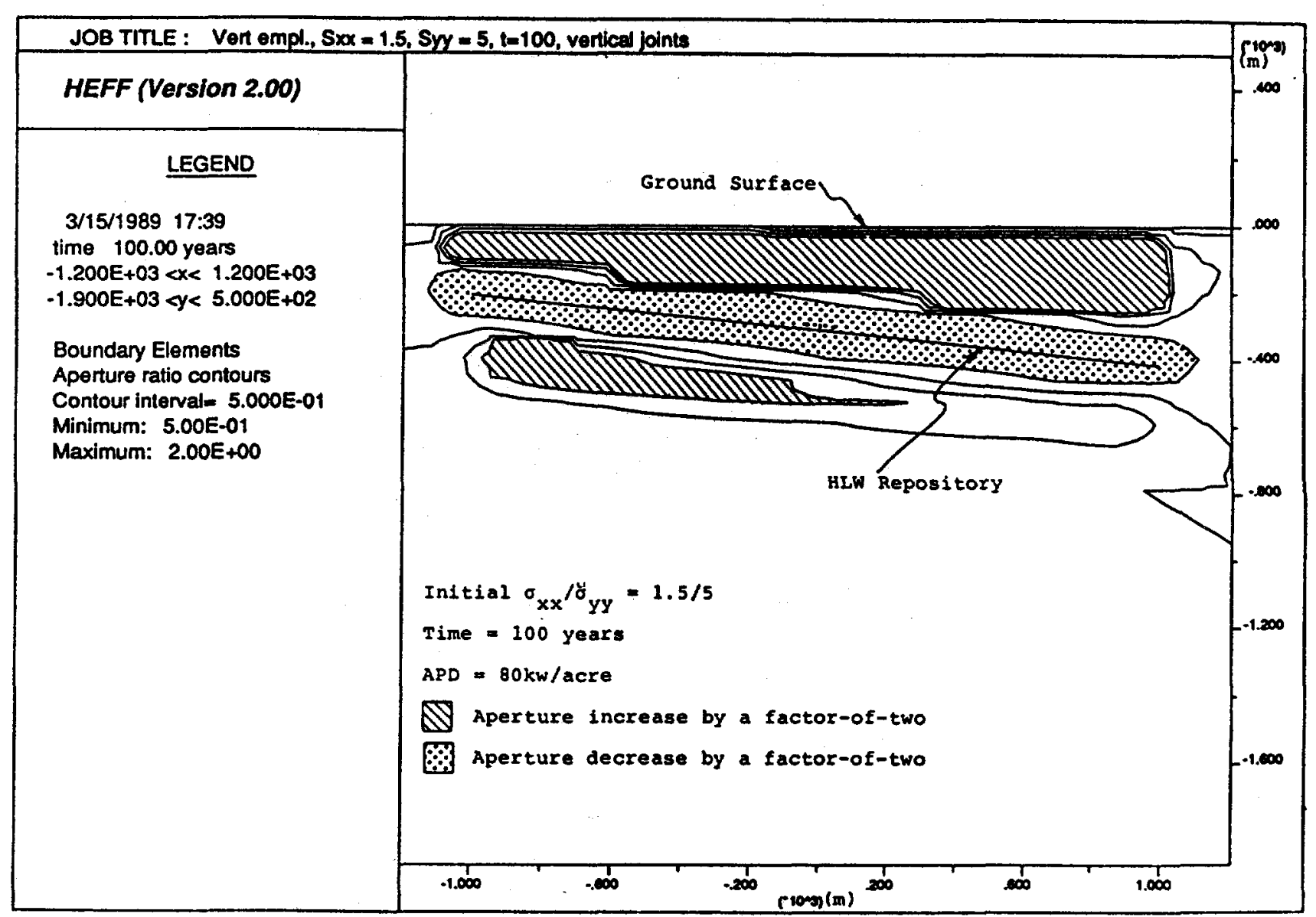

Fig. 3-17 Regions of Aperture Change By a Factor of Two, 100 Years After Waste Emplacement $\left(\sigma_{X X} / \sigma_{Y Y}=1.5 / 5\right)$ 


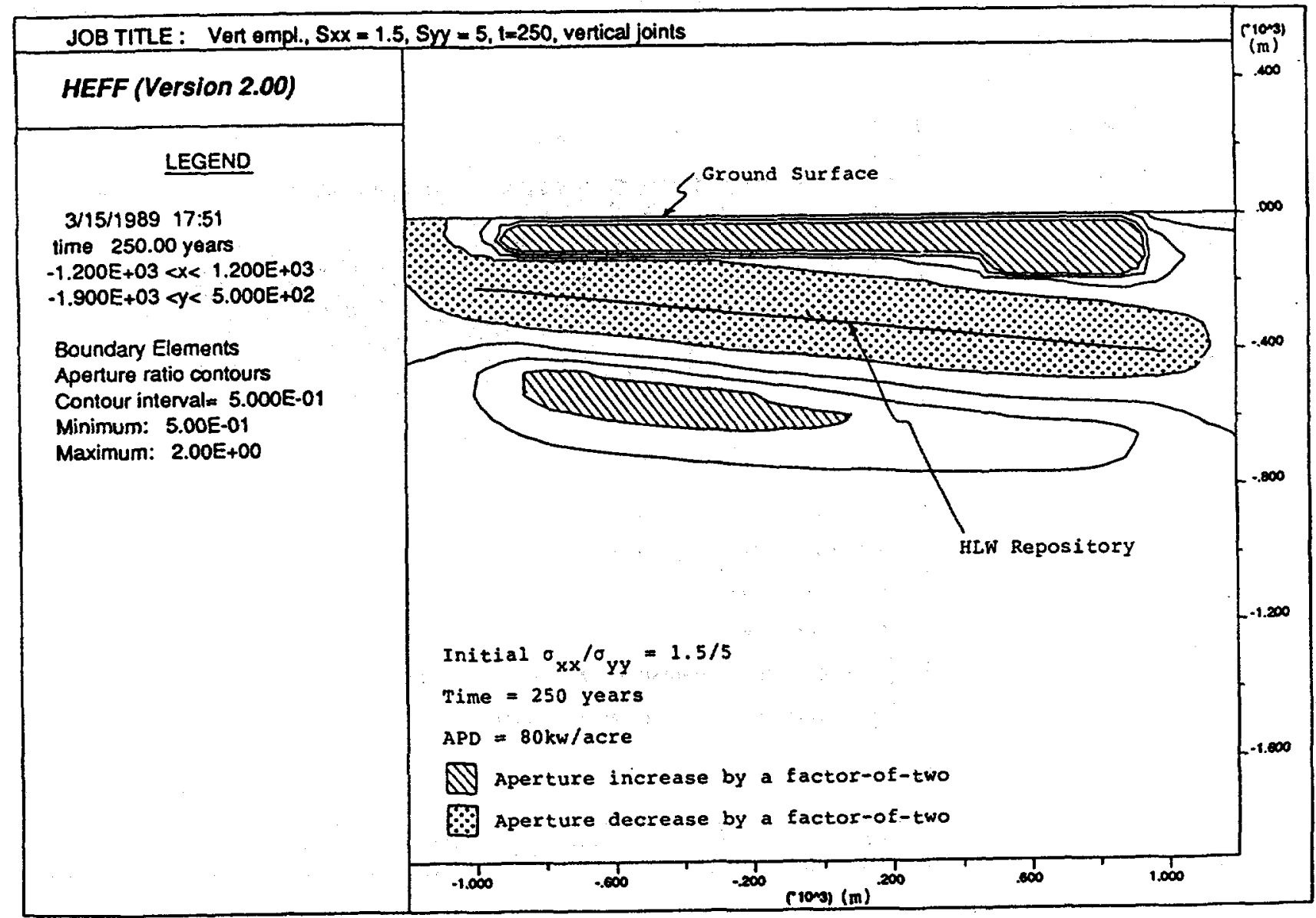

Fig. 3-18 Regions of Aperture Change By a Factor of Two, 250 Years After Waste Emplacement $\left(\sigma_{\mathrm{XX}} / \sigma_{\mathrm{YY}}=1.5 / 5\right)$ 


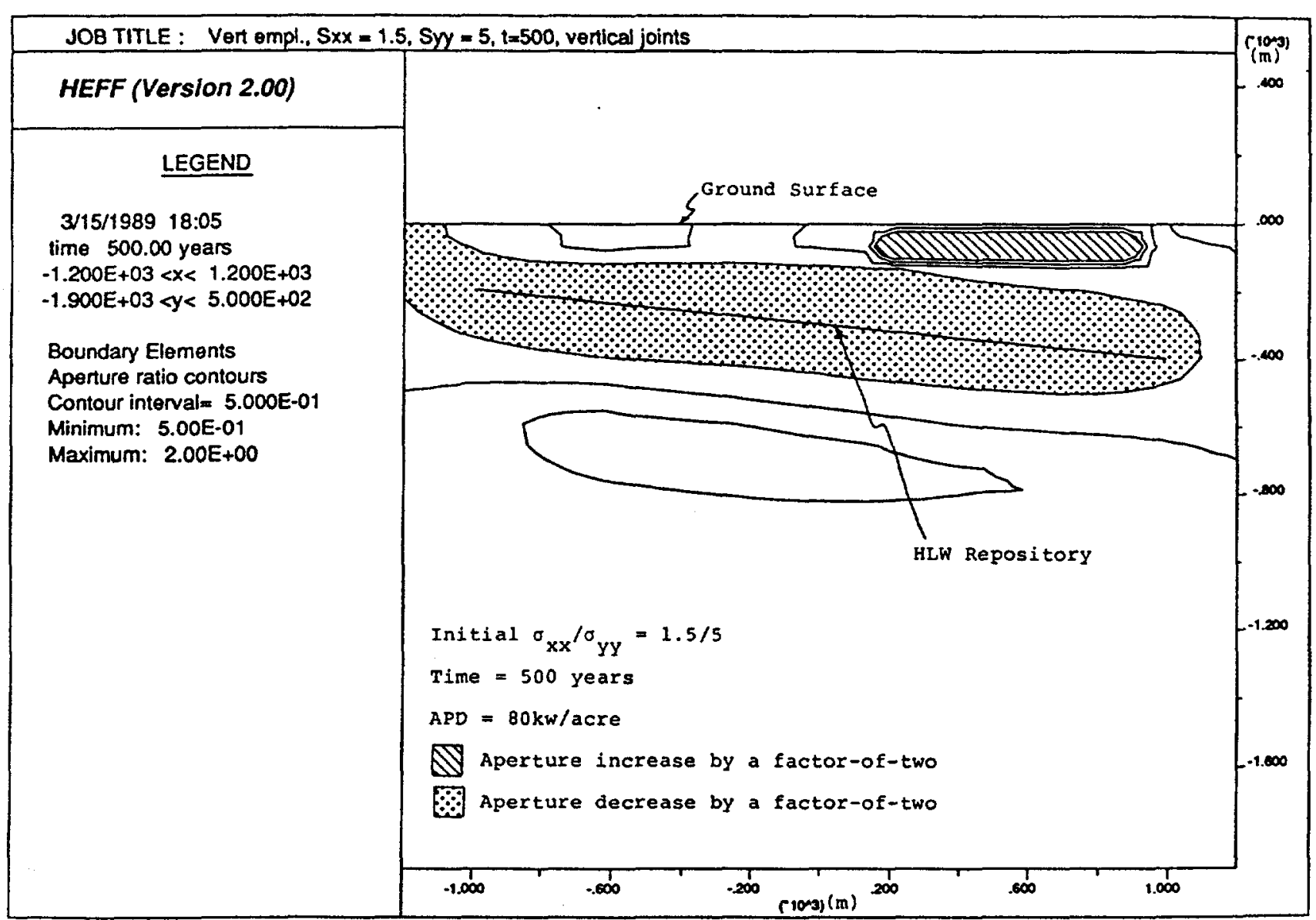

Fig. 3-19 Regions of Aperture Change By a Factor of Two, 500 Years After Waste Emplacement $\left(\sigma_{X X} / \sigma_{Y y}=1.5 / 5\right)$ 


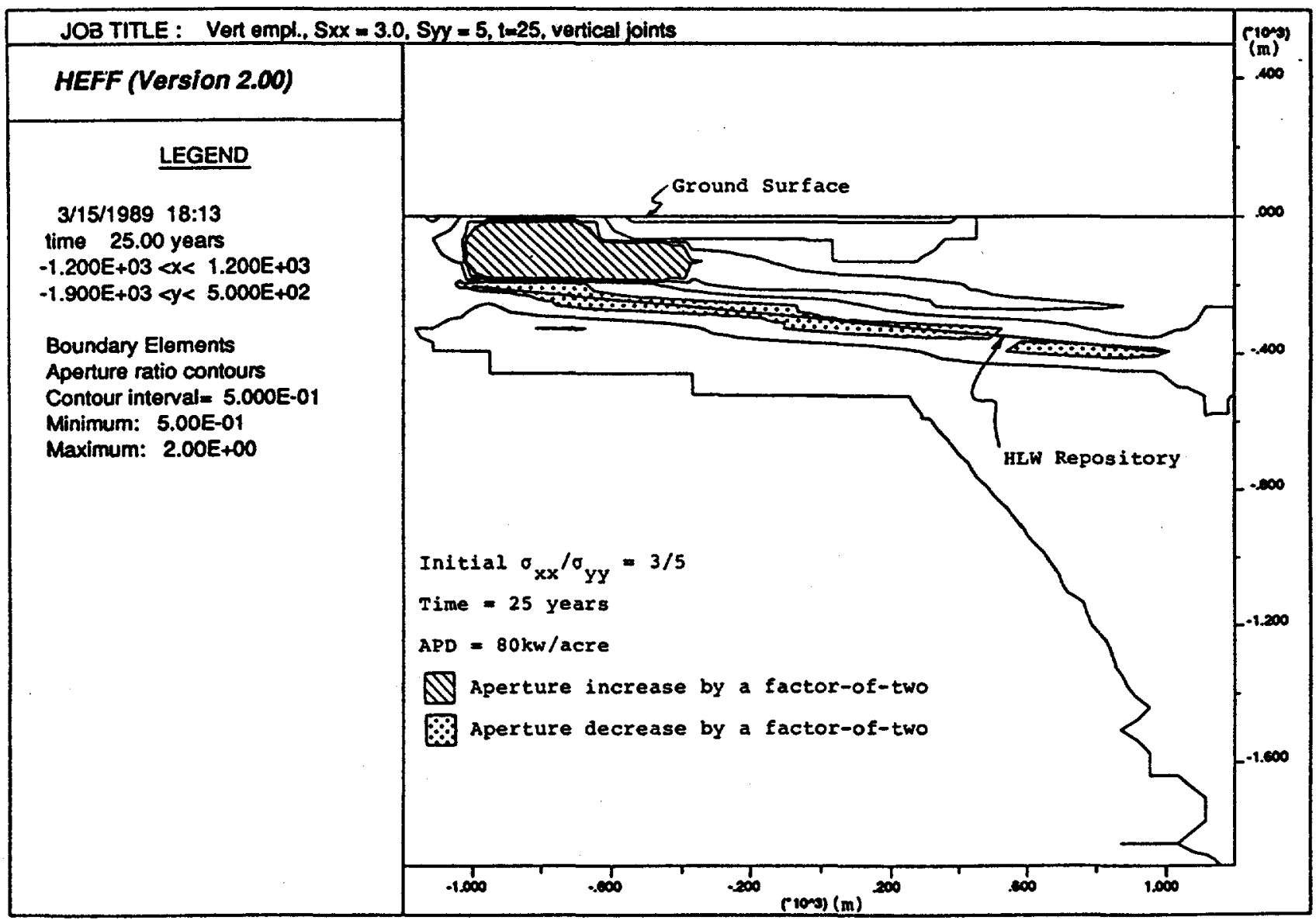

Fig. 3-20 Regions of Aperture Change By a Factor of Two, 25 Years After Waste Emplacement $\left(\sigma_{X X} / \sigma_{Y Y}=3 / 5\right)$ 


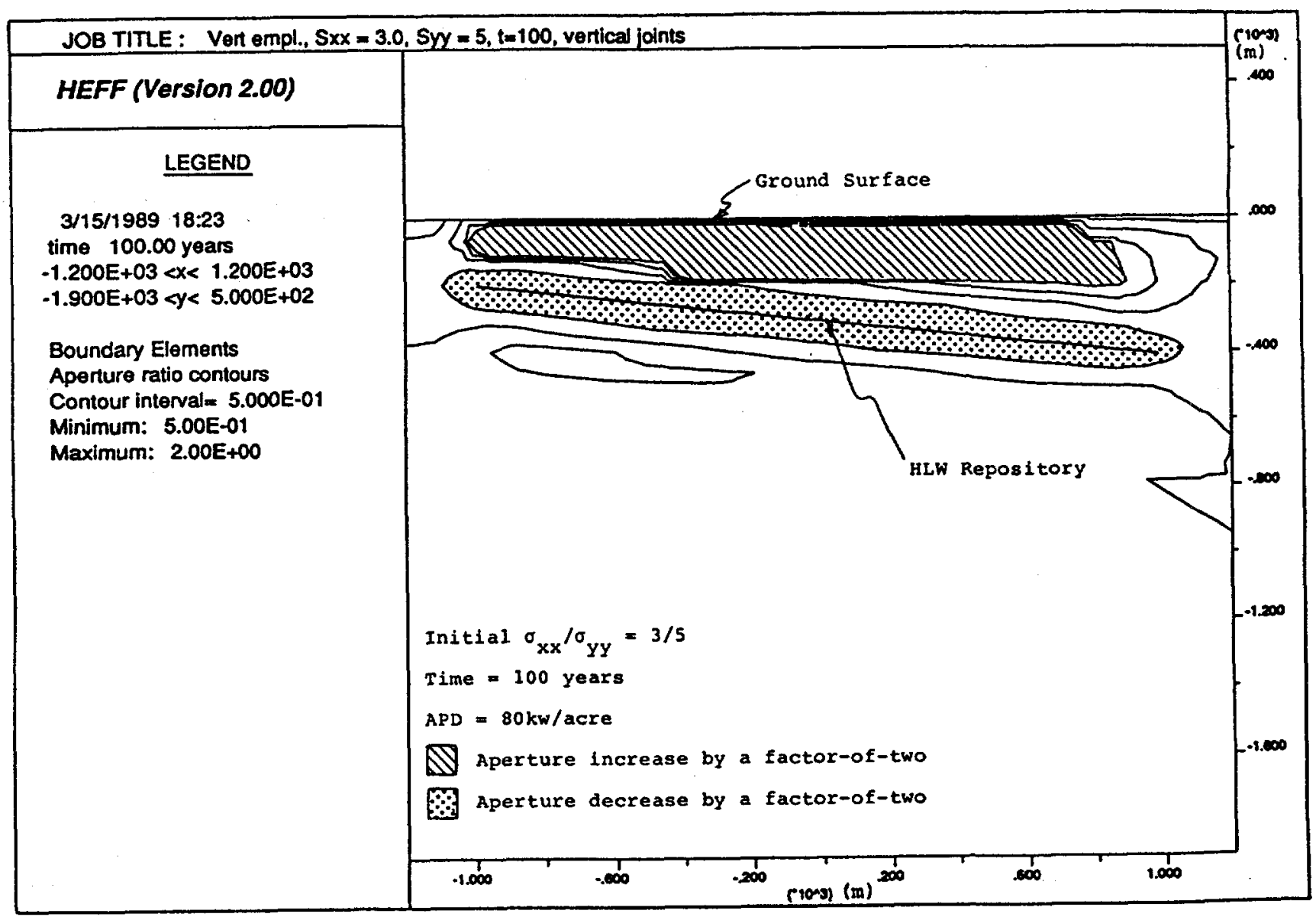

Fig. 3-21 Regions of Aperture Change By a Factor of Two, 100 Years After Waste Emplacement $\left(\sigma_{X X} / \sigma_{Y Y}=3 / 5\right)$ 


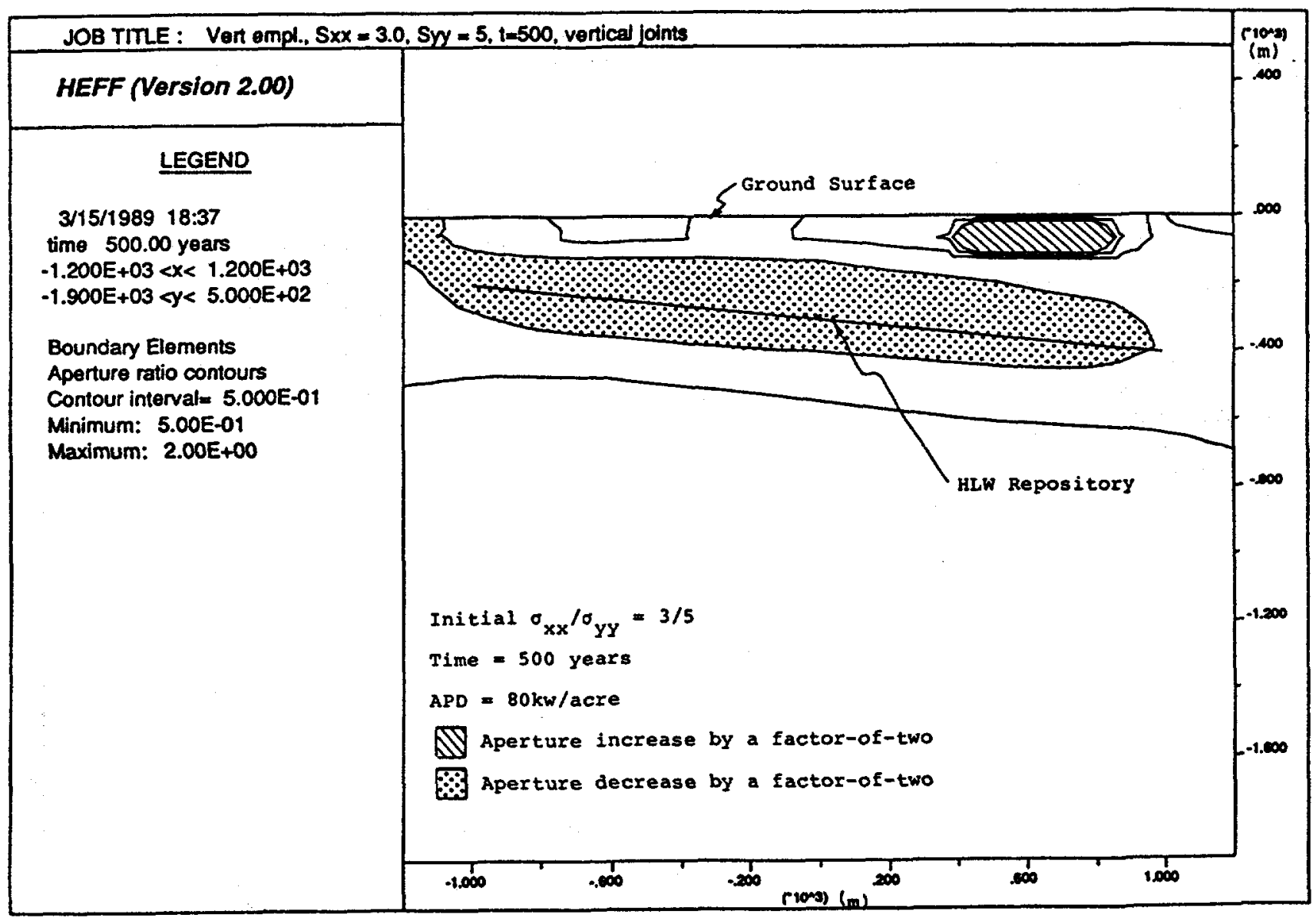

Fig. 3-22 Regions of Aperture Change By a Factor of Two, 500 Years After Waste Emplacement $\left(\sigma_{X X} / \sigma_{Y Y}=3 / 5\right)$ 


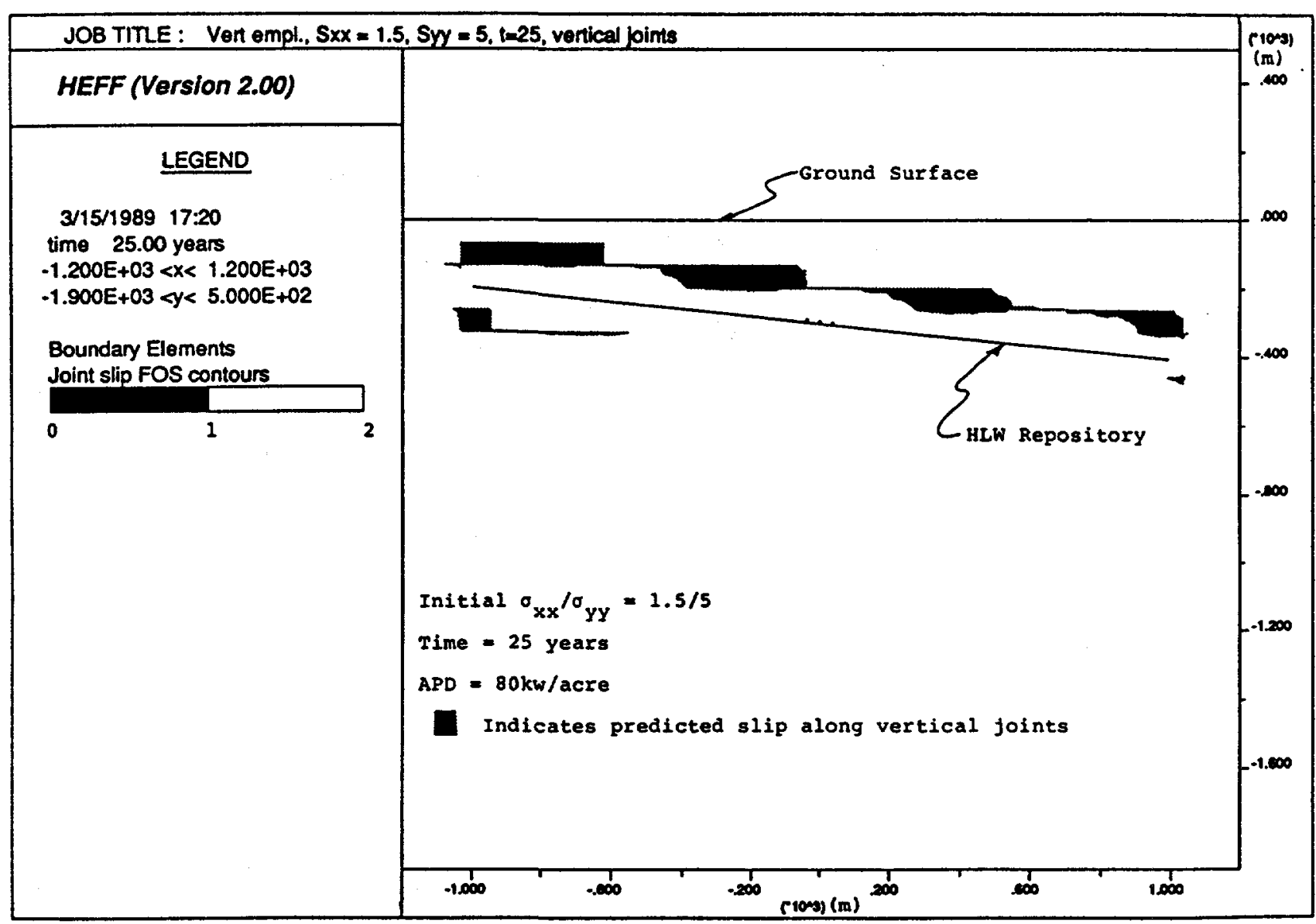

Fig. 3-23 Region of Predicted Slip Along Vertical Joints 25 Years After Waste Emplacement 


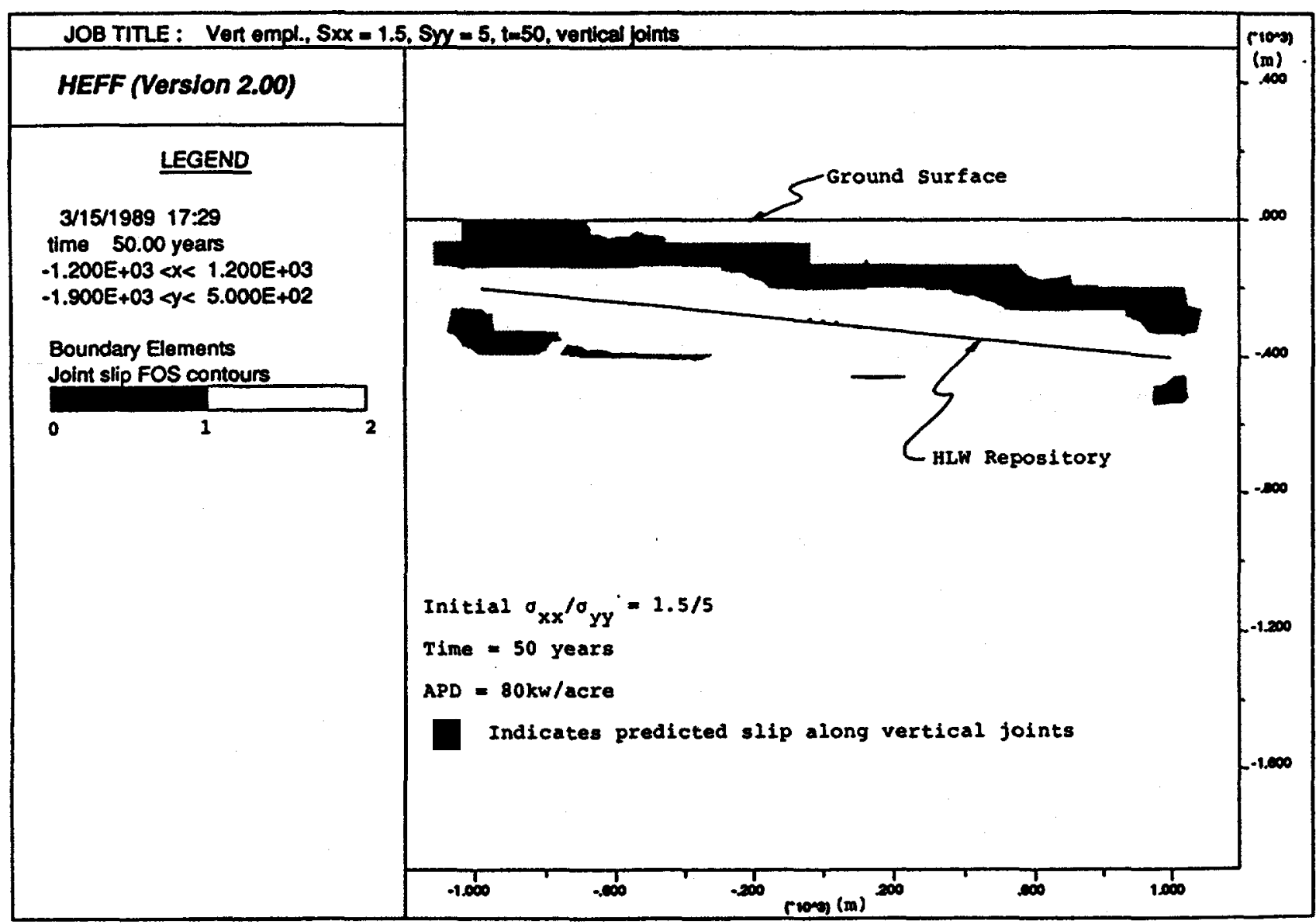

Fig. 3-24 Region of Predicted Slip Along Vertical Joints 50 Years After Waste Emplacement 


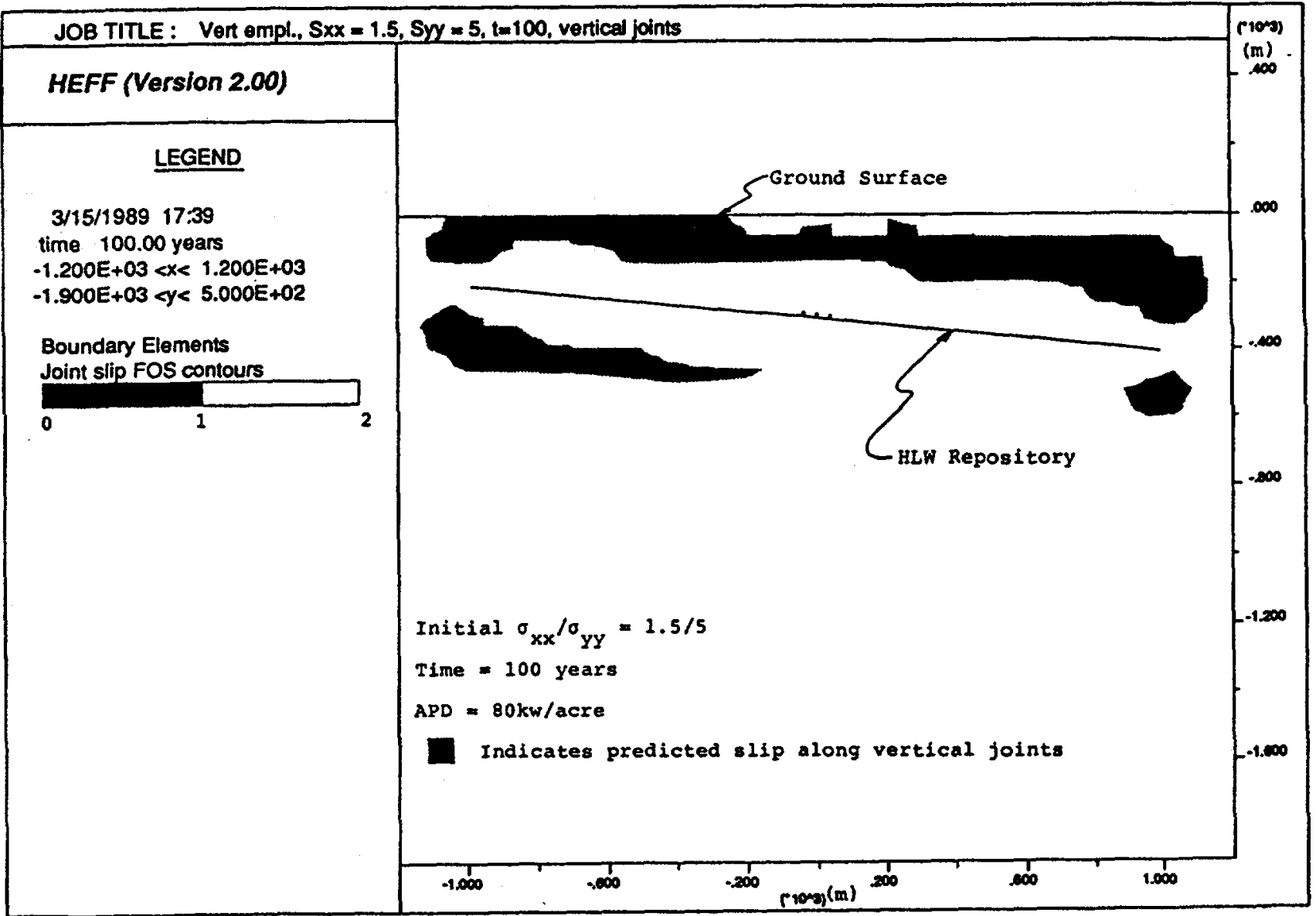

Fig. 3-25 Region of Predicted Slip Along Vertical Joints 100 Years After Waste Emplacement 


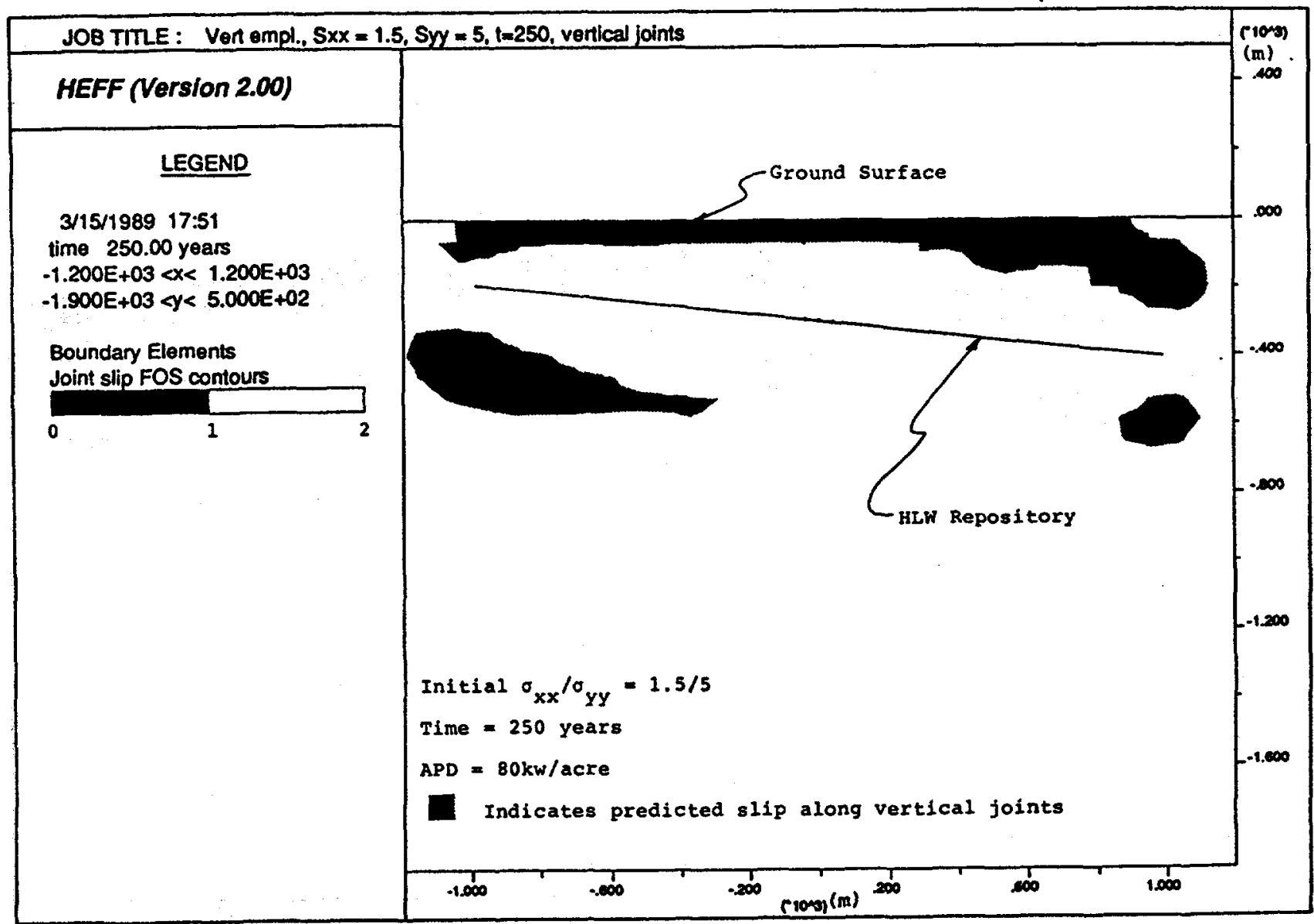
$\begin{aligned} \text { Fig. 3-26 } & \begin{array}{l}\text { Region of Predicted Slip Along Vertical Joints } 250 \\ \text { Years After Waste Emplacement }\end{array}\end{aligned}$ 


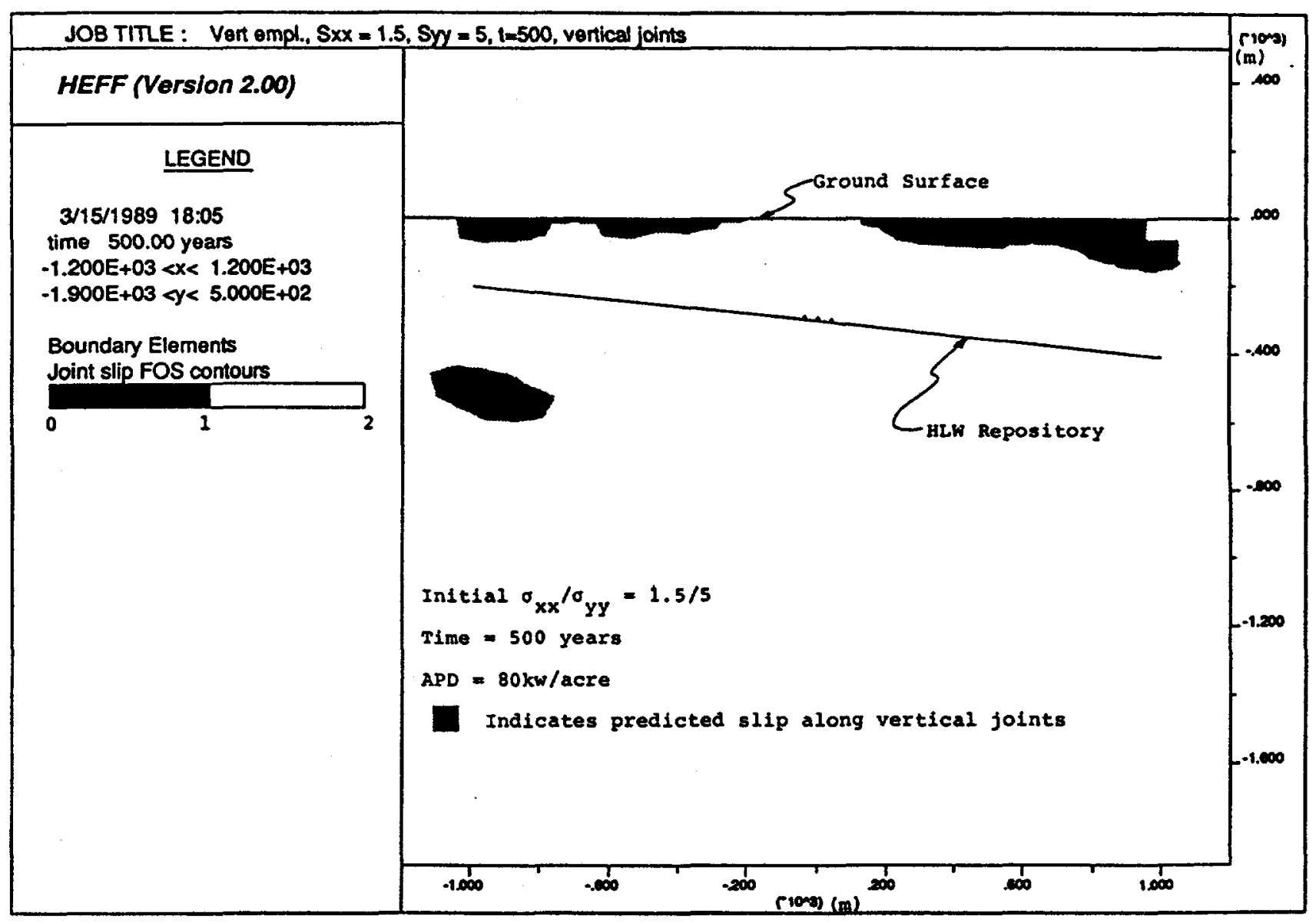

Fig. 3-27 Region of Predicted Slip Along Vertical Joints 500 Years After Waste Emplacement 


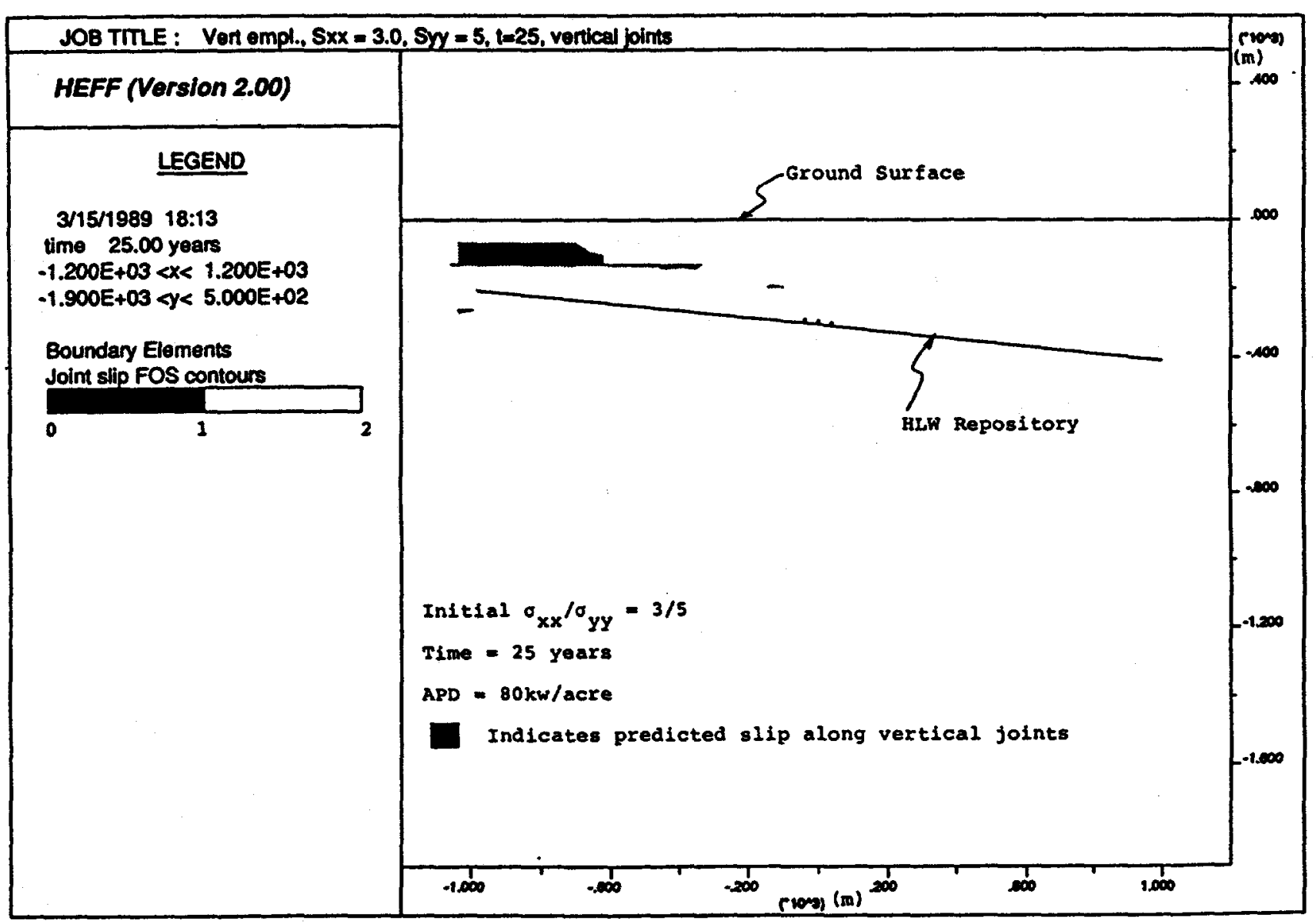

Fig. 3-28 Region of Predicted Slip Along Vertical Joints 25 Years After Waste Emplacement $\left(\sigma_{X X} / \sigma_{Y Y}=3 / 5\right)$ 


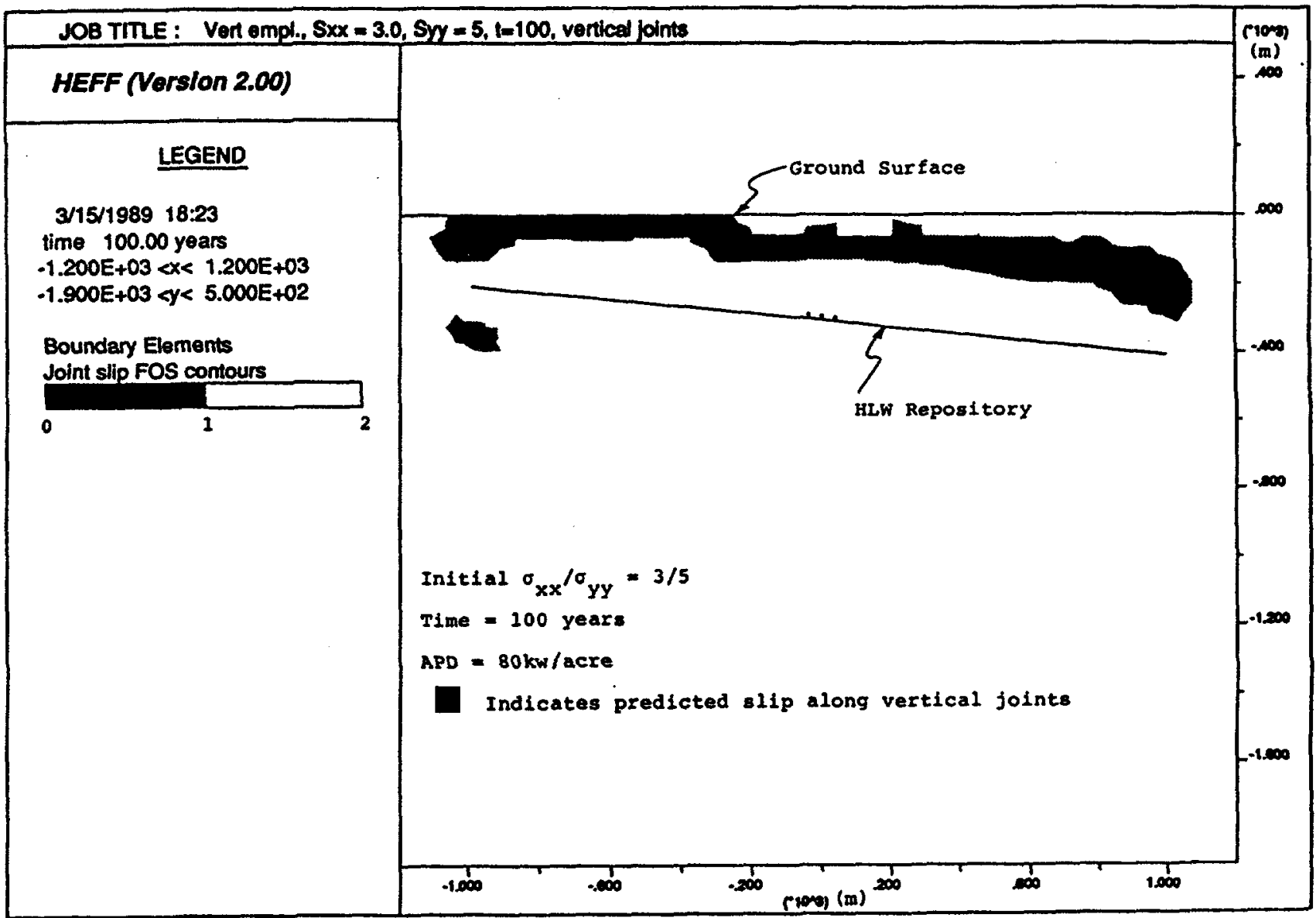

Fig. 3-29 Region of Predicted Slip Along Vertical Joints 100 Years After Waste Emplacement $\left(\sigma_{x x} / \sigma_{Y y}=3 / 5\right)$ 


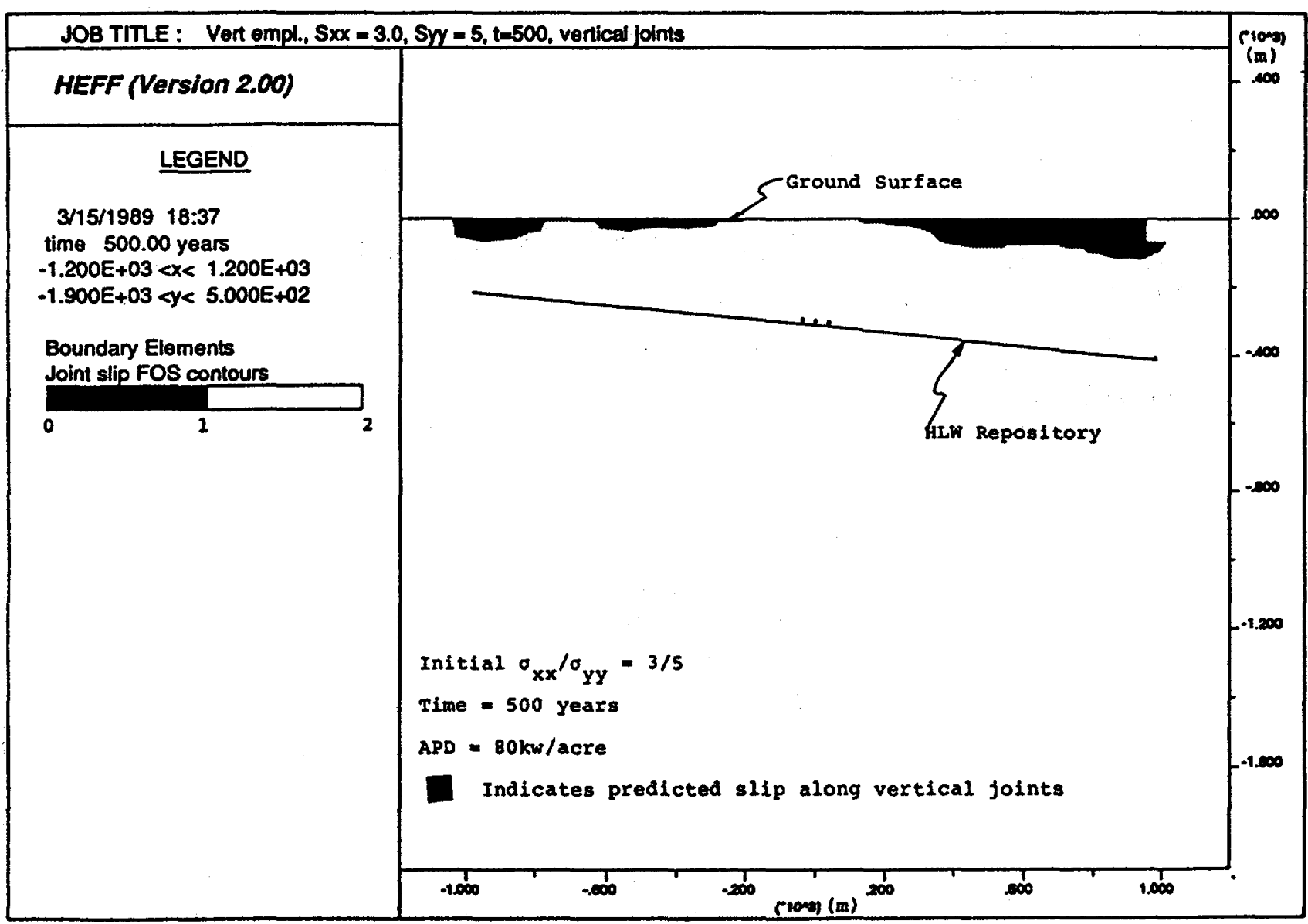

Eig. 3-30 Region of Predicted Slip Along Vertical Joints 500 Years After Waste Emplacement $\left(\sigma_{X X} / \sigma_{Y Y}=3 / 5\right)$ 


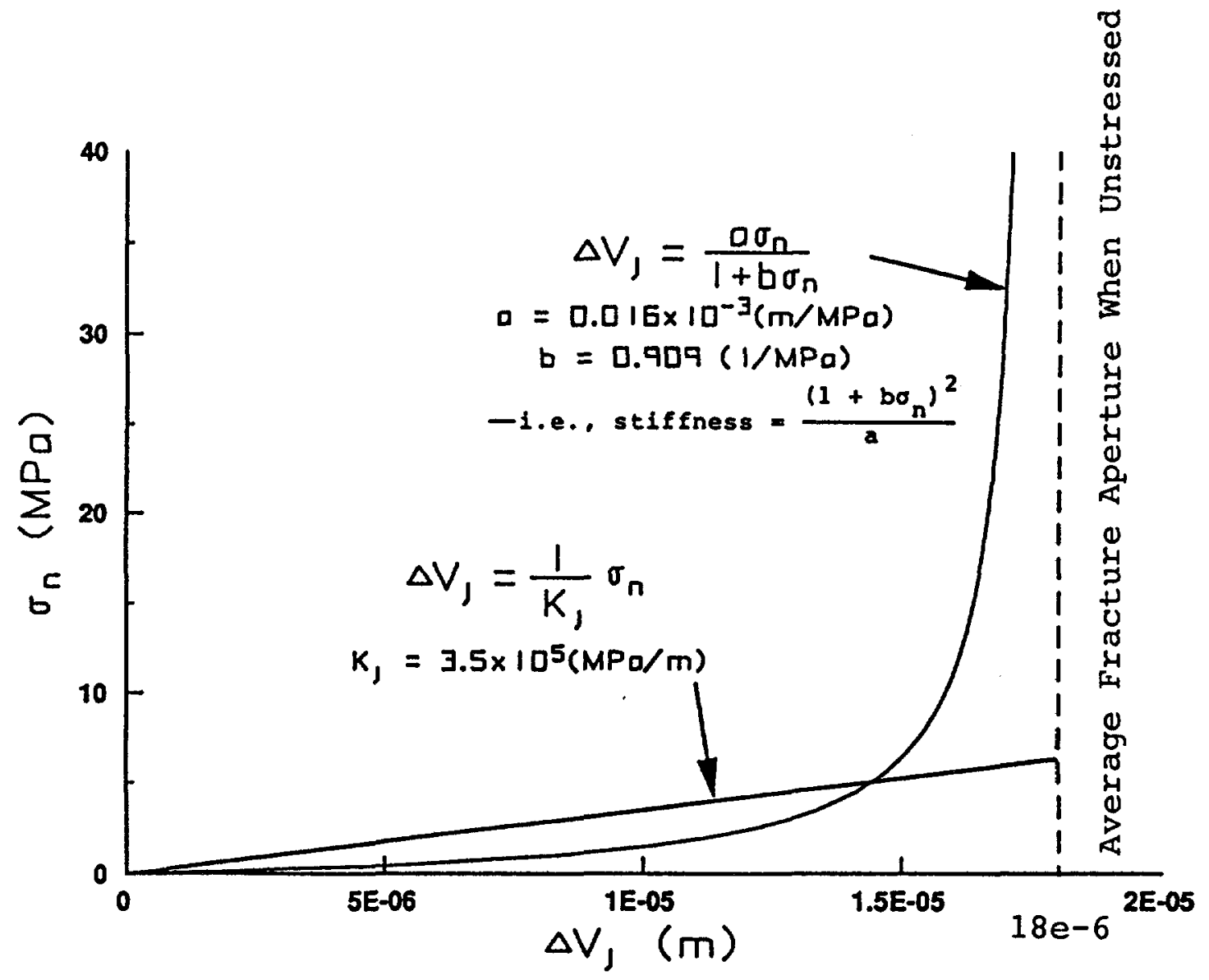

Eig. 3-31 Linear and Hyperbolic Joint Deformation Models 
JOB TITLE : temperatures atter 50 years ...

\section{UDEC (Version 1.5)}

\section{LEGEND}

\section{3/15/1989 13:47}

cycle 415

$-2.000 E+02<x<1.400 E+03$

$-1.000 E+03<y<6.000 E+02$

boundary plot

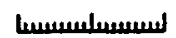

0 2E $2(\mathrm{~m})$

temp contours $(: \mathrm{C})$

contour interval $=1.000 E+01$

$\min =0.000 E+00 \max =1.100 E+02$

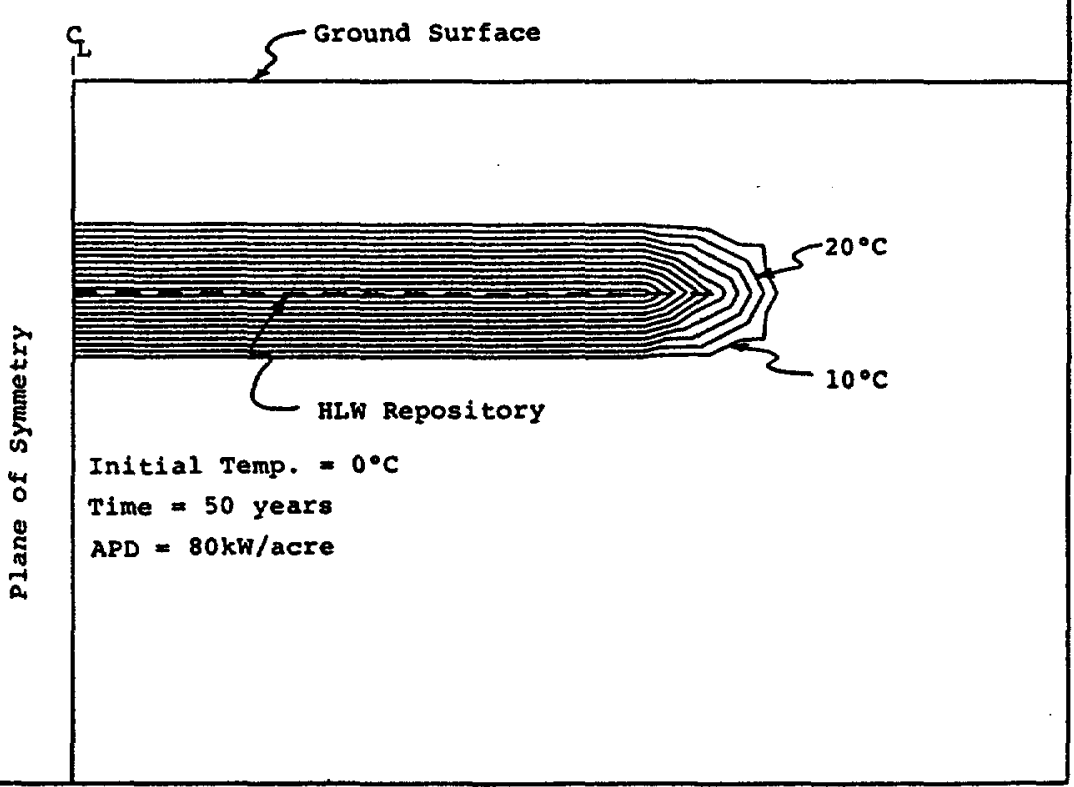

Fig. 3-32 Contours of Rock Temperature Rise $\left({ }^{\circ} \mathrm{C}\right) 50$ Years After Waste Emplacement 


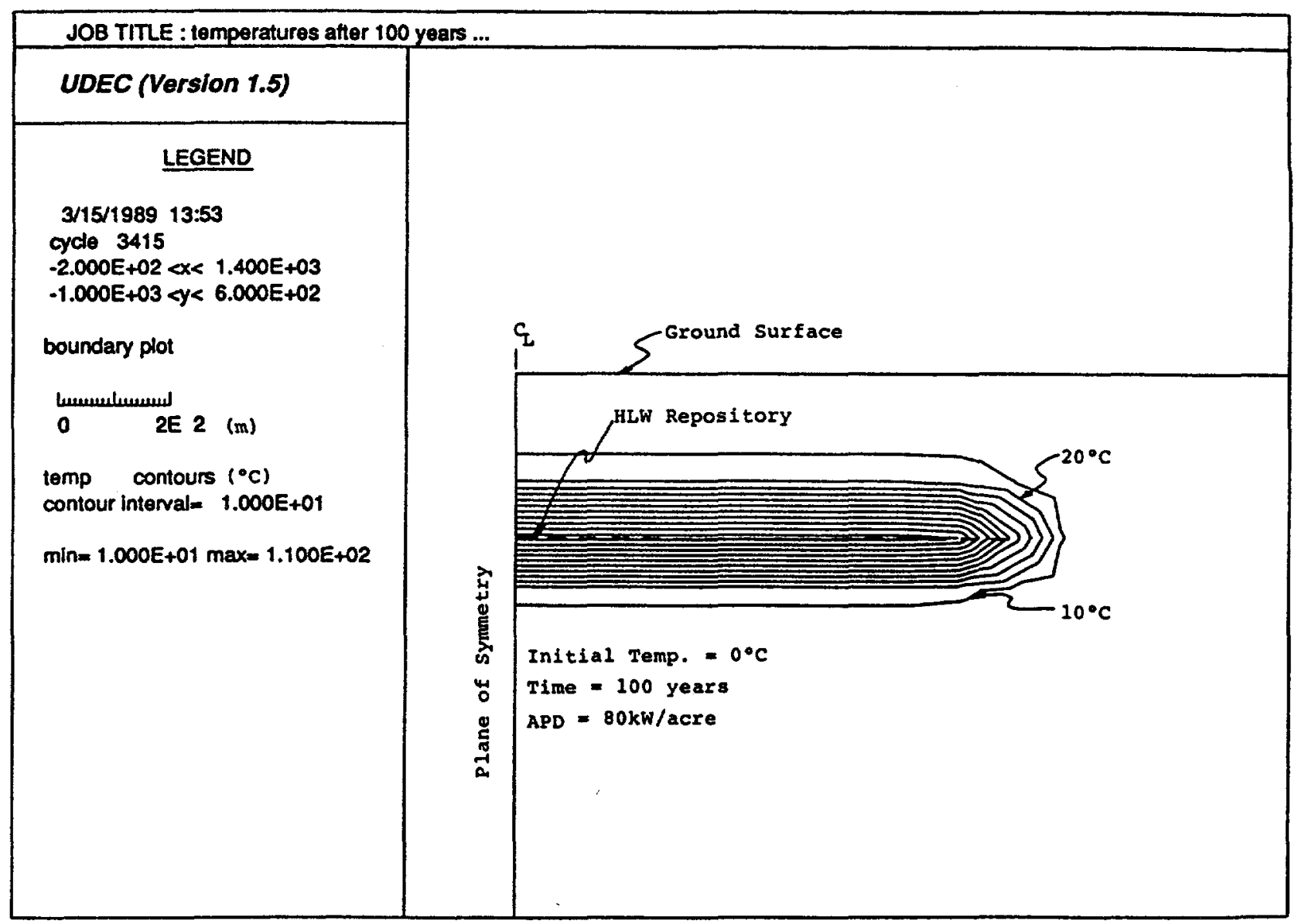

Fig. 3-33 Contours of Rock Temperature Rise $\left({ }^{\circ} \mathrm{C}\right) 100$ Years After Waste Emplacement 


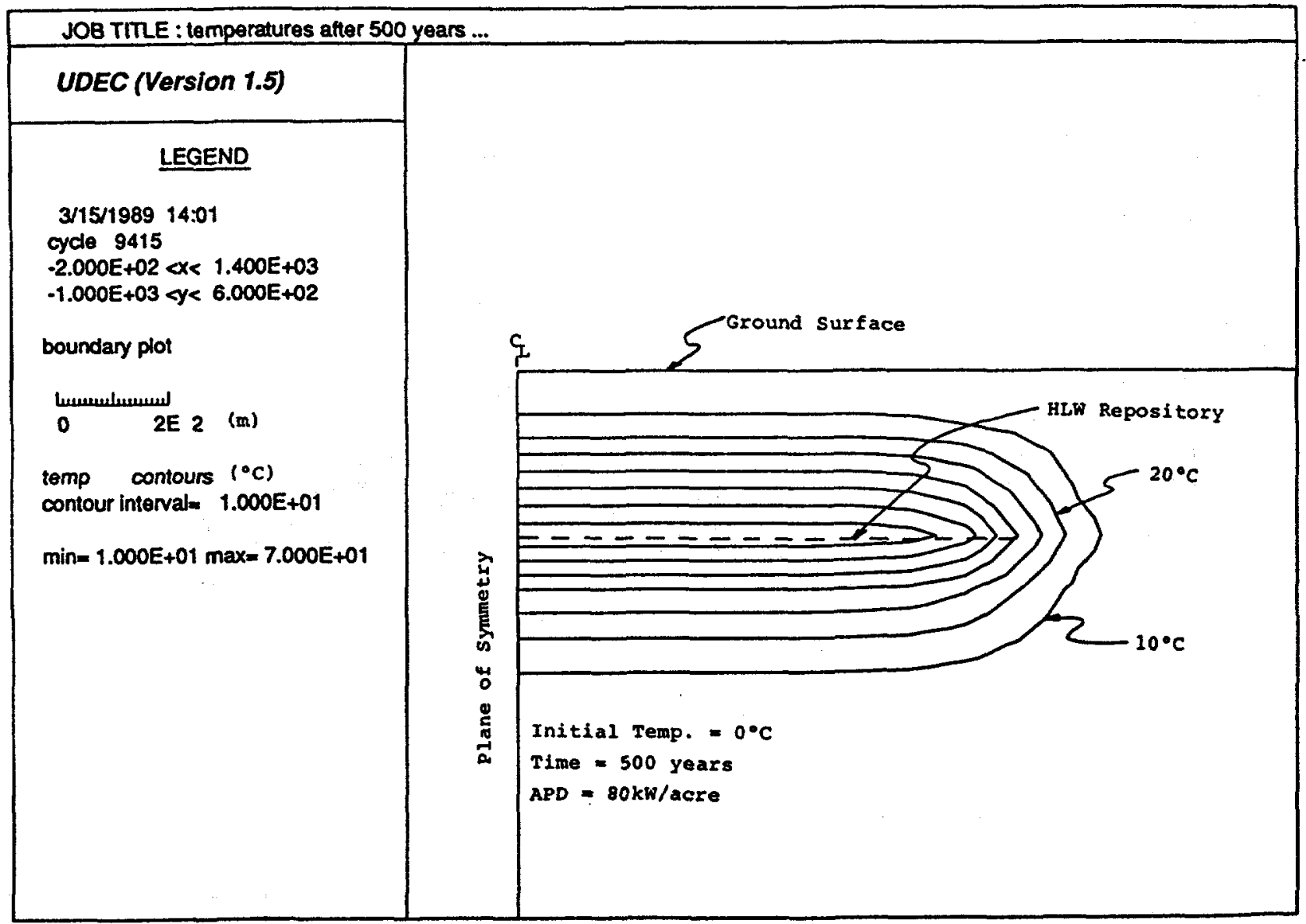

Fig. 3-34 Contours of Rock Temperature Rise ( $\left.{ }^{\circ} \mathrm{C}\right) 500$ Years After Waste Emplacement 

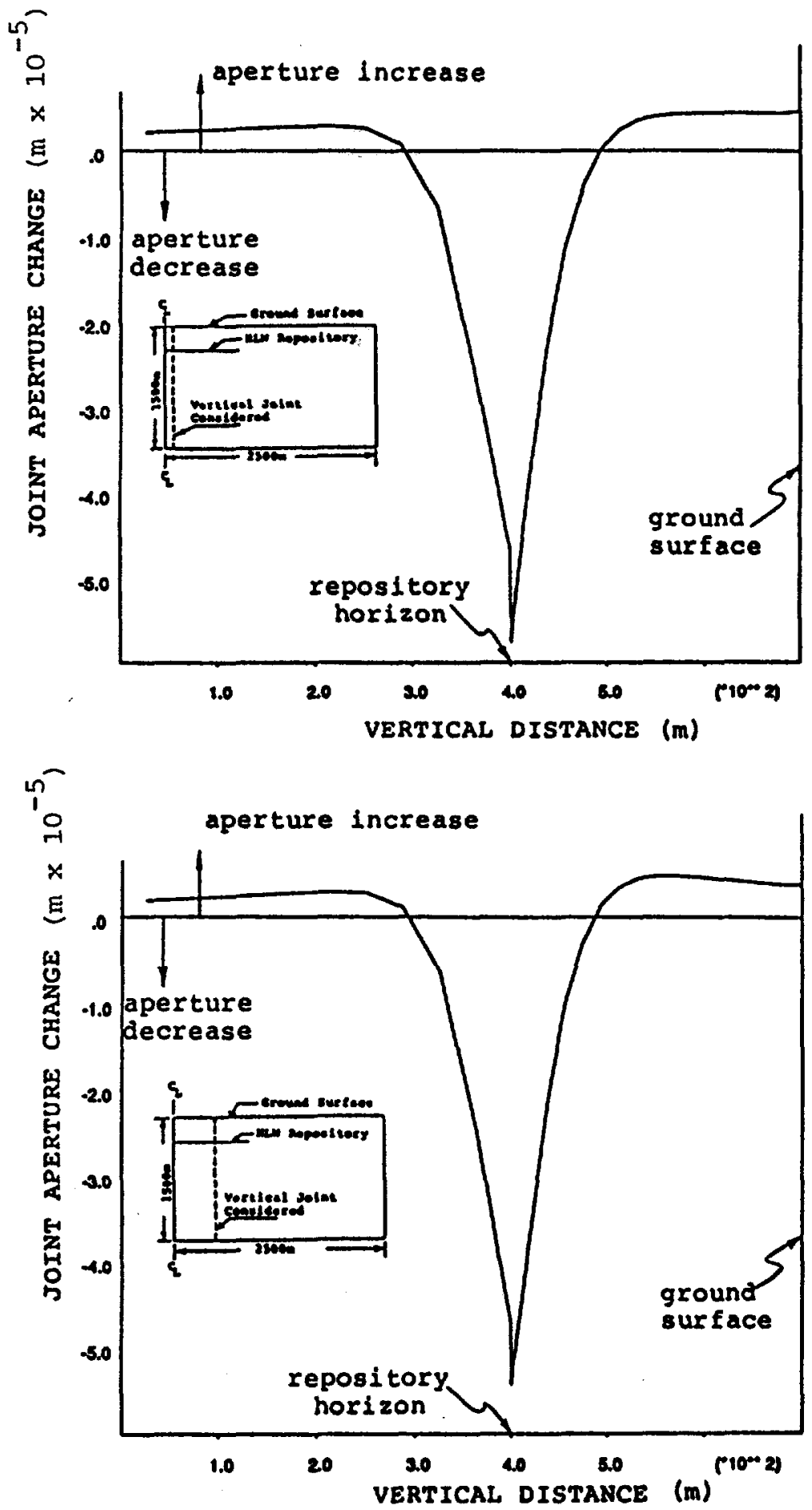

Fig. 3-35 Change in Joint Aperture From Thermomechanical Effects 50 Years After Waste Emplacement (Joint locations are near the repository center and $500 \mathrm{~m}$ to the right of the center; horizontal features are omitted.) 

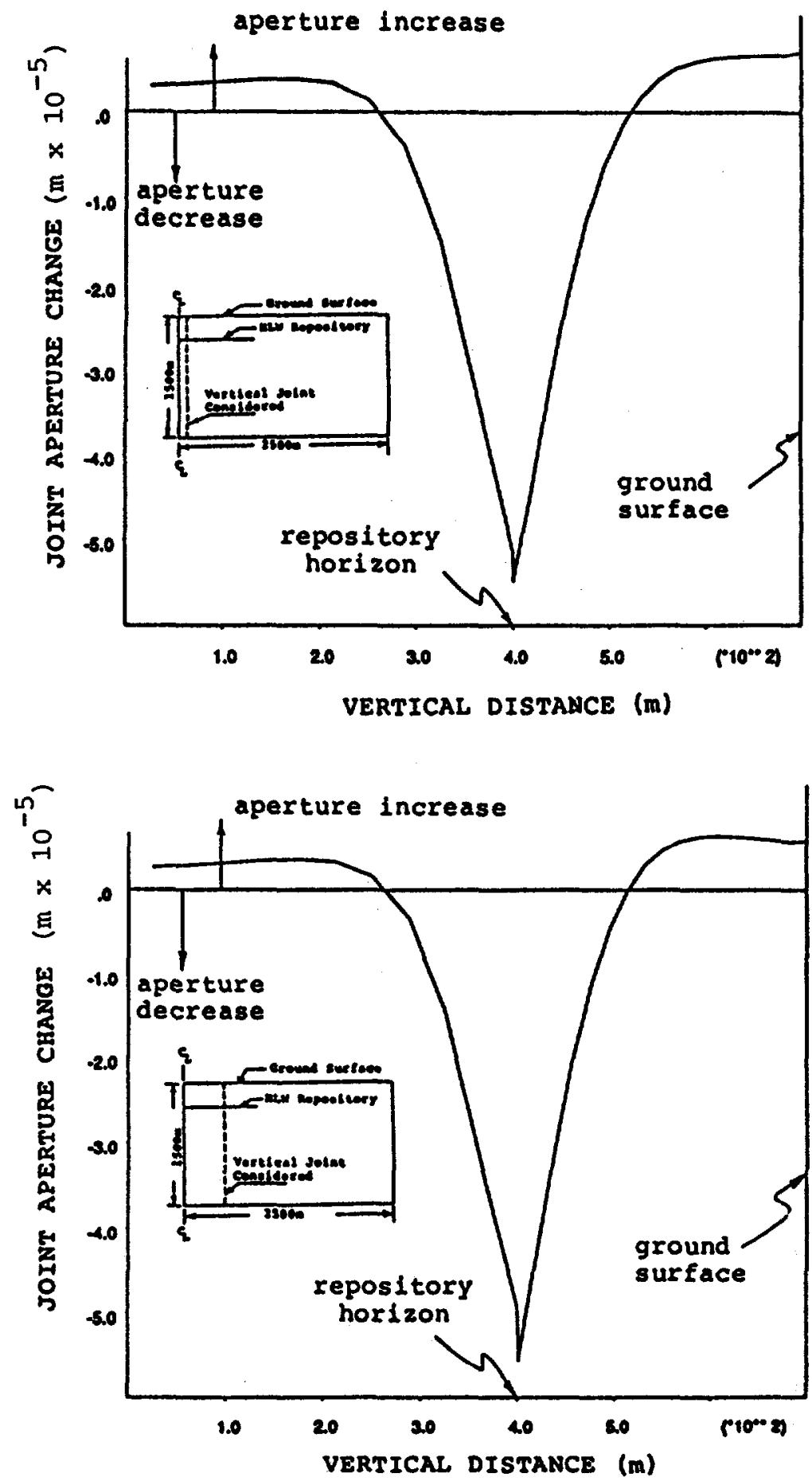

Fig. 3-36 Change in Joint Aperture From Thermomechanical Effects 100 Years After Waste Emplacement (Joint locations are near the repository center and $500 \mathrm{~m}$ to the right of the center; horizontal features are omitted.) 

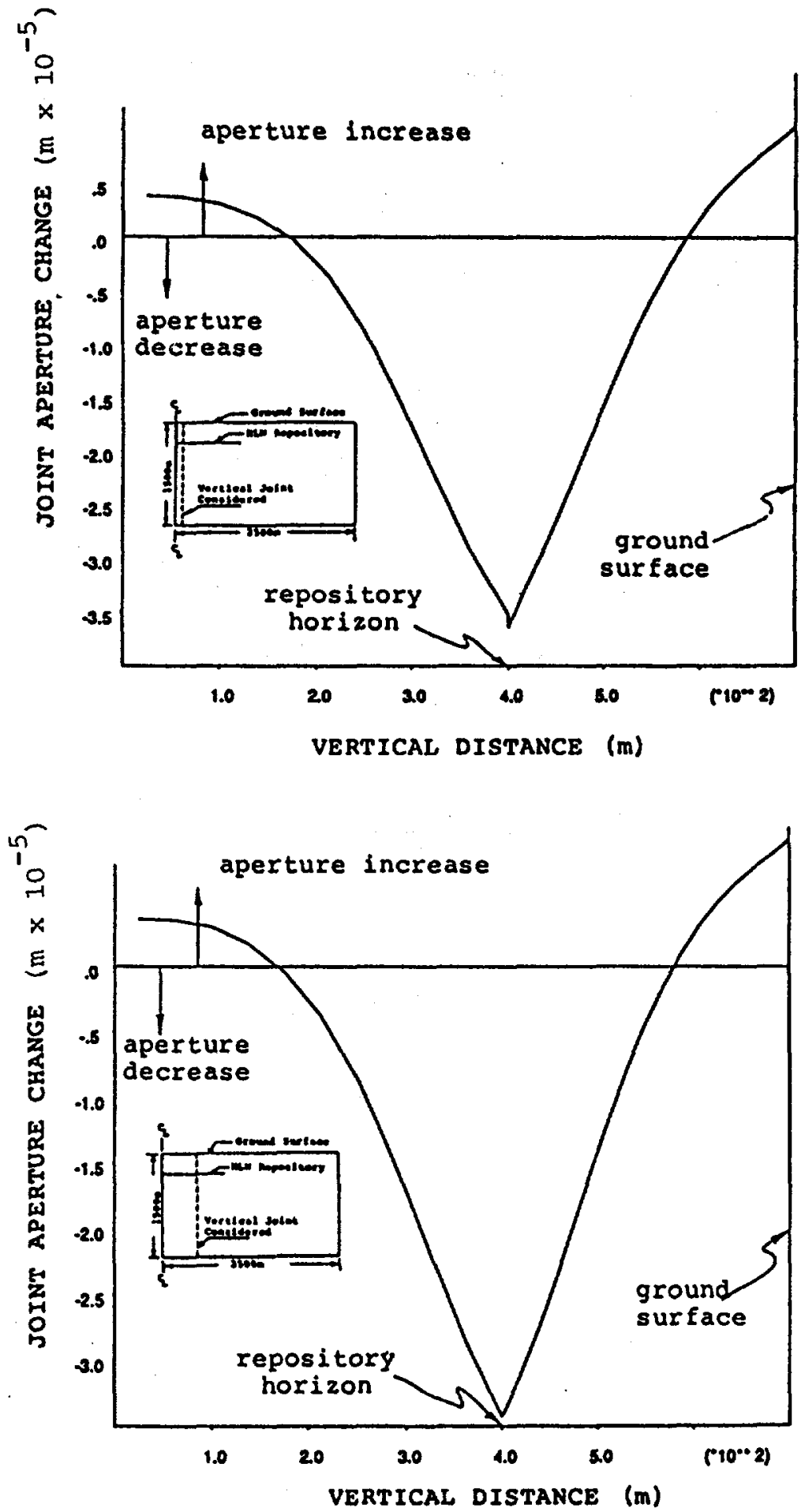

Fig. 3-37 Change in Joint Aperture From Thermomechanical Effects 500 Years After Waste Emplacement (Joint locations are near the repository center and $500 \mathrm{~m}$ to the right of the center; horizontal features are omitted.) 


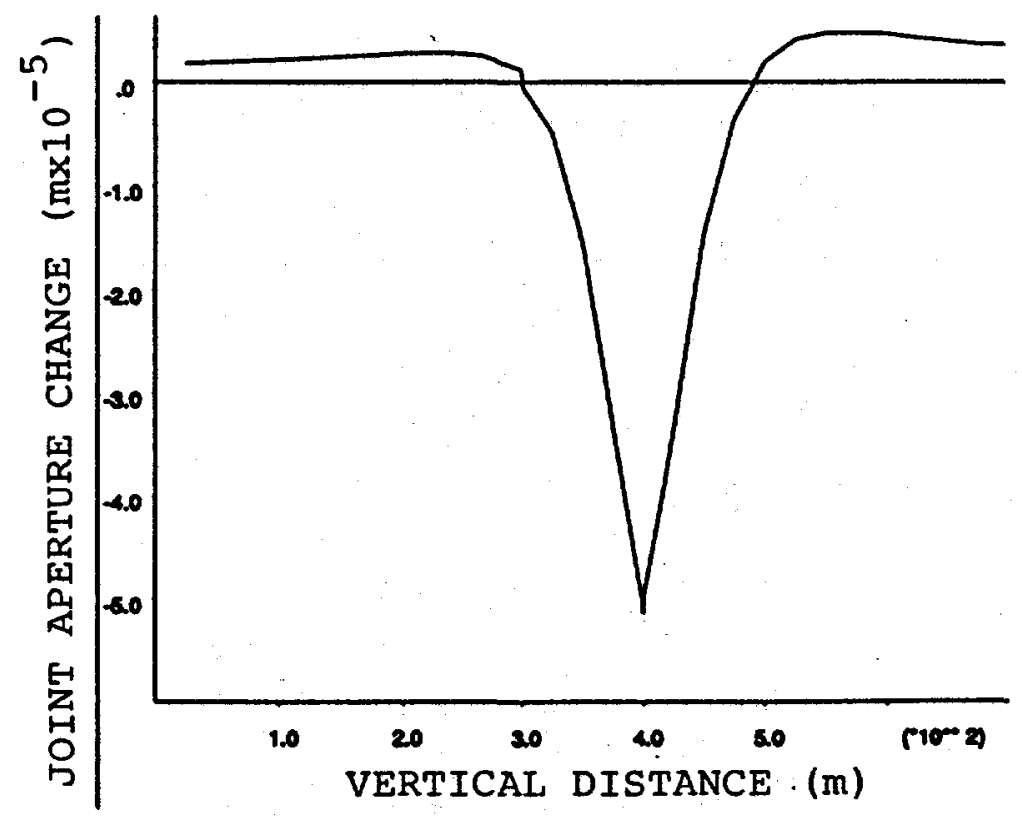

(a)

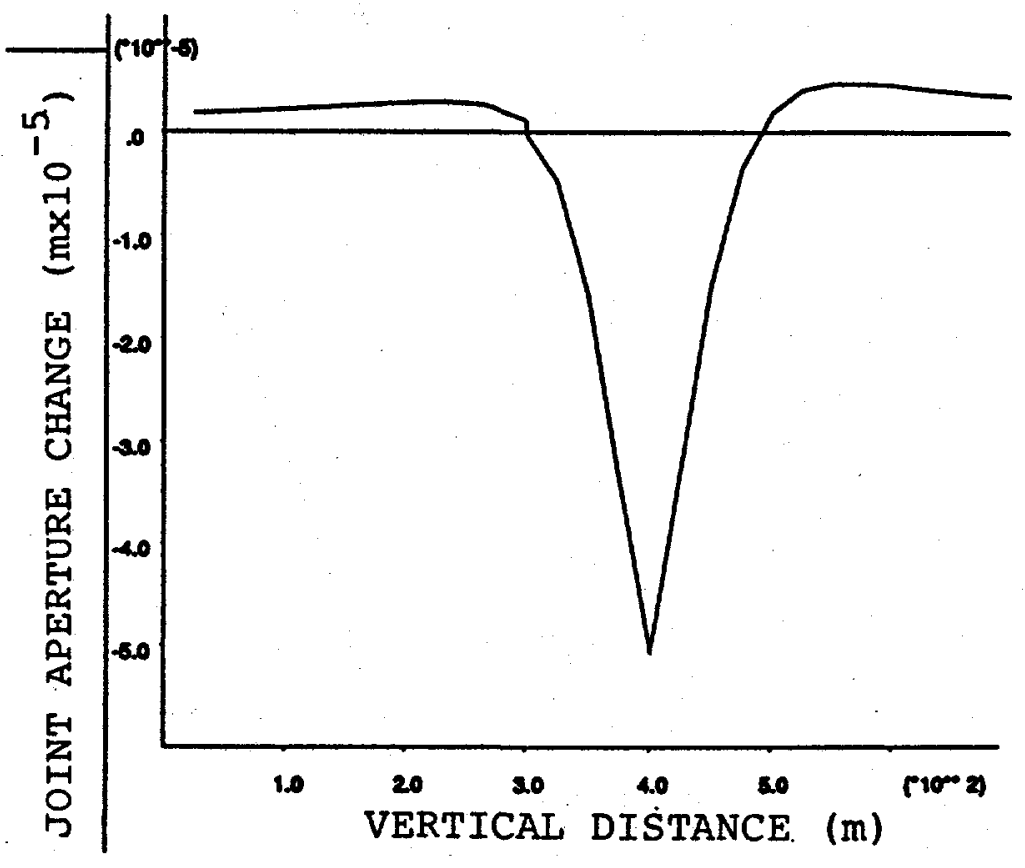

(b)

Fig. 3-38 Change in Joint Aperture From Thermomechanical Effects 50 Years After Waste Emplacement on Joint $500 \mathrm{~m}$ From Repository Center: (a) friction angle $=10^{\circ}$ on horizontal features; (b) friction angle $=28^{\circ}$ on horizontal features 


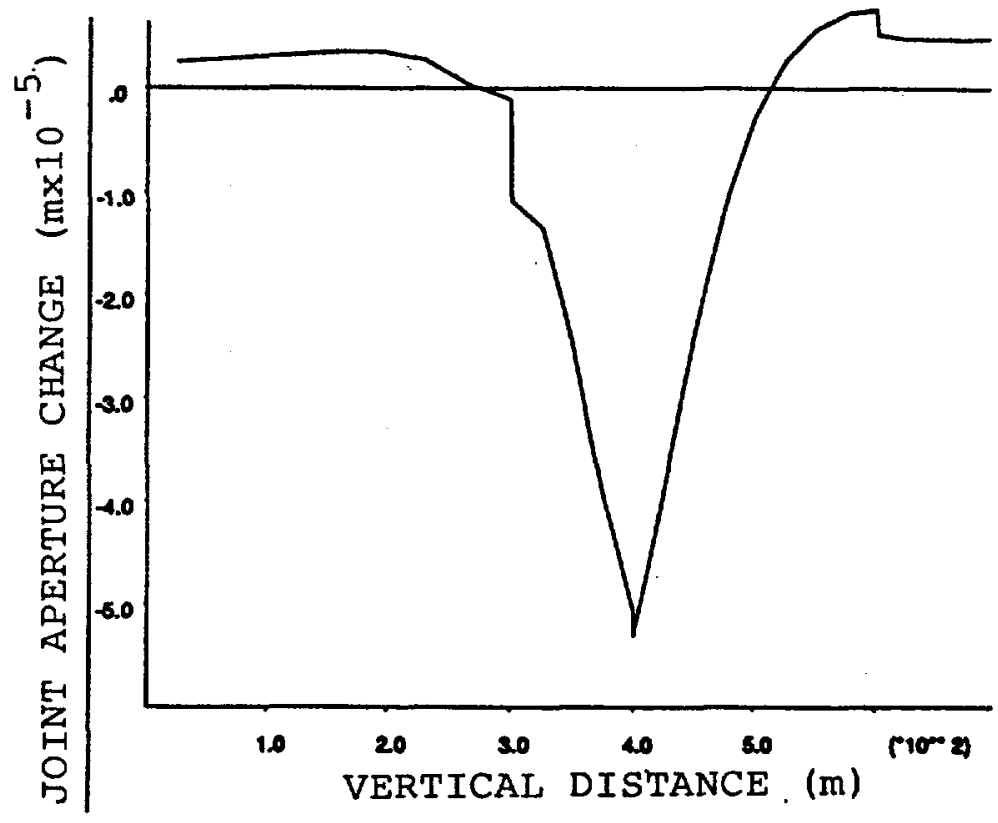

(a)

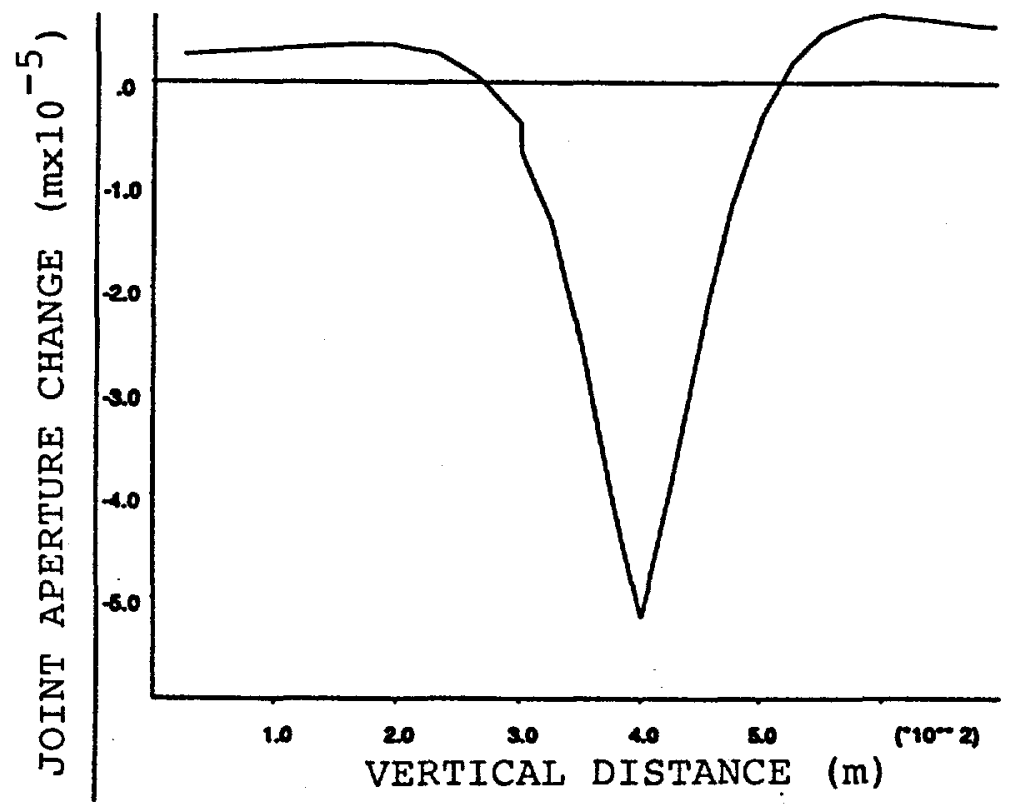

(b)

Fig. 3-39 Change in Joint Aperture From Thermomechanical Effects 100 Years After Waste Emplacement on Joint $500 \mathrm{~m}$ From Repository Center: (a) friction angle $=10^{\circ}$ on horizontal features; (b) friction angle $=28^{\circ}$ on horizontal features 


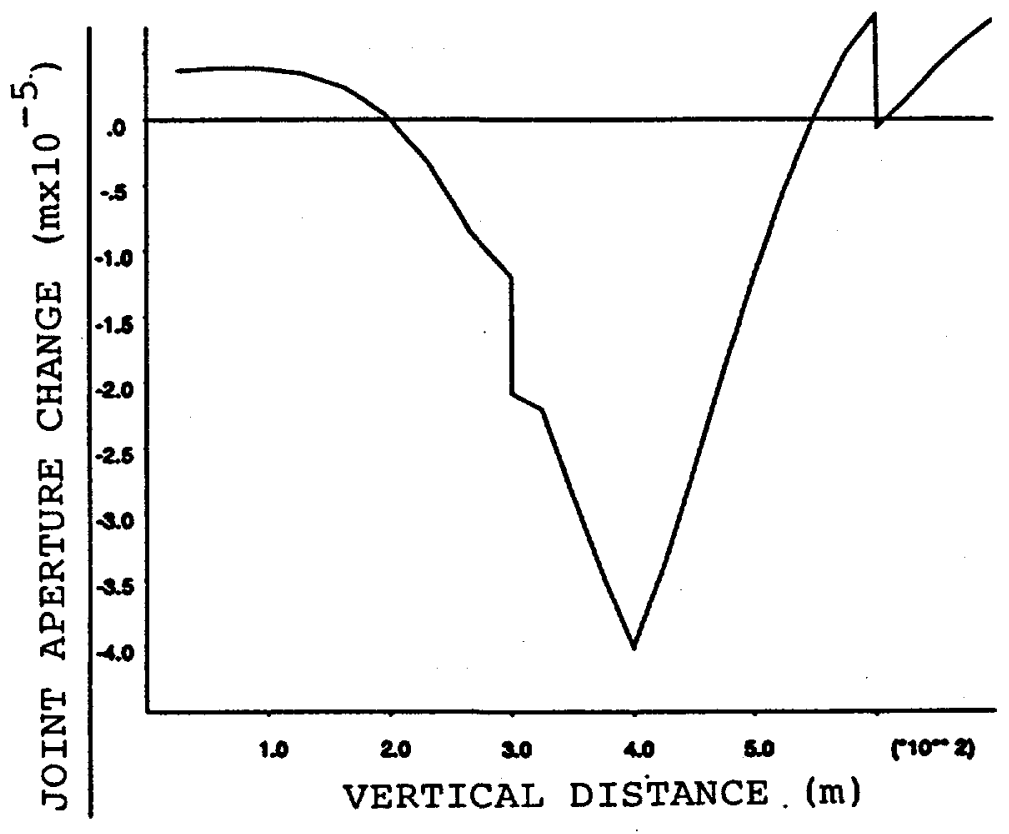

(a)

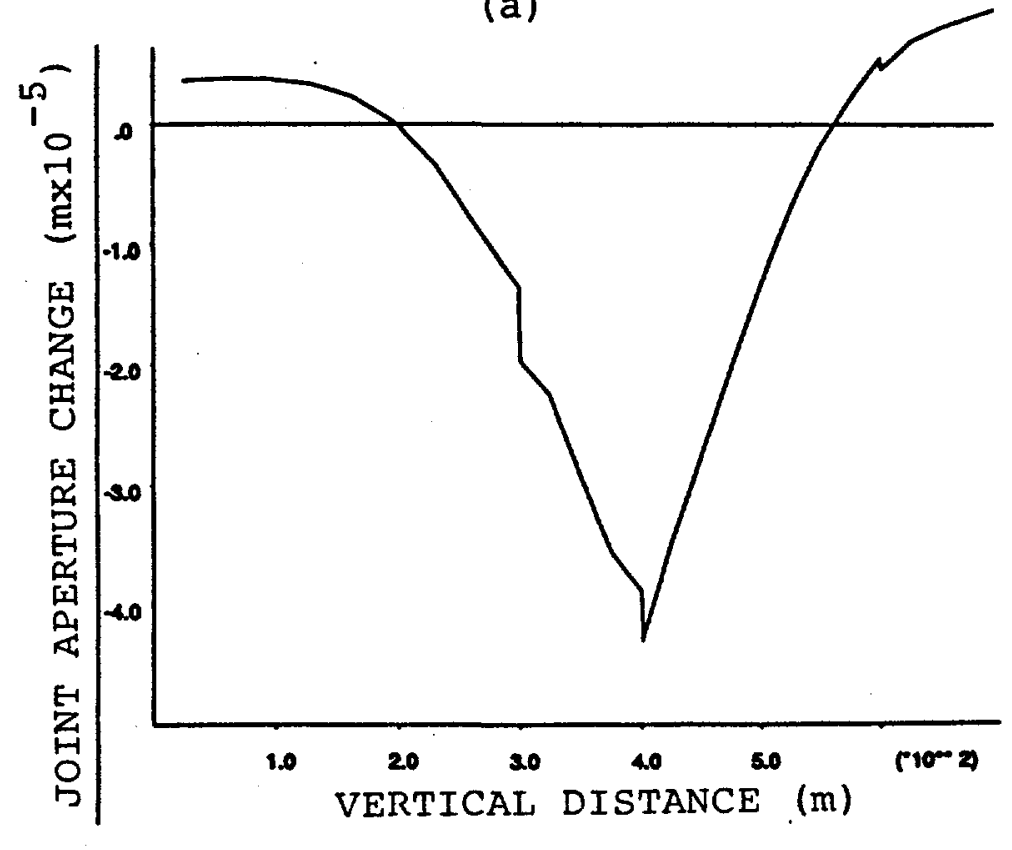

(b)

Fig. 3-40 Change in Joint Aperture From Thermomechanical Effects 250 Years After Waste Emplacement on Joint $500 \mathrm{~m}$ From Repository Center: (a) friction angle $=10^{\circ}$ on horizontal features; (b) friction angle $=28^{\circ}$ on horizontal features 

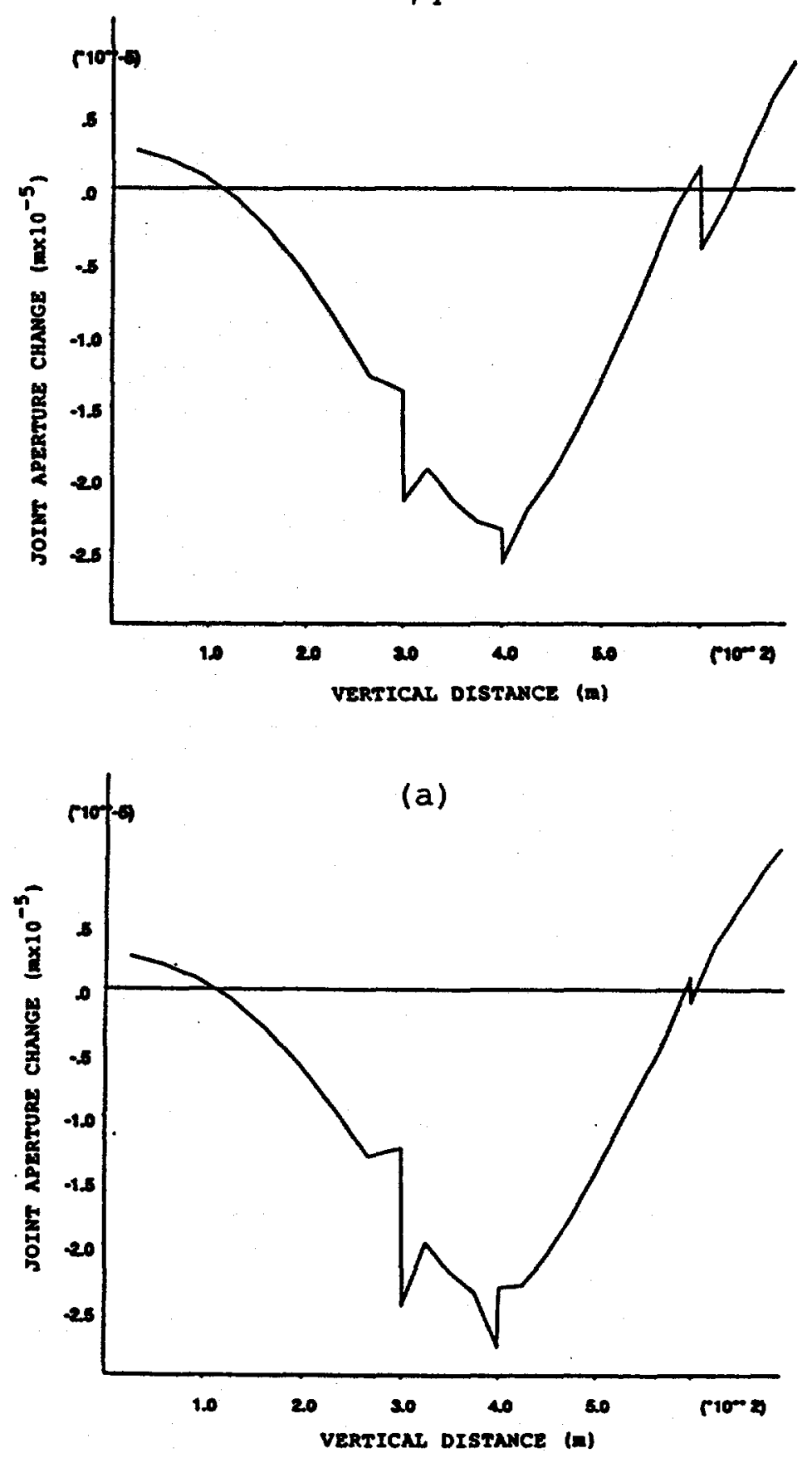

(b)

Fig. 3-41 Change in Joint Aperture From Thermomechanical Effects 500 Years After Waste Emplacement on Joint $500 \mathrm{~m}$ From Repository Center: (a) friction angle $=10^{\circ}$ on horizontal features; (b) friction angle $=28^{\circ}$ on horizontal features 
(1) Initial state

$$
\begin{aligned}
& \sigma_{\mathrm{h}}=0 \\
& \sigma_{\mathrm{h}}=0 \\
& \sigma_{\mathrm{h}}=0
\end{aligned}
$$

(2) After Heating, If Not Allowed to Slip

$$
\sigma_{\mathrm{h}} \text { tensile }
$$

$\sigma_{\mathrm{h}}$ compressive

$$
\sigma_{\mathrm{h}} \text { tensile }
$$

(3) After Heating, If Allowed to slip

\begin{tabular}{c}
$\sigma_{\mathrm{h}}=0$ \\
$\sigma_{\mathrm{h}}=0$ \\
\hline$\sigma_{\mathrm{h}}=0$
\end{tabular}

Fig. 3-42 Three Plates Stacked Together 

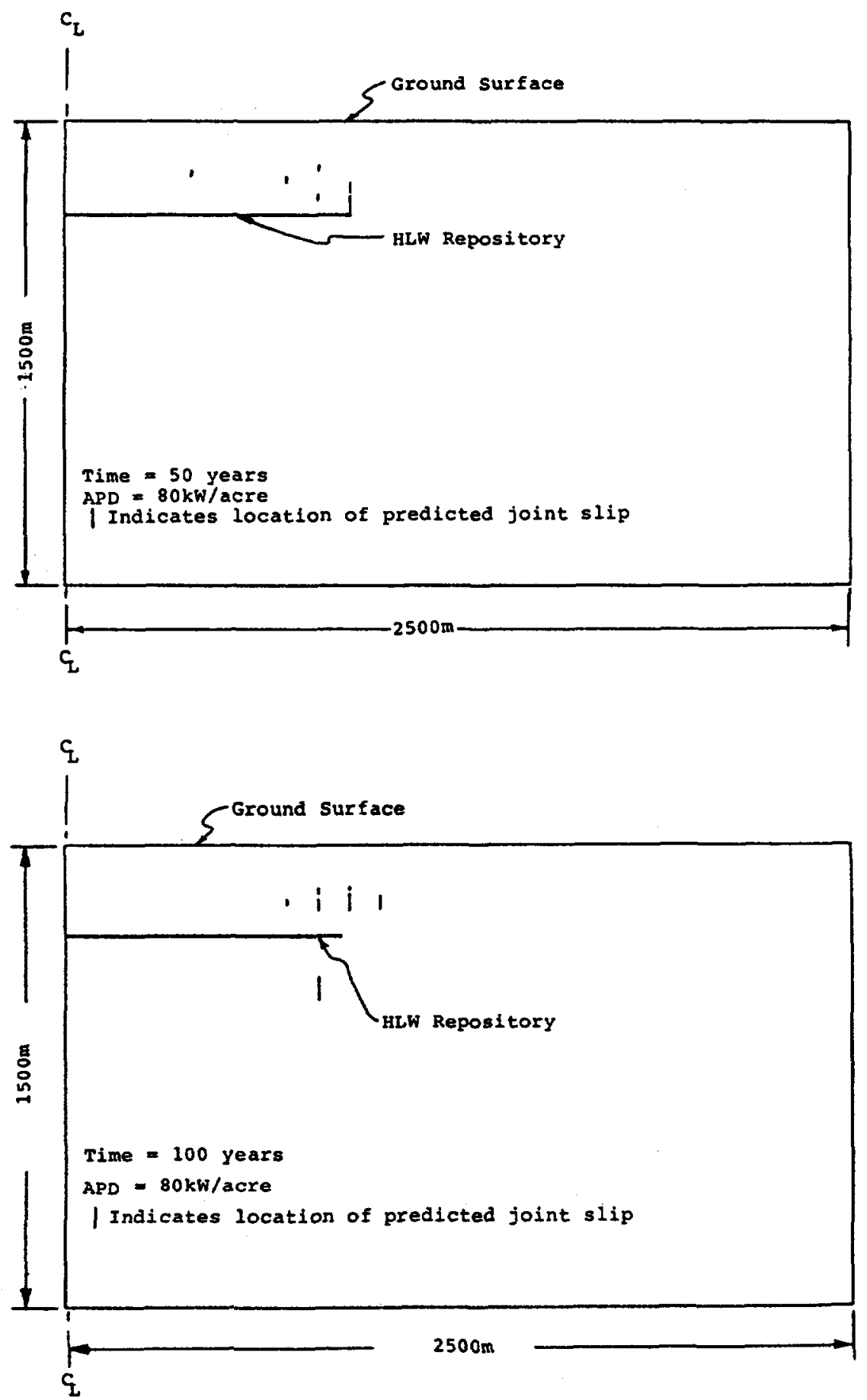

Fig. 3-43 Location of Predicted Joint Slip After 50 and 100 Years in the UDEC Model 

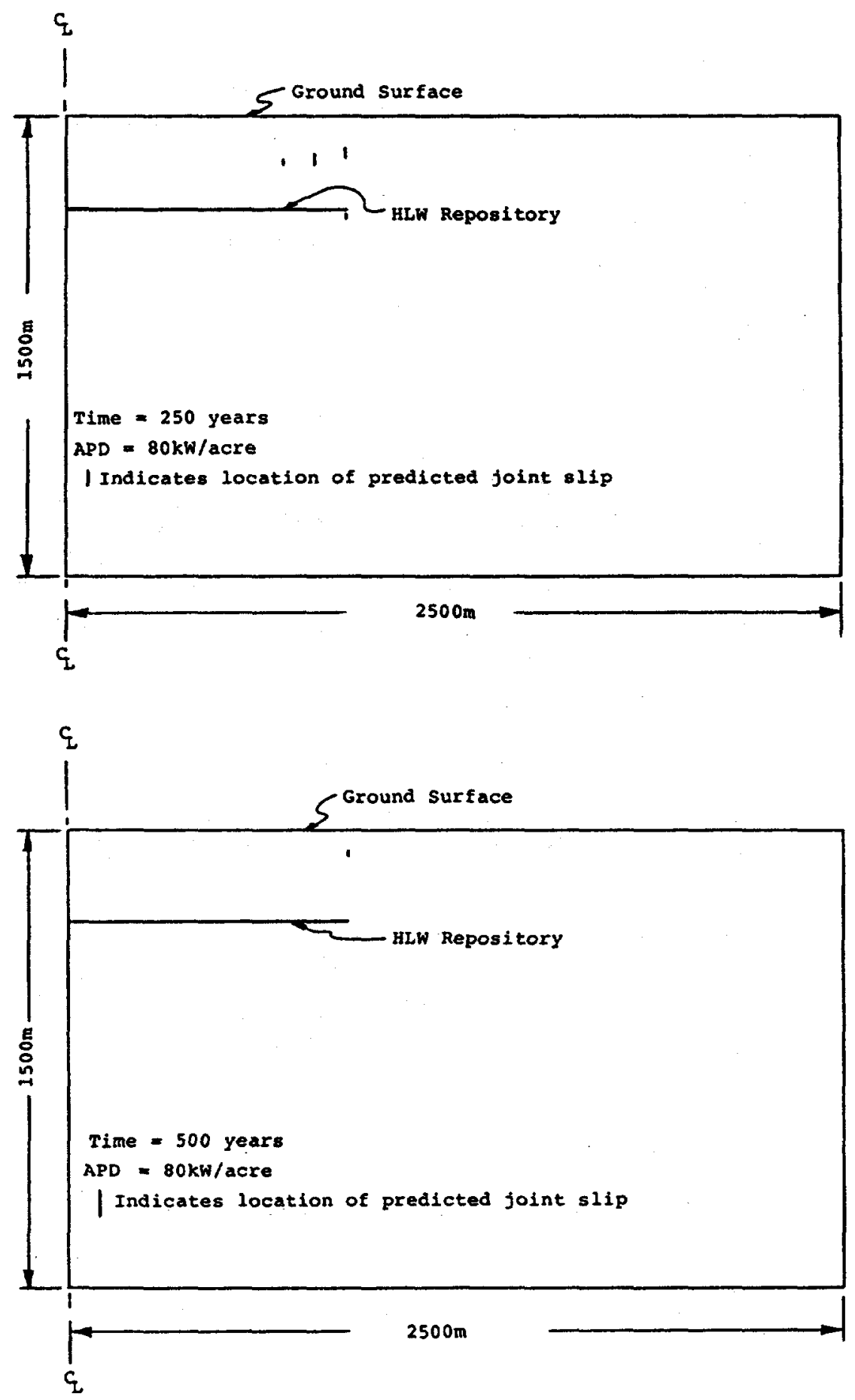

Fig. 3-44 Location of Predicted Joint Slip After 250 and 500 Years in the UDEC Model 


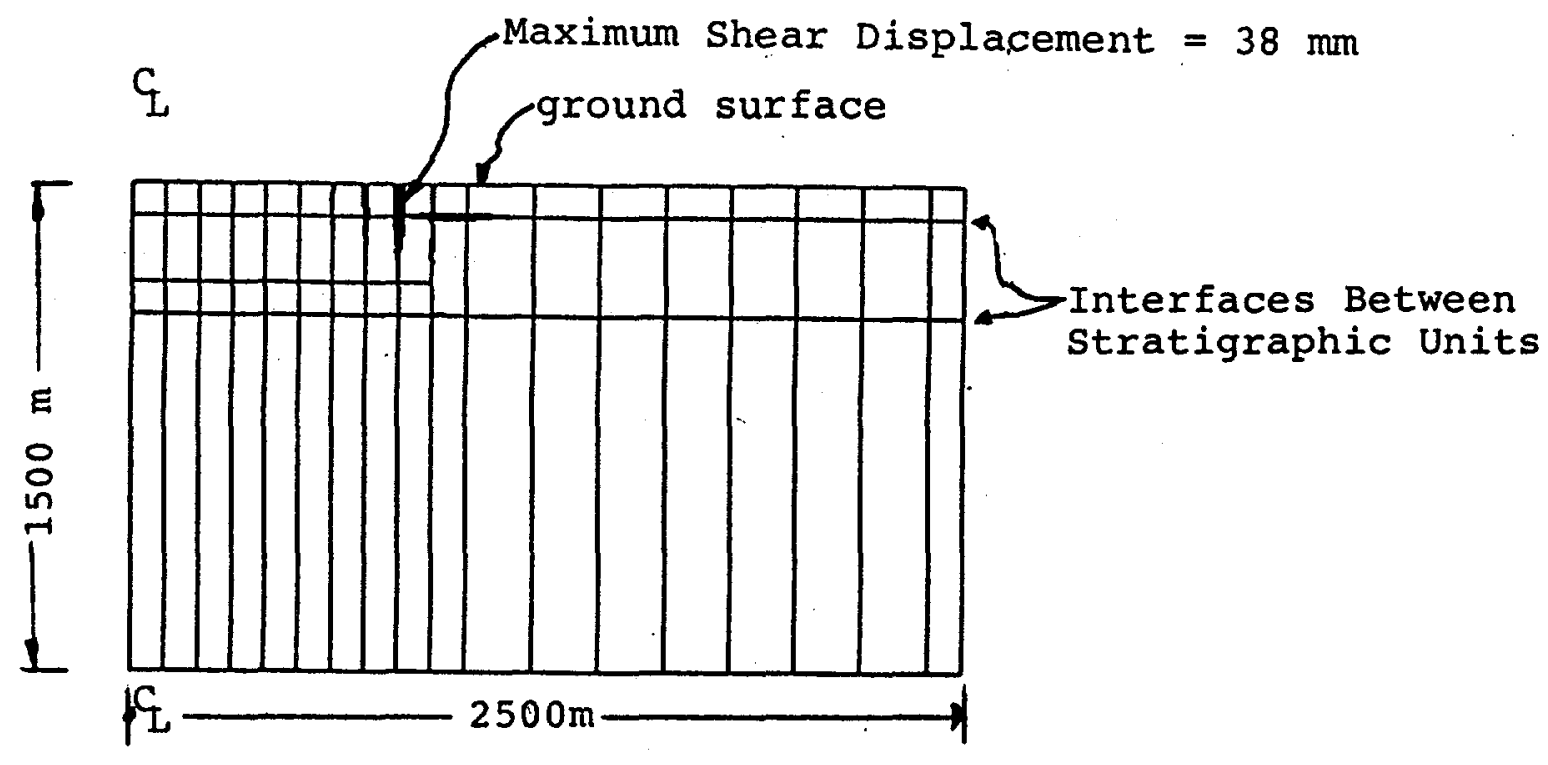

Time $=50$ years

(a)

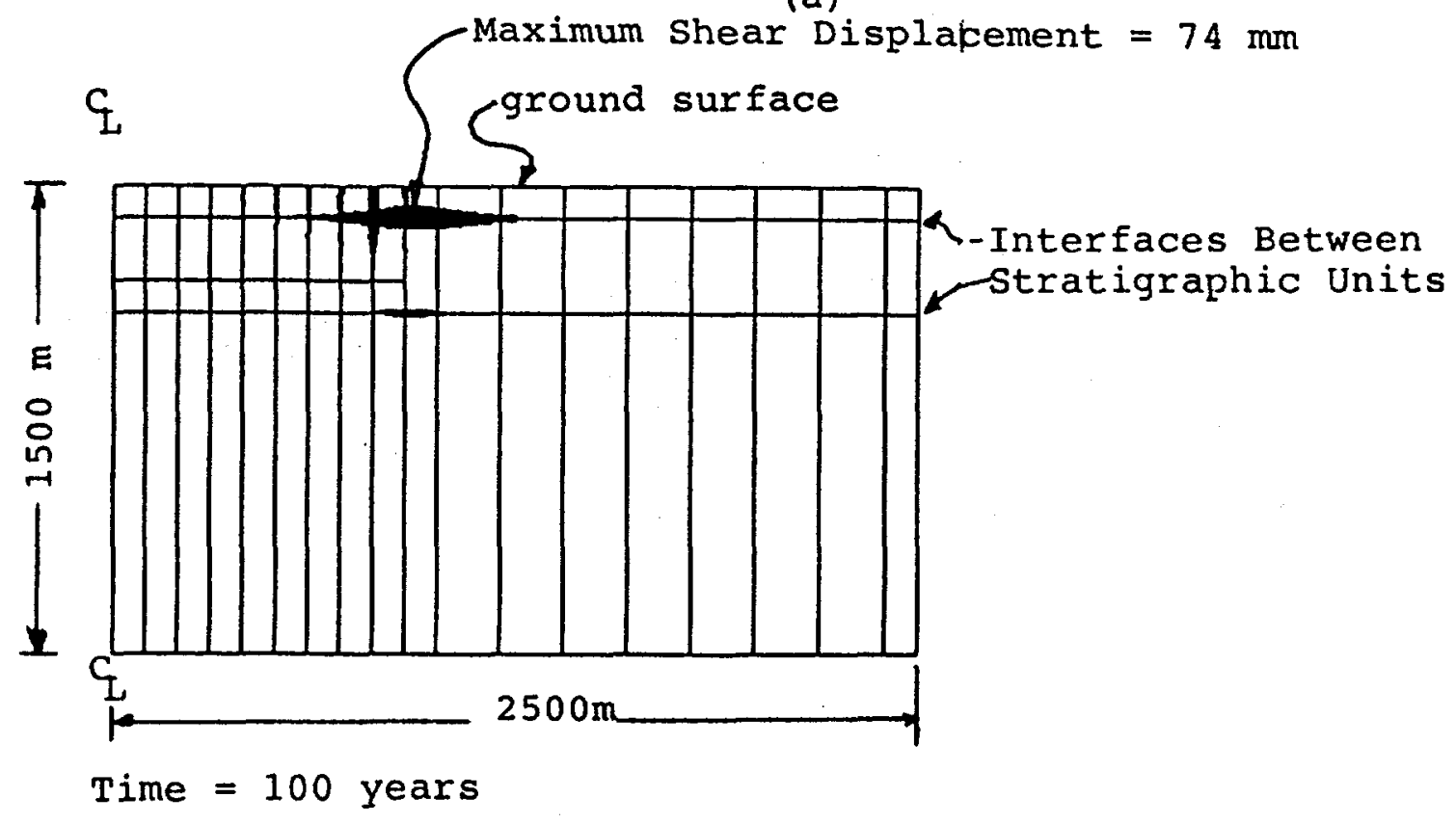

(b)

Eig. 3-45 Location of Predicted Joint Slip in UDEC Model with Horizontal Features for (a) 50 and (b) 100 years (Line thickness is proportional to magnitude of predicted slip.) 


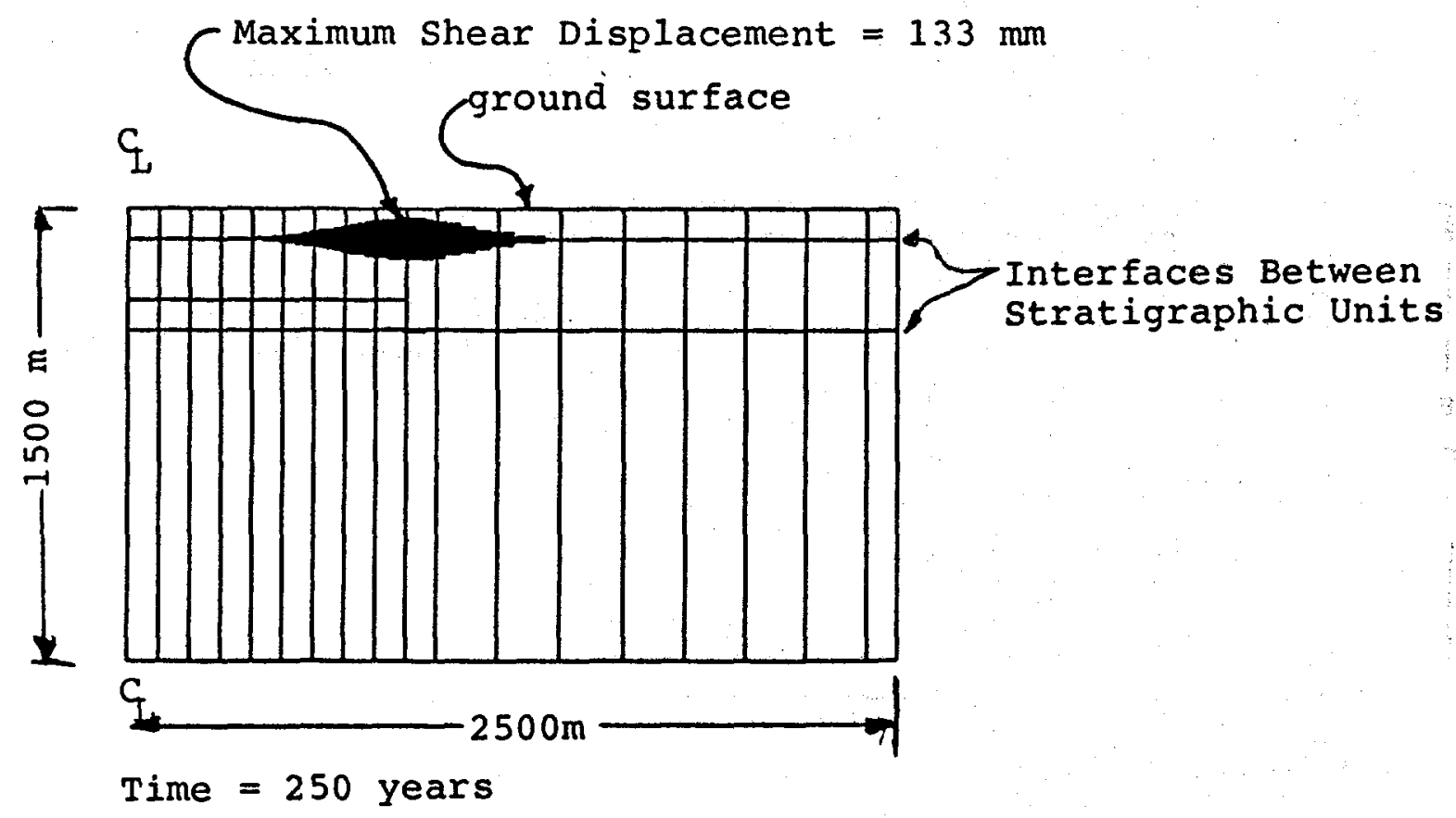

(a)

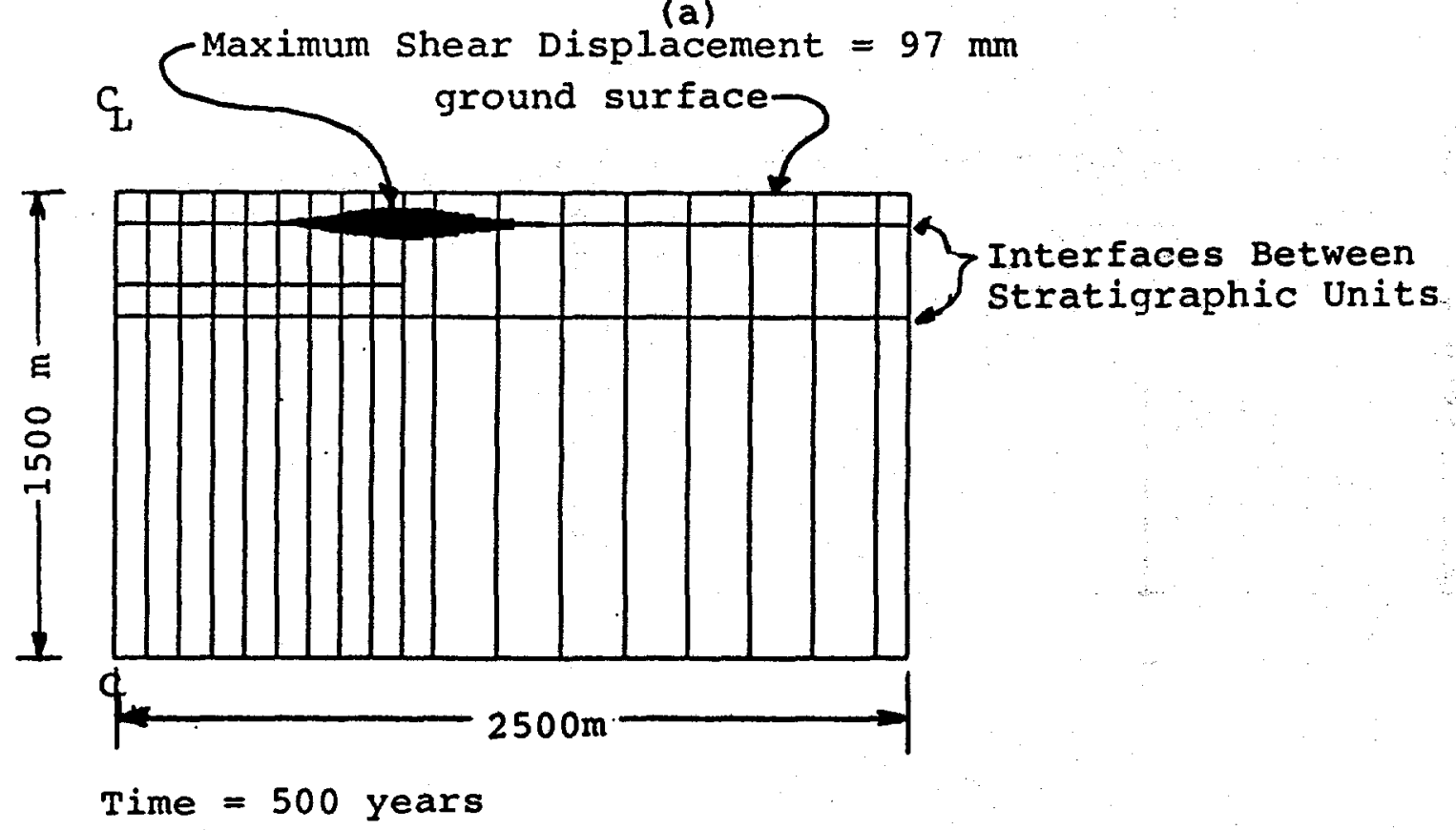

(b)

Fig. 3-46 Location of Predicted Joint Slip in UDEC Model with Horizontal Features for (a) 250 and (b) 500 years (Iine thickness is proportional to magnitude of predicted slip.) 


\subsection{DISCUSSION AND CONCLUSIONS}

Modification of the mechanical state and hydraulic properties of the host rock mass is an important issue in regulatory and 1icensing aspects of siting and construction of a high-level nuclear waste repository. Factors which have been evaluated in these analyses are changes in temperature, changes in stress, changes in joint aperture, and slip on joints, all resulting from the presence of a HLW repository. Although the effects of construction methods are discussed in section 1.2.2, no account is taken of them in this assessment of rock mass modification. Also, thermochemical effects are not considered.

The intention of the current work has been to identify zones in which there is significant modification of the intrinsic hydraulic properties of the host rock mass by repository construction and heat emission. Clearly, a quantitative evaluation of the term "significant modification" in this context would require analyses far beyond the scope of this study. For the purposes of preliminary evaluations, "significant" has been taken to mean a change in. the joint aperture by a factor of two, or the indication of slip on joints. When using the cubic law relation for joint permeability (Snow, 1968), a factor-of-two joint aperture change results in approximately one order-of-magnitude change in permeability. This translates to a change in flow rate of about one order of magnitude if Darcy flow is assumed. Joint slip is associated with joint dilation to various degrees, depending on the joint roughness. The dilation is caused by the joints "riding up" on asperities, resulting in an aperture increase. Bandis et al. (1983) have shown that dislocation of joints (which occurs when joints slip) affects the normal stiffness of joints and, thus, the normal stress-deformation relation, to a degree that larger joint apertures may result. Because joint slip is a permanent deformation, the associated effect on joint apertures is also permanent.

Closure of joints results in a reduction of joint permeability. For saturated conditions, joint closure (as a result of increasing effective normal stress from thermal expansion of the rock) may result in an increase in the pore pressure and, therefore, in the initiation of, or increase in, the groundwater flow. Similarly, for unsaturated conditions, where joints of very small apertures are the most effective fluid conductors, joint closure may increase flow in these joints. If the capillary-bundle theory for unsaturated flow is used (e.g., Baver et al., 1972), in which fractures offer resistance to flow across their boundaries, closure of the joints may result in a redirection of groundwater flow. Because of these complex phenomena, it is pos- 
sible that zones of joint closure by a factor of two should be interpreted as a significant modification of the hydraulic conductivity of the rock mass. In the current work, joint closure is not considered to be a significant change in conditions. It is noted, however, that because of the transient nature of the problem, joint slip may precede joint closure. As described previously, joint slip is considered significant with respect to the determination of the size and location of the zone of rock mass modification.

When applying these criteria to the room-scale model (for both horizontal and vertical waste emplacement), the results indicate that joint slip will develop as a result of excavation, and extend to a distance of about two equivalent room diameters into the rock surrounding the room. This is consistent with results obtained by Brandshaug (1989) and Christianson (1988) for similar conditions. Predictions of change in joint aperture using the nonlinear joint constitutive model described in Eq. (1), do not indicate any regions where joints have opened by a factor of two or more. As a result of excavation, therefore, the modified zone is based on the region of joint slip, and estimated to include the rock surrounding the room for a distance of two room diameters from the excavated surface. It is notable that this zone extends further than the rock disturbance of half-a-room diameter estimated in section 1.2.2 to result from construction (i.e., smooth-wall blasting).

The room-scale analysis for thermomechanical effects up to 100 years after initial waste emplacement shows that the region of significantly modified rock, due to either joint slip or joint opening, has not increased from that predicted after room excavation. This result is consistent with that obtained by Brandshaug (1989) and Christianson (1988) for similar conditions. Thus, the modified zone indicated by the room-scale analysis remains unchanged from that predicted as a result of excavation.

The investigation of rock mass response to thermomechanical loading on a repository scale shows that the repository remains within a region of high horizontal compressive stresses, where joints are predicted to close by a factor of two. The vertical extent of this region increases due to rock thermal expansion throughout the time period analyzed ( 0 to 500 years). Beyond the regions of compression above and below the repository, the development of joint opening by a factor of two is predicted as a result of differential thermal expansion of the rock. However, as the region of high horizontal compression around the repository increases with time (because of thermal expansion from increasing temperatures throughout the host rock), the region of joint open- 
ing by a factor of two disappears below the repository, and is expressed increasingly closer to the ground surface above the repository by the expanding region of joint closure. The region of joint opening by a factor of two, which begins early in time about $100 \mathrm{~m}$ above the repository, eventually extends to the ground surface. At that stage, it appears to be related to surface bending as a result of surface uplift from the accumulated effect of rock thermal expansion.

Because different joint deformation models were used in the different codes, the results from the distinct element analysis using UDEC cannot be compared quantitatively with the results of the repository-scale analysis using HEFF. However, the joint normal behavior observed in the UDEC analysis is consistent with the joint behavior inferred in the HEFF repository-scale analysis. This is an important observation which provides confidence in the ability of the numerical models to predict similar rock mass performance for similar conditions in the conceptual model. It is notable, also, that the rock mass response determined in this study has been observed in independent work by St.John (1987).

With regard to predicted joint slip in the host rock mass, a region of high horizontal compression adjacent to the repository remains free of joint slip. However, the development of joint slip is predicted in regions starting approximately $100 \mathrm{~m}$ above and below the repository. This slip is expected to occur as infinitesimal adjustments along the vertical joints, sufficient to accommodate induced thermal deformations. However, even small joint shear deformations may result in joints becoming unmated with the potential for increased apertures and, thus, increased fracture permeability. The prediction of joint slip is of concern because it indicates not only the potential for aperture opening, but also the permanence of such opening. Assuming that fracture flow could occur in some regions of the Yucca Mountain site (which is not an unreasonable assumption given the large volume of rock under consideration, and the frequency of fractures reported for the site in the SCPCDR [MacDougall et al., 19871), the increase in fracture permeability suggested by the results of these analyses could increase flow rates significantly. This would be the case for regions above as well as below the repository horizon. If evidence should indicate that the rock matrix permeability is sensitive to stress, the region of high horizontal compression in the rock adjacent to the repository could also be considered as a zone of modified rock mass permeability. 
Important interactions have been observed in this study between slip on horizontal and vertical joints. Slip on horizontal structural features may reduce the aperture changes on vertical joints by accommodating the effects of different degrees of thermal expansion between different layers. However, this could affect horizontal flow, thus allowing water to move along the horizontal features and down any anomalous vertical joints.

At the Yucca Mountain site, several faults are oriented perpendicular to the repository horizon. In the analyses performed for this report, these have not been distinguished from the many vertical joints. However, it is likely that they have different deformation and strength properties from the joints. One issue to consider is the possibility that one or more of these faults may be in a state of limiting equilibrium, so that they are on the verge of slipping if a disturbance is introduced. For example, if the ratio of horizontal to vertical stress is $1: 3$, if these are the principal stresses, and if the fault dips at $84^{\circ}$, corresponding to a repository dipping at $6^{\circ}$, the limiting friction angle is about $12^{\circ}$. Thus, if the friction angle of the fault is close to $12^{\circ}$, there is a potential for slip to occur under small perturbations from repository construction and rock mass heating.

Increased rock temperature is a perturbation that may not affect the intrinsic properties of the rock (Langkopf, 1987) and, therefore, is not considered to be significant with respect to determination of the zone of rock mass modification. However, depending on hydrologic conditions at the site, which may change as a result of joint closure, opening and slip, fluid flow induced by thermal buoyancy could become significant.

An estimate of the location and size of the zone of rock mass modification, based on the criteria adopted here and on the results and analyses of the repository-scale model, would include regions of rock approximately $200 \mathrm{~m}$ high starting approximately $100 \mathrm{~m}$ above the repository, and a region of rock approximately $150 \mathrm{~m}$ high starting roughly $100 \mathrm{~m}$ below the repository. This would locate the outer boundaries of the modified zone $300 \mathrm{~m}$ above and $250 \mathrm{~m}$ below the repository horizon, as indicated in Fig. 4-1.

This estimate of the extent of the modified zone must be considered in the context of uncertainties with respect to the hydraulic conditions of the site, numerical model input parameters, and simplifying assumptions made concerning material models, including the rock structure and stratigraphy. For example, a 
higher initial horizontal stress has the effect of reducing the regions predicted to be significant with respect to the intrinsic hydraulic parameters of the rock mass. An estimate of the modified zone based on results of the HEFF room-scale model agrees with the proposed preliminary definition of a disturbed zone as described by Langkopf (1987). However, this study suggests that the significance of rock mass modification due to repository construction and rock heating should be based on detailed analysis of rock mass performance at the site, instead of introducing a concept such as a "disturbed zone". 


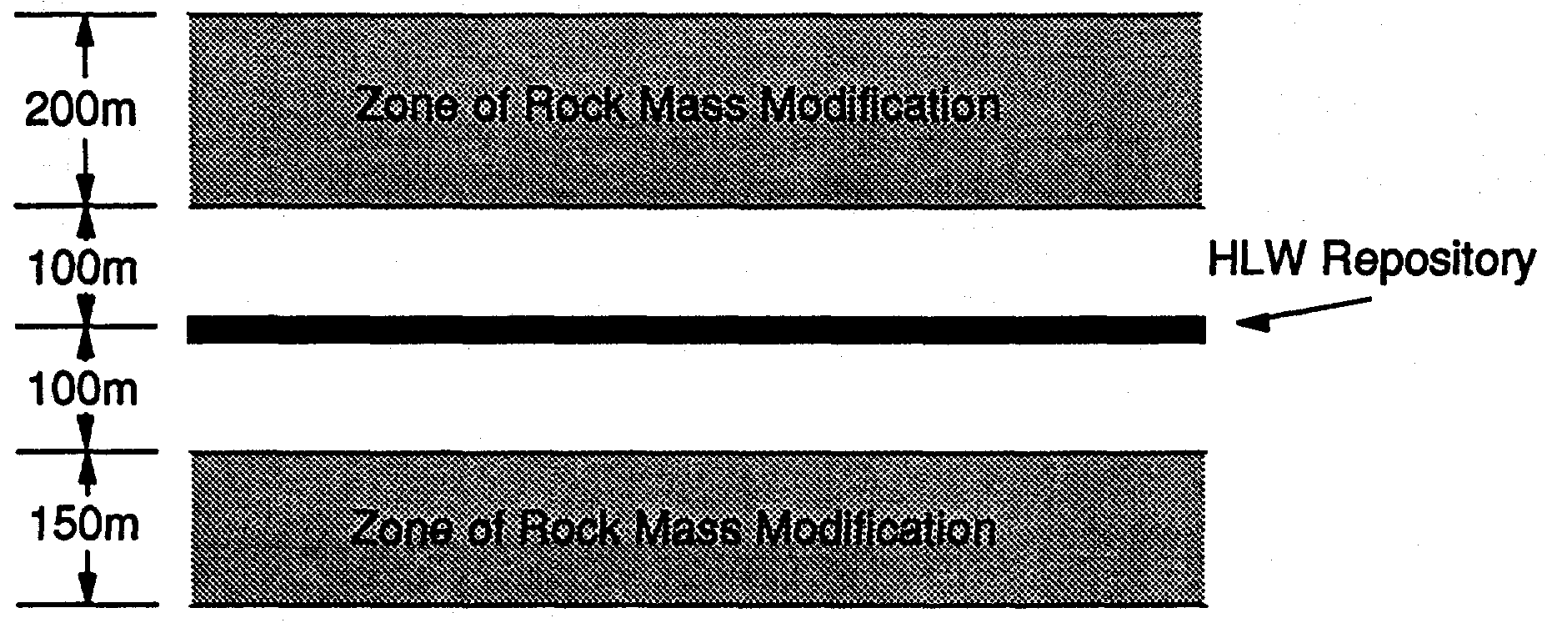

Fig. 4-1 Conceptual Illustration of the Extent of the zone of Rock Mass Modification 


\subsection{RECOMMENDATIONS}

Determination of rock mass modification on a repository scale must rely to a great extent, if not exclusively, on predictions from numerical models. Therefore, the appropriate level of detail about the rock structure and stratigraphy should be included in the models. A thorough description of the deformational response of rock joints under thermomechanical loading is essential for evaluating changes in rock mass permeability resulting from the presence of a HLW repository. The development of such a knowledge base must necessarily involve laboratory and site-specific field testing of rock joints, and ultimately must be translated into rock joint constitutive models for use in numerical modeling schemes. Because a rock mass may be more complex than can be accounted for in a numerical model, it is also essential to evaluate the numerical model for its capability to simulate the behavior of interest. This would require validation of the model against physical experiments.

These considerations indicate that thermomechanical repositoryscale models should be developed for Yucca Mounting to include suitable detail about the rock structure and stratigraphy, and reflect the prevailing understanding of the in-situ stress conditions, temperature, mechanical properties and constitutive relations of the rock mass. When site observations result in changes to rock mass parameters or specified site conditions, the models should be modified and re-analyzed to evaluate the effect of the changes on the behavior of the repository host rock. In this way, it is possible to provide a current perspective of the waste isolation capability of the host rock (i.e., within the context of numerical models), and to identify parameters and conditions which may require further definition. 


\subsection{REFERENCES}

Bandis, S. C., A. C. Lumsden, and N. R. Barton. "Fundamentals of Rock Joint Deformation," Int. J. Rock Mech. Min. Sci. \& Geomech. Abstr., 20 (6), 249-268, 1983.

Barton, N., S. Bandis and K. Bahktar. "Strength, Deformation and Conductivity Coupling of Rock Joints," Int. J. Rock Mech. Min. Sci. \& Geomech. Abstr., 22, 11-140 (1985).

Baver, I. D., W. H. Gardner and W. R. Gardner. Soil Physics, 4th Ed. New York: John Wiley \& Sons, 1972.

Brady, B. "HEFF - A Boundary Element Code for Two-Dimensional Thermo-Elastic Analysis of a Rock. Mass Subject to Constant or Decaying Thermal Loads," University of Minnesota Project Report to BWIP, Rockwell Hanford Operations, July 1980.

Brady, B. "HEFE (Version 2.0) User's Guide," Itasca Consulting Group Report to U.S. Nuclear Regulatory Commission, 1988.

Brady, B. H. G., and E. T. Brown. Rock Mechanics for Underground Mining. London: George Allen \& Unwin, 1985.

Brandshaug, T. Stability of Disposal Rooms During Waste Retrieval, U.S. Nuclear Regulatory Commission, NUREG/CR-5335, March 1989.

Bray, J. W. "Some Applications of Elastic Theory," in Analytical and Computational Methods in Rock Mechanics. E. T. Brown, Ed. London: Allen \& Unwin, 1987.

Christianson, Mark. "Sensitivity of the Stability of a Waste Emplacement Drift to Variation in Assumed Rock Joint Parameters in Welded Tuff," U.S. Nuclear Regulatory Commission, NUREG/CR5336, April 1989.

Crotty, J. M., and L. J. Wardle. "Boundary Integral Analysis of Piecewise Homogeneous Solids with Structural Discontinuities," Int. J. Rock Mech. Min. Sci. \& Geomech. Abstr., 22, 419-427 (1985).

Goodman, R. E. Methods in Geological Engineering in Discontinuous Rock. St. Paul: West Publishing Company, 1976. 
Hocking, G., and C. M. St.John. Annual Report - Fiscal Year '79 - Numerical Modeling of Rock Stresses Within a Basaltic Nuclear Waste Repository. Rockwell Report, September 1979.

Itasca Consulting Group, Inc. UDEC Version 1.5 User Manual. Minneapolis, Minnesota, ICG, 1989.

Kelsall, P. C., J. B. Case and C. R. Chabannes. A Preliminary Evaluation of the Rock Mass Disturbance Resulting from Shaft, Tunnel, or Borehole Excavation (Technical Report). ONWI-411, November 1982 .

Labreche, D. A. "Thermomechanical Analysis of a Near-Field Region Around a Horizontal Spent Fuel Emplacement Hole in a Jointed Rock Mass T/M Analysis 10," RE/SPEC Technical Letter Memorandum, RSI/TLM-0013, to B. S. Langkopf, SLTR86-2002, June 1986.

Langkopf, B. S. Proposed Preliminary Definition of the Disturbed-Zone Boundary Appropriate for a Repository at Yucca Mountain. Sandia National Laboratories, SAND86-1955, December 1987.

MacDougall, Hugh R., Leo W. Scully, and Joe R. Tillerson (Compilers). Site Characterization Plan Conceptual Design Report. Sandia National Laboratories, SAND84-2641, September 1987.

Mansure, A. J. "Expected Temperatures for Spent Fuel Borehole Walls and Drifts," Memo to J. Flores, Sandia National Laboratories, Sandia Keystone Memo 6310-85-8, April 15, 1985.

Montazer, P., and W. E. Wilson. "Conceptual Hydrologic Model of Flow in the Unsaturated Zone, Yucca Mountain, Nevada," U.S. Geological Survey, USGS-WRI-84-4345, 1984.

Obert, Leonard, and Wilbur I. Duvall. Rock Mechanics and the Design of Structures in Rock. New York: John Wiley \& Sons, 1967.

O'Brian, Paul D. "Reference Nuclear Waste Descriptions for a Geologic Repository at Yucca Mountain, Nevada," Sandia National Laboratories, SAND84-1848, September 1985.

Peters, Ralph R. "Thermal Response to Emplacement of Nuclear waste in Long, Horizontal Boreholes," Sandia National Laboratories, SAND82-2497, April 1983. 
Peters, R. R. and E. A. Klavetter. "A Continuum Model for Water Movement in an Unsaturated Fractured Rock Mass," Water Resources Research, 24 (3), 416-430 (March 1988).

Peters, R. R., J. H. Gauthier, and A. L. Dudley. "The Effect of Percolation Rate on Water-Travel Time in Deep, Partially Saturated Zones," Sandia National Laboratories, SAND85-0854; February 1986.

Scott, R. B., B. W. Spengler, S. Diehl, A. R. Lappin, and M. P. Chornack. "Geologic Character of Tuffs in the Unsaturated Zone at Yucca Mountain, Southern Nevada," in Role of the Unsaturated Zone in Radioactive and Hazardous Waste Disposal, pp. 289-335. J. W. Mercer, P. S. C. Rao and I. W. Marine, Eds. Ann Arbor: Butterworth Publishing Company, 1983.

Sinnock, S... Y. T. Iin and J. P. Brannen. Preliminary Bounds on the Expected Postclosure Performance of the Yucca Mountain Repository Site, Southern Nevada. Sandia National Laboratories, SAND 84-1492, December 1984.

Snow, D. T. "Rock Eracture Spacings, Openings and Porosities," J. Soil Mech. and Found. Div., Proc. ASCE, 94, 73-91 (1968).

St.John, C. M. Interaction of Nuclear Waste Panels with Shafts and Access Ramps for a Potential Repository at Yucca Mountain. Sandia National Laboratories, SAND84-7213, 1987.

U.S. Government. Code of Eederal Requlations: Title 10, Parts 0 to 199 (Energy). 10CFR0-199. January 1988 (Revised annually)

U.S. NRC (U.S. Nuclear Regulatory Commission). Draft Generic Technical Position: Interpretation and Identification of the Extent of the Disturbed Zone in the High-Level waste Rule 110 CER 60). U.S. NRC, Division of Waste Management, Office of Nuclear Material Safety and Safeguards, June 1986.

Wang, J. S. Y., and T. N. Narasimhan. Hydrologic Mechanisms Governing Partially-Saturated Fluid Flow in Fractured Welded Units and Porous Nonwelded Units at Yucca Mountain. Sandia National Laboratories, SAND85-7114, October 1986.

Zimmerman, Roger M., Robert L. Schuch, Donald S. Mason, Michael L. Wilson, Michael E. Hall, Mark P. Board, Robert P. Bellman, and Mark L. Blanford. Final Report: G-Tunnel Heated Block Experiment. Sandia National Laboratories, SAND84-2620, May 1986. 
APPENDIX A

HEFF DATA

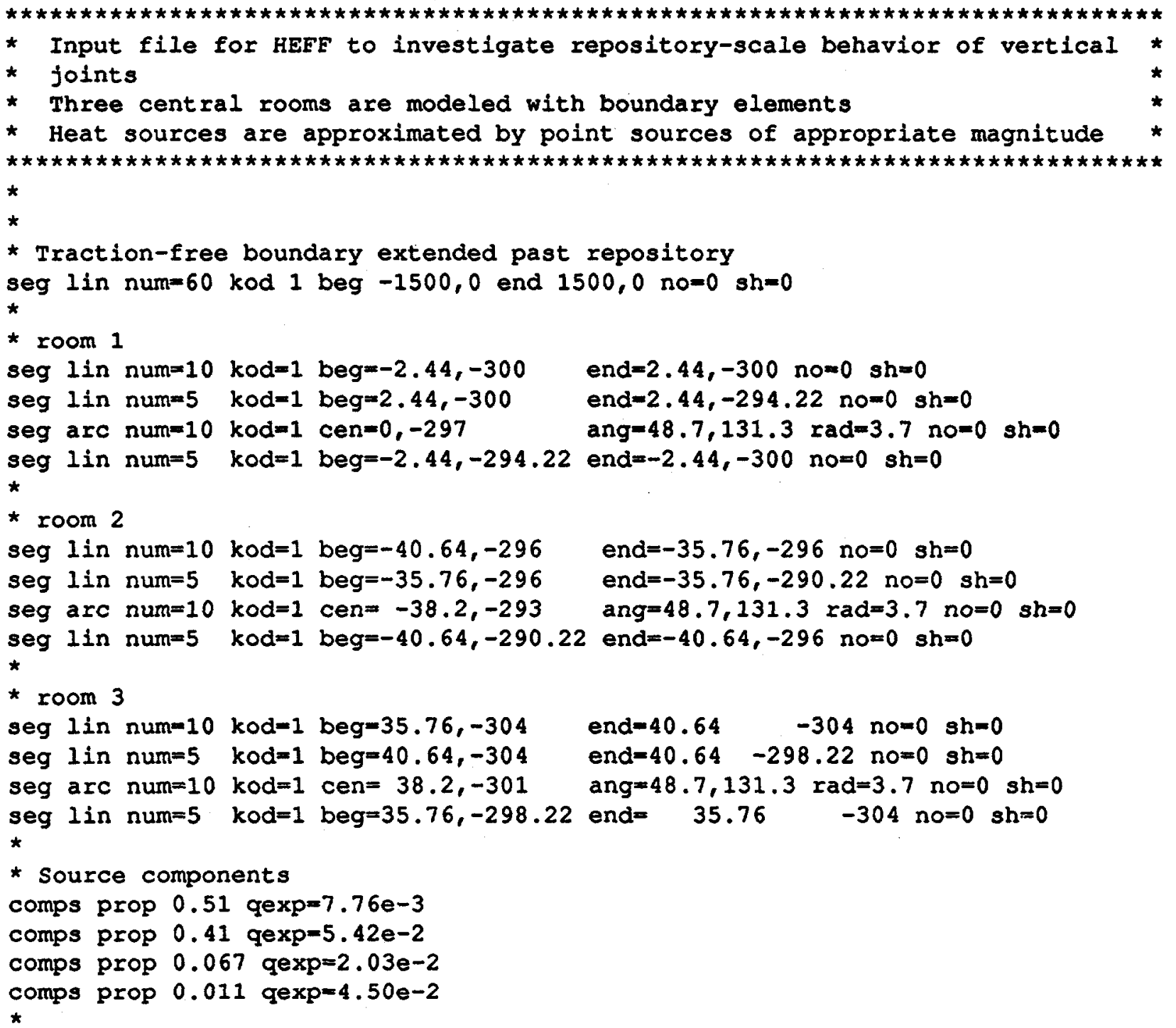


* Sources approximated by 3 points for three central rooms * .................... lsewhere one source per room source $x s=-38.2$ ys $=-299.77 \mathrm{qs}=263.3$ tos $=0.0$

source $x s=-38.2$ ys $=-301.3$ qs $=263.3$ tos $=0.0$

source $x s=-38.2$ ys $=-302.87 \mathrm{qs}=263.3$ tos $=0.0$

*

source $x s=0$ ys $=-303.77$ qs $=263.3$ tos $=0.0$

source $x s=0$ ys $=-305.3 \mathrm{gs}=263.3$ tos $=0.0$

source $x s=0$ ys $=-306.87$ qs $=263.3$ tos $=0.0$

*

source $x s=38.2$ ys $=-307.77 \mathrm{qs}=263.3$ tos $=0.0$

source $x s=38.2$ ys $=-309.3$ gs $=263.3$ tos $=0.0$

source $x s=38.2$ ys $=-310.87 \mathrm{qs}=263.3$ tos $=0.0$

*

source $x s=76.4$ ys $=-313.3$ qs $=790$ tos $=0.0$

source $x s=114.6$ ys $=-317.3$ qs $=790$ tos $=0.0$

source $x s=152.8$ ys $=-321.3 \quad q s=790$ tos $=0.0$

source $x s=191$ ys $=-325.3$ qs $=790$ tos $=0.0$

source $x s=229.2$ ys $=-329.3$ qs $=790$ tos $=0.0$

source $x s=267.4$ ys $=-333.3$ qs $=790$ tos $=0.0$

source $x s=305.6$ ys $=-337.3$ qs $=790$ tos $=0.0$

source $x s=343.8$ ys=-341.3 qs $=790$ tos $=0.0$

source $x s=382$ ys $=-345.3$ qs $=790$ tos $=0.0$

source $x s=420.2$ ys $=-349.3$ qs $=790$ tos $=0.0$

source $x s=458.4$ ys $=-353.3$ qs $=790$ tos $=0.0$

source $x s=496.6$ ys $=-357.3$ qs $=790$ tos $=0.0$

source $x s=534.8$ ys $=-361.3$ qs $=790$ tos $=0.0$

source $x s=573$ ys $=-365.3$ qs $=790$ tos $=0.0$

source $x s=611.2$ ys $=-369.3$ qs $=790$ tos $=0.0$

source $x s=649.4$ ys $=-373.3$ gs $=790$ tos $=0.0$

source $x s=687.6$ ys $=-377.3$ qs $=790$ tos $=0.0$

source $x s=725.8$ ys $=-381.3$ qs $=790$ tos $=0.0$

source $x s=764$ ys $=-385.3$ qs $=790$ tos $=0.0$

source $x s=802.2$ ys $=-389.3$ qs $=790$ tos $=0.0$

source $x s=840.4$ ys $=-393.3$ qs $=790$ tos $=0.0$

source $x s=878.6$ ys $=-397.3$ qs $=790$ tos $=0.0$

source $x s=916.8$ ys $=-401.3$ qs $=790$ tos $=0.0$

source $x s=955$ ys $=-405.3$ qs $=790$ tos $=0.0$

source $x s=993.2$ ys $=-409.3$ qs $=790$ tos $=0.0$

source $x s=-76.4$ ysm $-297.3 \mathrm{qg}=790$ tos $=0.0$

source $x s=-114.6$ ys $=-293.3$ qs $=790$ tos $=0.0$

source $x s=-152.8$ ys $=-289.3$ qs $=790$ tos $=0.0$

source $x s=-191$ ys $=-285.3$ qs $=790$ tos $=0.0$

source $x s=-229.2$ ys $=-281.3$ qs $=790$ tos $=0.0$

source $x s=-267.4$ ys $=-277.3$ qs $=790$ tos $=0.0$

source $x s=-305.6$ ys $=-273.3$ qs $=790$ tos $=0.0$

source $x s=-343.8$ ys $=-269.3$ qs $=790$ tos $=0.0$

source $x s=-382$ ys $=-265.3$ qs $=790$ tos $=0.0$ 


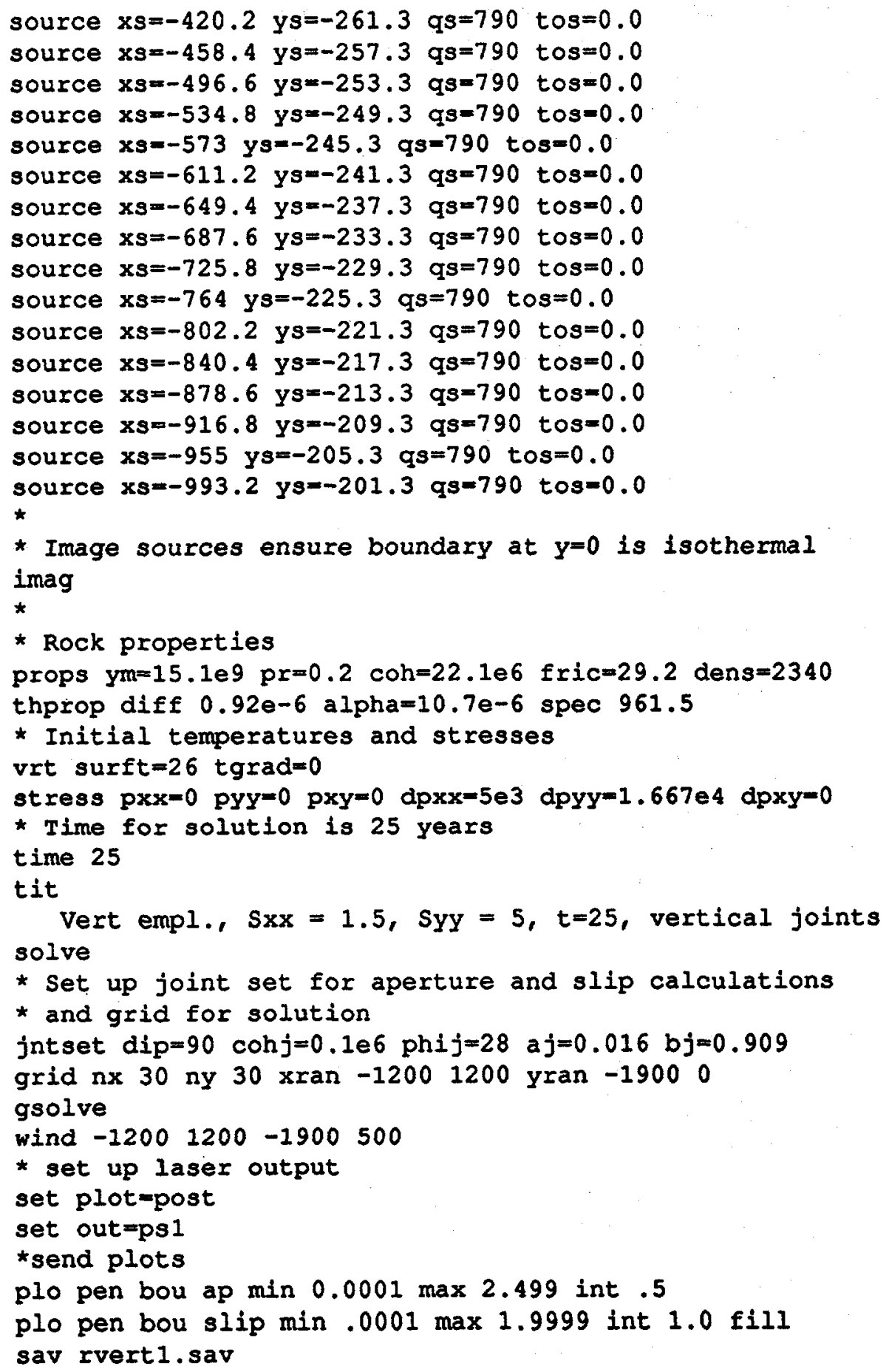


APPENDIX B

UDEC DATA

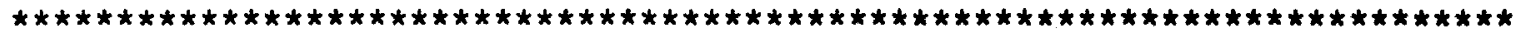

* This is an input file for UDEC to investigate the thermomechanical *

* behavior of the rock, especially the response of vertical joints *

* on a repository scale.

*

* The initial stress field is gravitational, and the free surface *

* is at the top of the model. The size of the model (HxV) is $2500 \mathrm{~m}$ *

* by $1500 \mathrm{~m}$. The repository is at $300 \mathrm{~m}$ depth $(1 . e .,-300 \mathrm{~m})$. *

* Input parameters are taken from the SCP-CDR (MacDougall et al., *

$\star \quad 1987$

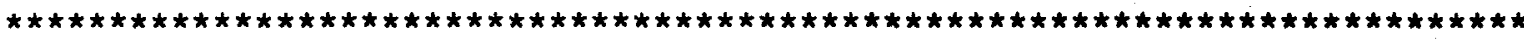

set ega
\end{abstract}

*--- Invoke thermal logic ...

thermal

ro 0.5

*--- Start defining the model domain ...

block $0,02500,02500,-15000,-1500$

Joints spaced at $100 \mathrm{~m}$ for first $1000 \mathrm{~m}$...

split $100-2000100100$

split $200-2000200 \quad 100$

split $300-2000300 \quad 100$

split $400-2000 \quad 400 \quad 100$

split $500-2000500100$

split $600-2000600 \quad 100$

split $700-2000700100$

split $800-2000 \quad 800 \quad 100$

split $900-2000900100$

split $1000-20001000100$

Repository horizon ...

split $-1 \quad-300 \quad 900-300$

*--- Splits below repository to enable zoning to change ...

*split $-1-500 \quad 1000-500$

*split $-1 \quad-900 \quad 1200-900$ 


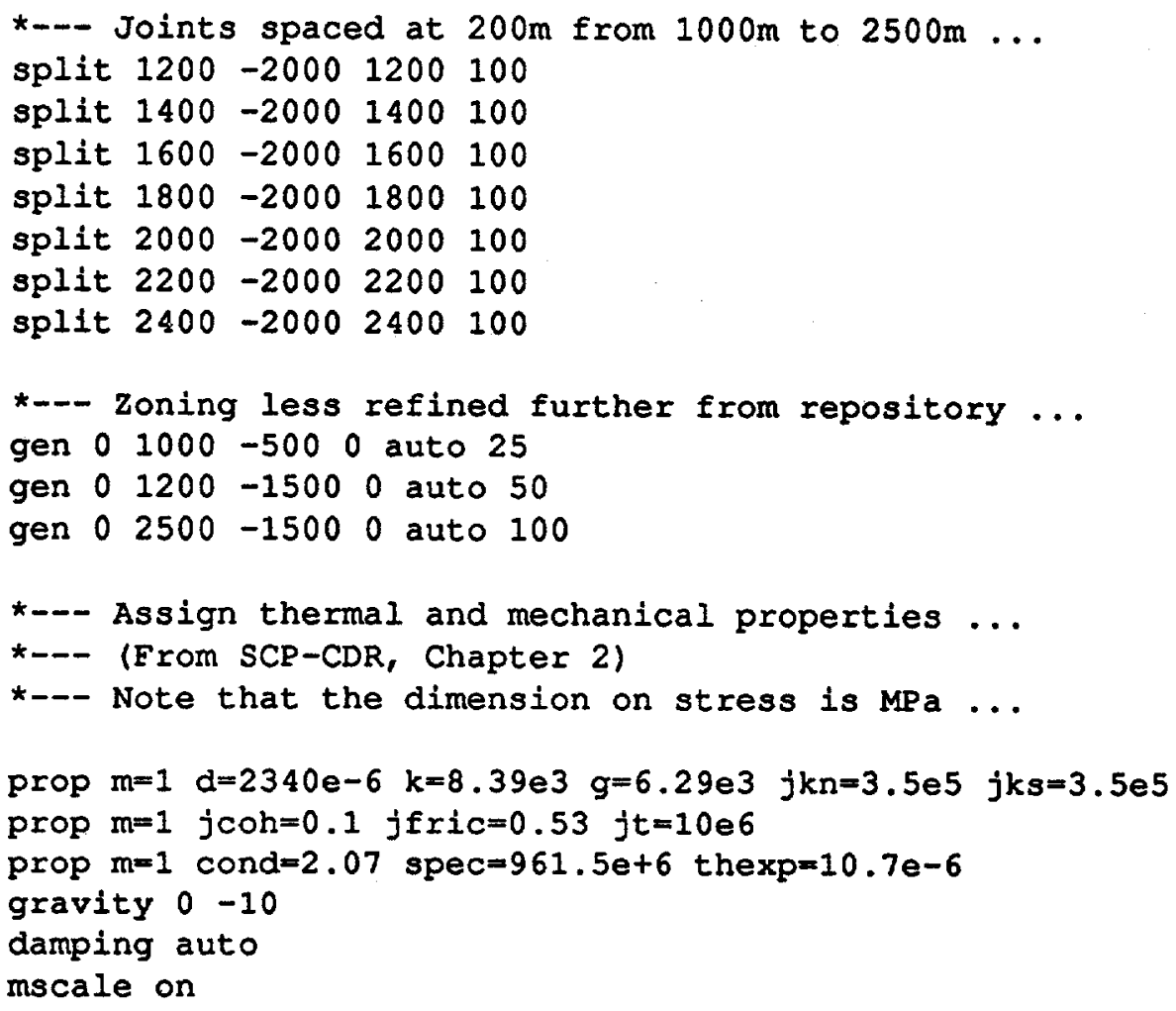


*-- Assign the initial temperature to 0 degrees C... initem $0-1,2501-1501,1$

*--- Assign a fixed temperature boundary of 0 degrees $C$ *--- at the ground surface ...

tfix $\begin{array}{lllllll} & 0 & -1 & 2501 & -1 & 1\end{array}$

*--- Assign the decaying heat source which simulates the

*--- commingled $\mathrm{SF}$ and DHLW ...

thapp $-1,900-301,-299$ flux $4.86-2.46 e-10$

thapp $-1,900-301,-299$ flux $3.96-1.72 e-9$

thapp $-1,900-301,-299$ flux $0.86-6.43 e-10$

thapp $-1,900-301,-299$ flux $0.14-1.45 e-9$

*--- Assign history functions to monitor the heat transfer ... thist temp $0,-300$

thist temp $450,-300$

thist temp $900,-300$

*--- Assign in situ stress (i.e., the initial stress field) ... insitu str 000 ygrad $720 e-502340 e-5$ nodisp

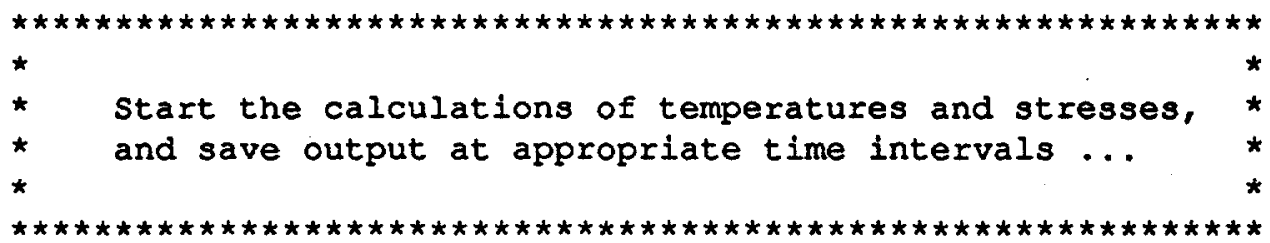

cy 4000

head

initial stress conditions time $=0 \ldots$

save mctoyr.sav

run step 1000 temp 1500 age $1.5768 \mathrm{e} 9$

head

temperatures after 50 years ...

save tht $50 y r . s a v$

cy 4000

head

$T / M$ stresses after 50 years ...

save tmt50yr.sav 


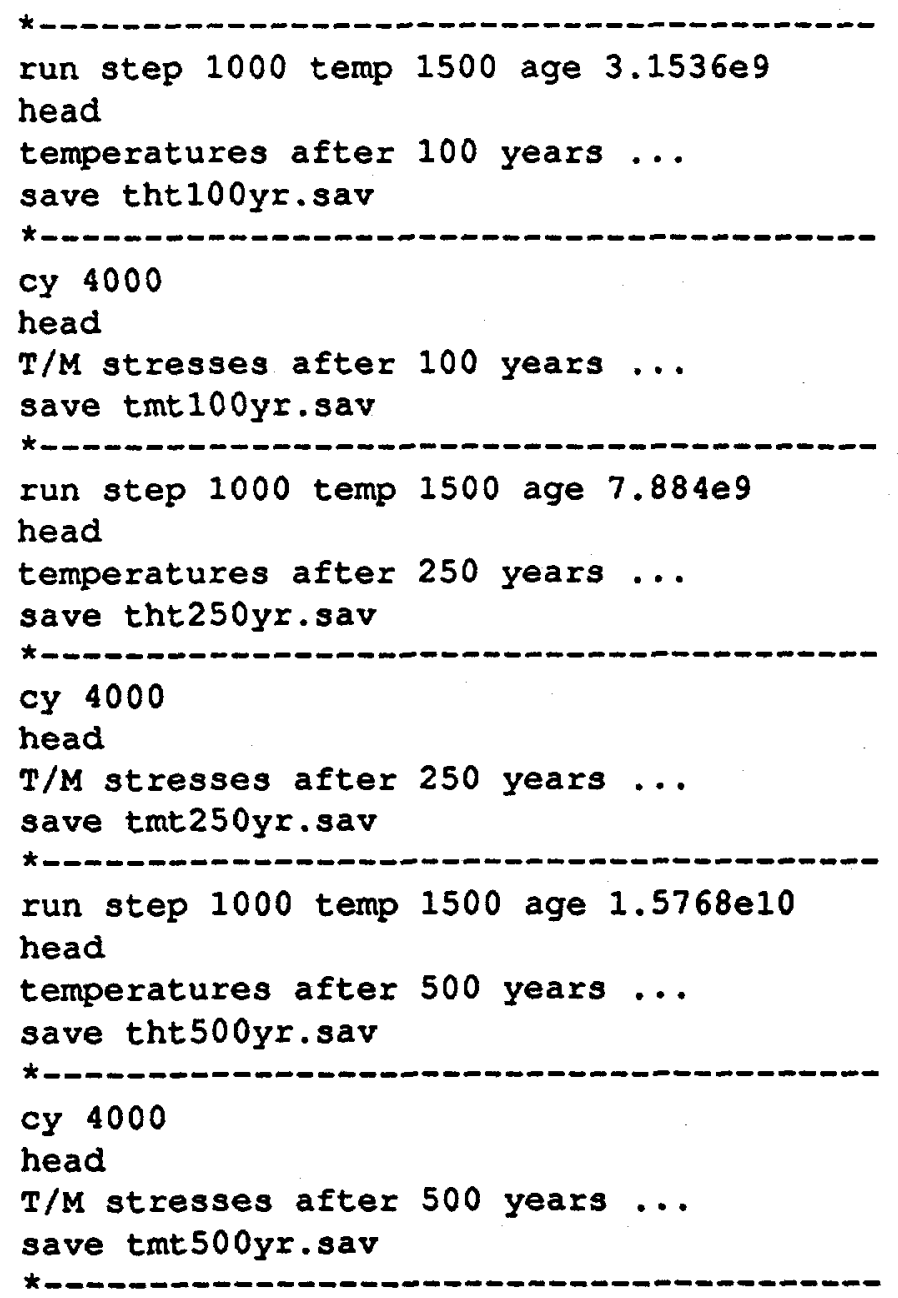




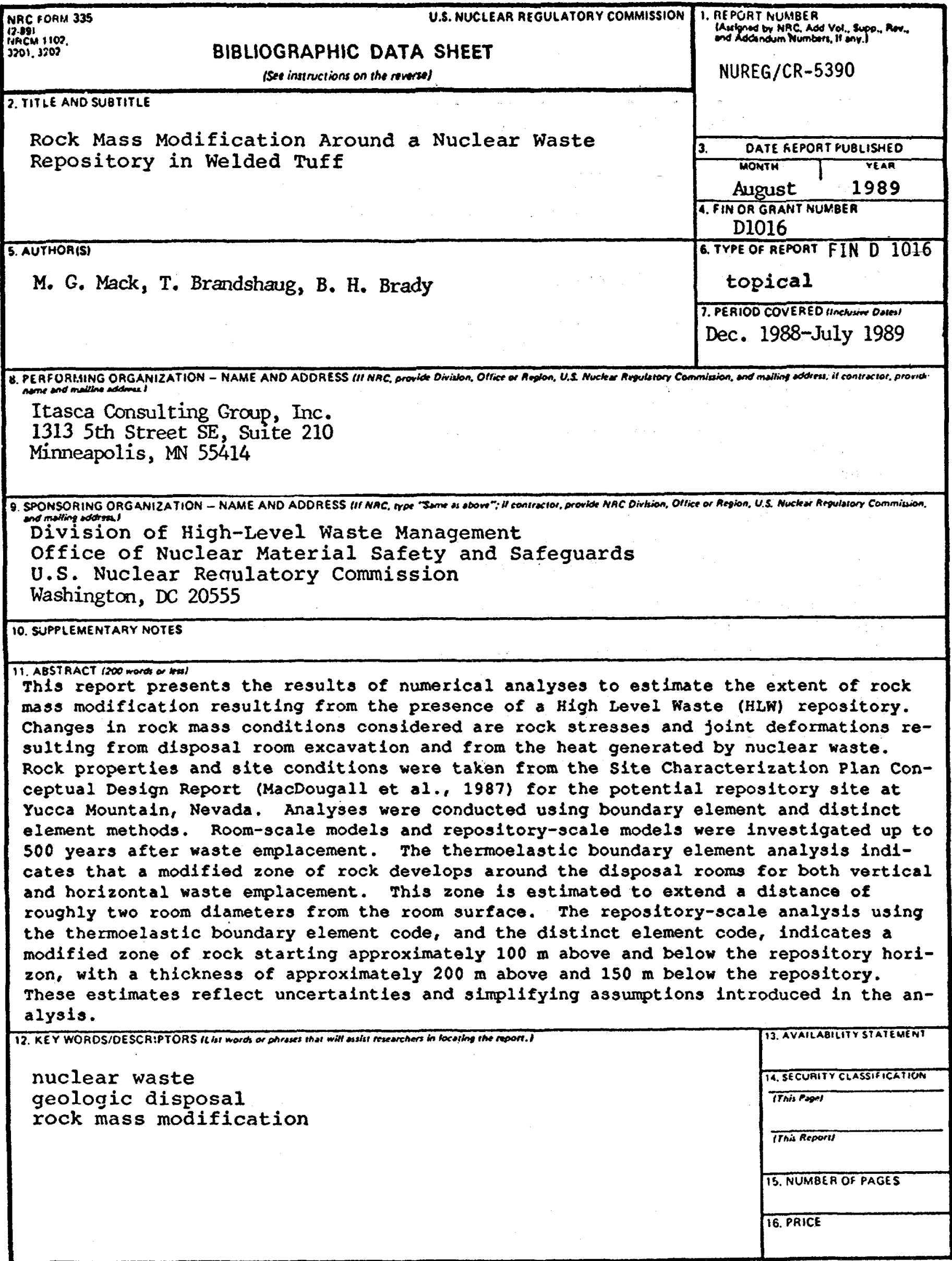

